$$
\text { University of São Paulo }
$$

The University of Astronomy, Geophysics and Atmospheric

Sciences

Deparment of Atmospheric Sciences

Alan Jesús García Rosales

\title{
Valley-mountain circulation associated with precipitation formation in the tropical Andes (Rio Santa Basin)
}

(Circulação de Vale-Montanha associados com a formação de precipitação nos Andes tropicais (Bacia do Rio Santa))

São Paulo 



\author{
Alan Jesús García Rosales
}

\title{
Valley-mountain circulation associated with precipitation formation in the tropical Andes (Rio Santa Basin)
}

(Circulação de Vale-montanha associados com a formação de precipitação nos Andes tropicais (Bacia do Rio Santa))

\begin{abstract}
Dissertion presented at the Institute of Astronomy, Geophysics and Atmospheric Sciences at the University of São Paulo as a partial requirement for obtaining the title of Master of Sciences.
\end{abstract}

Area of concentration: Meteorology

Advisor: Dr. Rosmeri Porfirio da Rocha

Co-Advisor: Dr. Clementine Junquas

"Corrected version. The original is avaible at the Unity"

São Paulo

2019 

To my family for their constant concern with me, especially my brother Kevin for his scientific curiosity. 



\section{Acknowledgments}

In the following lines, I wish to thank all the people who helped me in the conclusion of this work:

To my advisor Ph.D. Rosmeri Porfirio da Rocha, for all her patience, constant support and for motivating me to improve myself and continue my research career.

To my co-advisor Ph.D. Clementine Junquas for the productive and fun discussions, and the constant support since I began my adventure with the numerical models.

To Professor Ricardo Camargo for the support from the first day of the master program, not only as a teacher but also as a friend.

To the Postgraduate Program in Meteorology of the Institute of Astronomy, Geophysics and Atmospheric Sciences (IAG), for giving me the opportunity to develop professionally and to prove to myself that I can improve.

To Ph.Ds Thomas Condom and Lise Mourre for the availability of weather station data.

To Victor Mayta for the constant support in the first year of masters and all the hours of discussion.

To Angel and Mario for all their support and assistance to any query.

To Fernando Prudencio for the support in the topography data.

To my friends from the master's program, because despite the distance of my family, they make me feel like part of theirs. Especially to Camila, Isabela, and Victoria.

This study was financed in part by the Coordenação de Aperfeiçoamento de Pessoal de Nível Superior - Brasil (CAPES) - Finance Code 001 



\begin{abstract}
During the austral summer season, the precipitation in the Rio Santa basin, localized in the Tropical Andes, is strongly influenced by the interaction between large-scale circulation with local processes. However, this interaction has not been fully explored in the region. Therefore, the identification of the circulation patterns, and how occurs the interaction with local and regional-scale mechanisms influences the rainfall development is the main objective of this work. The analysis used fine resolution Weather Research and Forecasting (WRF) simulations nested in ERA5 reanalysis data. Different combinations of parameterizations were evaluated with a horizontal grid size of $5 \mathrm{~km}$, in order to find the most suitable configuration for simulating the observed diurnal cycle of precipitation. Once identified the configuration, longer nested simulations (December 2012 until March 2013) with horizontal grid size of $6 \mathrm{~km}$ and $2 \mathrm{~km}$ were performed. Estimated (TRMM, CMORPH, PISCO, CHIRPS) and local observations were used to validate the simulations. The chosen WRF configuration consists mainly of the Goddard microphysics and the Betts-Miller-Janjic cumulus parametrization. This configuration is able to simulate the main features of the observed diurnal cycle of precipitation, according to the in-situ data. However, the model still overestimates precipitation. In assessing the circulation associated with the precipitation diurnal cycle it was identified as a westerly flow during the daytime, which is perpendicular to the Andes and enters through the north of the basin. This near surface flow is vital for the development of rainfall over the western slopes-highlands of the basin from noon to midafternoon. At same time, in eastern side of basin the coastal moisture transport converges with Amazon easterly flow over the mountains causing precipitation. On the other hand, between the late afternoon and early night, the rainfall predominates on the eastern slope associated with the upslope valley winds persisting in this period. These results contrast with most of studies that have indicated the Amazon basin as an exclusive source of moisture for the formation of precipitation over the Andes.
\end{abstract}




\section{RESUMO}

Durante o verão austral, a precipitação na bacia do rio Santa, localizada nos Andes tropicais, é fortemente influenciada pela interação entre a circulação de grande escala e os processos locais. No entanto, essa interação não é totalmente conhecida até o momento. Portanto, a identificação dos padrões de circulação, e como a interação dos mecanismos de escala local e regional influenciam no desenvolvimento das chuvas é o objetivo principal deste trabalho. A análise utilizou simulações de alta resolução do Weather Research and Forecasting (WRF) aninhadas na reanálise do ERA5. Diferentes combinações de parametrizações foram avaliadas, em simulações do WRF com espaçamento de grade horizontal de $5 \mathrm{~km}$, a fim de encontrar a configuração mais adequada para simular o ciclo diurno observado da precipitação. Uma vez identificada a configuração, simulações aninhadas mais longas (de dezembro de 2012 a março de 2013) com espaçamento de grade horizontal de $6 \mathrm{~km}$ e $2 \mathrm{~km}$

foram realizadas. Estimativas (TRMM, CMORPH, PISCO, CHIRPS) e observações locais de precipitação foram usadas para validar as simulações. A configuração selecionada para o WRF consiste principalmente na microfísica Goddard e parametrização do cumulus de BettsMiller-Janjic. Esta configuração é capaz de simular as principais características do ciclo diurno observado de precipitação, de acordo com as observações locais. No entanto, o modelo ainda superestima a precipitação. Ao avaliar a circulação associada ao ciclo diurno de precipitação, identificou-se um escoamento do oeste durante o dia, perpendicular aos Andes, adentrando pelo setor norte da bacia. Este escoamento próximo da superfície mostrou-se vital para o desenvolvimento das chuvas nas encostas ocidentais da bacia, desde o meio-dia até meio da tarde. Ao mesmo tempo, no lado leste da bacia, o transporte de umidade costeira converge com aquele vindo da Amazônia, causando precipitação. Por outro lado, entre o final da tarde e início da noite, as chuvas predominam na vertente leste associada à persistência de ventos ascendentes. Estes resultados contrastam com a maioria dos estudos que indicaram a bacia Amazônica como uma fonte exclusiva de umidade para a formação de precipitação sobre os Andes. 


\section{CONTENTS}

LIST OF FIGURES................................................................

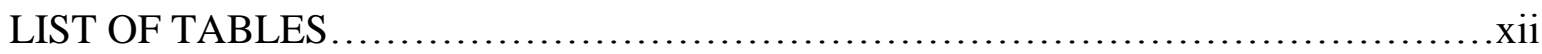

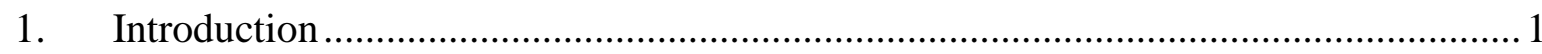

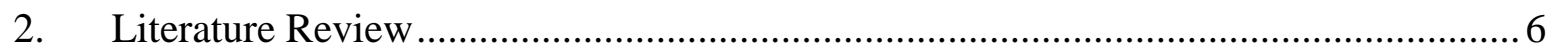

$2.1 \quad$ Valley-Mountain Circulations ..................................................................... 6

2.1.1 Diurnal Mountain Winds ...................................................................... 6

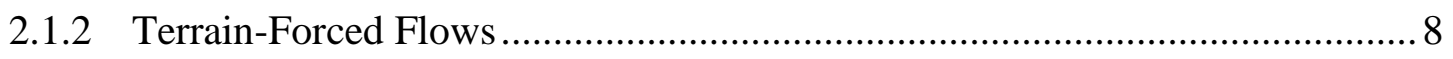

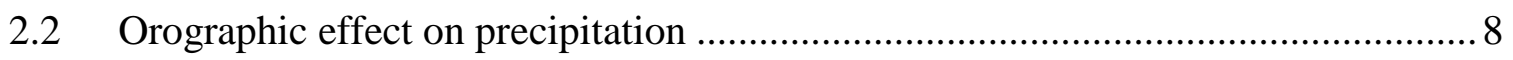

2.3 Regional climate modeling over complex topography .................................. 11

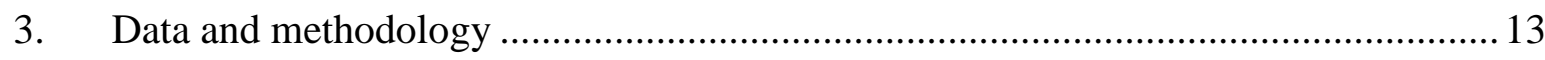

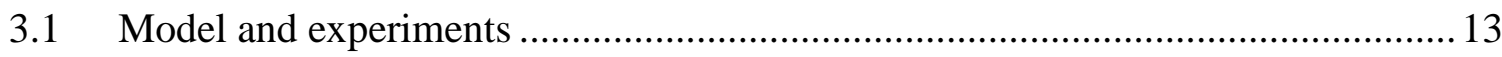

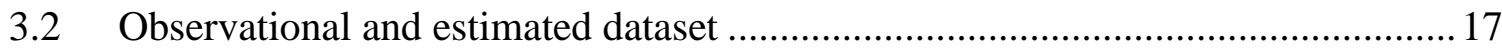

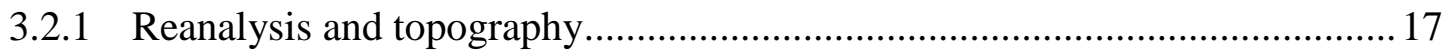

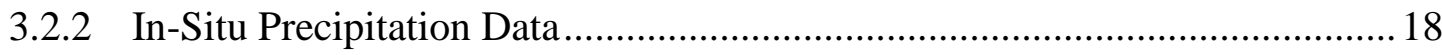

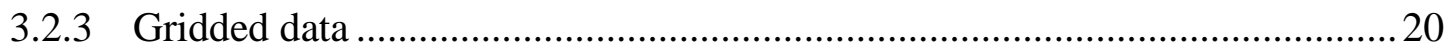

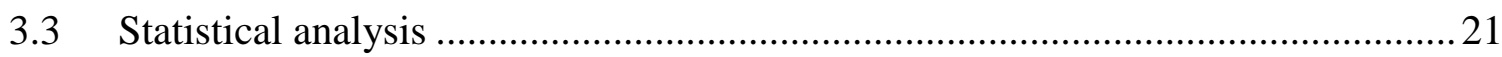

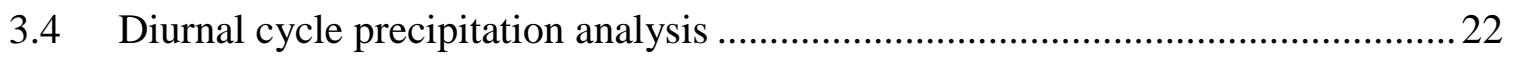

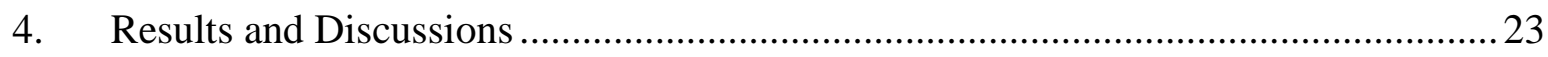

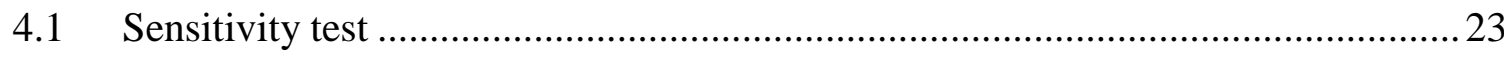

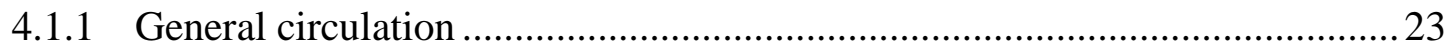

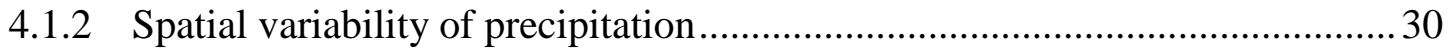

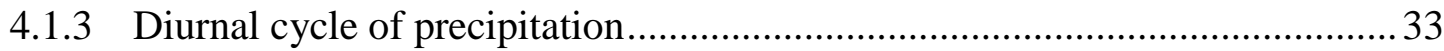

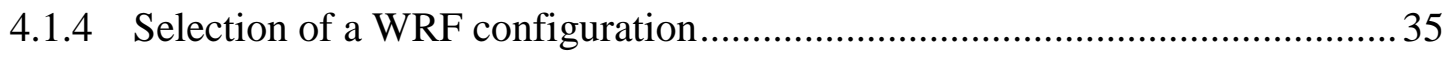

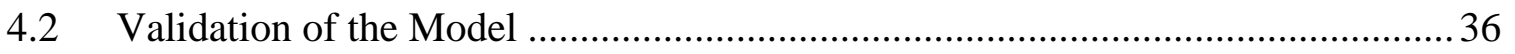




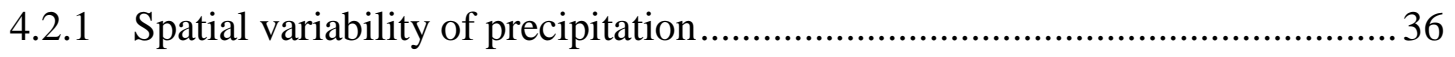

4.2.2 Variability of wind speed and direction .............................................. 40

4.2.3 Diurnal cycle of precipitation................................................................ 42

4.3 Atmospheric processes associated with the diurnal cycle precipitation.................44

4.3.1 Diurnal cycle of precipitation and moisture flux ......................................4 44

4.3.2 Diurnal cycles: wind at $10 \mathrm{~m}$, specific humidity and temperature at $2 \mathrm{~m} \ldots \ldots . .48$

4.3.3 Influence of regional on the local circulation associated with precipitation ... 50

4.3.4 Valley-mountain processes observed in cross-sections. .............................58

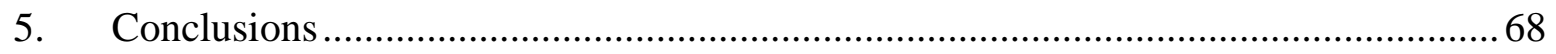

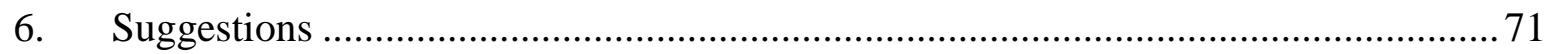

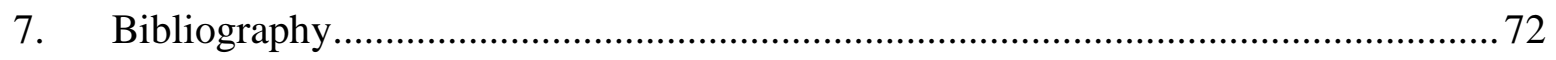

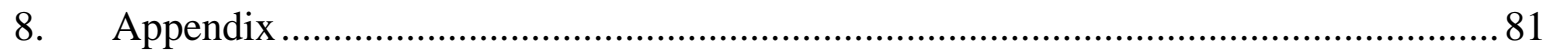

8.1 Appendix A: Complementary figures to the results ......................................... 81 


\section{LIST OF FIGURES}

Figure 2.1 - (a) Anabatic flow conditions during the day through the valley associated with the wind of the valley. (b) Conditions of katabatic flow. Source: Wallace and Hobbs (2006). 6

Figure 2.2 - Three interacting wind systems are found over mountainous terrain (the Appalachian Mountains). Source: Whiteman (2000). 7

Figure 2.3 - The Venturi effect creates a jet to create as winds pass through a terrain constriction and strengthen. Source: Whiteman (2000). .8

Figure 2.4 - The dividing streamline height is the height of the boundary between low-level air, which splits to flow around the barrier, and upper-level air, which is carried over the barrier (Source: Whiteman, 2000). 10

Figure 2.5 - The dividing streamline height is the height of the boundary between low-level air, which splits to flow around the barrier, and upper-level air, which is carried over the barrier (Source: Roe, 2005). 11

Figure 3.1 - (a) WRF domains for the $6 \mathrm{~km}$ (D01) and $2 \mathrm{~km}$ (D02) grid spacing simulations. (b) Location of the upper Santa watershed. Color dots indicate the meteorological station position. Blue and orange dots correspond to SENAMHI and UNASAM stations respectively. 17

Figure 4.1 - Averaged horizontal wind speed (color shaded, $\mathrm{m} \mathrm{s}^{-1}$ ) as well as wind vectors (arrows, $\mathrm{m} \mathrm{s}^{-1}$ ) from ERA5 data in March at: (a) 200hPa, (b) 500hPa and (c) $850 \mathrm{hPa}$. 24

Figure 4.2 - Averaged for March 2013 of horizontal wind speed (color shaded, $\mathrm{m} \mathrm{s}^{-1}$ ) and wind vectors (arrows, $\mathrm{m} \mathrm{s}^{-1}$ ) at $200 \mathrm{hPa}$ from WRF simulations: (a) EXPC1T, (b) EXP2CT, (c) EXP1GF, (d) EXP2GF, (e) EXP2NC, (f) EXP2CT..................................27

Figure 4.3 - Averaged for March 2013 of horizontal wind speed (color shaded, $\mathrm{m} \mathrm{s}^{-1}$ ) and wind vectors (arrows, $\mathrm{m} \mathrm{s}^{-1}$ ) at $500 \mathrm{hPa}$ from WRF simulations: (a) EXPC1T, (b) EXP2CT, (c) EXP1GF, (d) EXP2GF, (e) EXP2NC, (f) EXP2CT ...................................2 28

Figure 4.4 - Averaged for March 2013 of horizontal wind speed (color shaded, $\mathrm{m} \mathrm{s}^{-1}$ ) and wind vectors (arrows, $\mathrm{m} \mathrm{s}^{-1}$ ) at $850 \mathrm{hPa}$ from WRF simulations: (a) EXPC1T, (b) EXP2CT, (c) EXP1GF, (d) EXP2GF, (e) EXP2NC, (f) EXP2CT. 29 
Figure 4.5 - March precipitation (mm day ${ }^{-1}$ ) mean from (a) CHIRPS, (b) PISCO, (c) TRMM3B42, (d) CMORPH data and WRF simulations (e) EXP1CT, (f) EXP2CT, (g) EXP1GF, (h) EXP2GF (i) EXP2NC, and (j) EXP2T run. Brown contours show 500 and 3500 $\mathrm{m}$ orography limits.

Figure 4.6 - Color dots indicate accumulated precipitation $(\mathrm{mm} / \mathrm{month})$ amounts at in situ stations and WRF runs. Delimitation of the Rio Santa Basin watershed is indicated in bold black lines. The coastline is also indicated in black. 32

Figure 4.7 - Amount of hourly rainfall contribution to the total of the day in March 2013 for twelve automatic stations along the Santa River basin. In situ data are plotted in yellow bars and WRF outputs in color lines. .34

Figure 4.8 - DJFM precipitation mean from (a) TRMM3B42, (b) CMORPH, (c) CHIRPS, (d) PISCO data with the (e) WRF6 and (f) WRF2 run. Brown contours show 500 and $3500 \mathrm{~m}$ orography limits.

Figure 4.9 - Color dots indicate mean precipitation (mm/day) located in the stations' positions, using all the resources of validation and WRF runs. Delimitation of the Rio Santa Basin watershed and the coastline are indicated in bold black lines. 38

Figure 4.10 -Taylor Diagram of mean precipitation (mm/day) of TRMM3B42 (B), CMORPH (C), CHIRPS (D), PISCO (E), WRF6 (F), and WRF2 (G) compared to rain gauge precipitation (A). .38

Figure 4.11 - Observed (OBS) and simulated (WRF2) wind rose in the coordinates of measurements in situ. 41

Figure 4.12 - Amount of hourly rainfall contribution to the total of the day during the summer season (December 2012- March 2013) for twelve automatic stations along the Santa River basin. .43

Figure 4.13 - DFJM precipitation mean (mm/day) from WRF2 to (a) all times step mean, (b) daytime mean (7-18hr LT), (c) nighttime mean (19-6hr LT), and (d) One hour time step mean. Brown contours show 500 and 3500 m orography limits. Delimitation of the Rio Santa Basin watershed and the coastline are indicated in bold black lines. 45

Figure 4.14 - DFJM Vertically-integrated moisture flux (arrows) and its divergence (color) from WRF2 to (a) all times step mean, (b) daytime mean (7-18hr LT), (c) nighttime mean (19-6hr LT), and (d) One hour time step mean. Reference vector in $\mathrm{g} \mathrm{kg}^{-1} \mathrm{~m} \mathrm{~s}^{-1}$ is 
displayed at the lower right corner of each panel. Units of the divergence: $10^{3} \mathrm{~g} \mathrm{~kg}^{-1} \mathrm{~s}^{-1}$. Black contours show 500 and 3500 m orography limits, and the coastline. Delimitation of the Rio Santa Basin watershed is indicated in bold dark red lines. 47

Figure 4.15 - Diurnal cycle of surface wind (arrows) at $10 \mathrm{~m}$, its divergence (color), and temperature (colored arrows) at $2 \mathrm{~m}$ from WRF2. Reference vector in $\mathrm{m} \mathrm{s}^{-1}$ is displayed at the lower right corner of each panel. Units of the divergence: $10^{-3} \mathrm{~s}^{-1}$. Bold black contours show 500 and $3500 \mathrm{~m}$ orography limits. Delimitation of the coastline is indicated in thin black line.

Figure 4.16 - Diurnal cycle of surface wind (arrows) at $10 \mathrm{~m}$ and specific humidity (color) at $2 \mathrm{~m}$ from WRF2. Reference vector in $\mathrm{m} \mathrm{s}^{-1}$ is displayed at the lower right corner of each panel. Bold brown contours show 500 and 3500 m orography limits. Delimitation of the coastline is indicated in thin black line. 50

Figure 4.17 - DJFM averaged horizontal wind speed (color shaded, $\mathrm{m} \mathrm{s}^{-1}$ ) as well as wind direction (arrows, $\mathrm{m} \mathrm{s}^{-1}$ ) from WRF6 for 13, 15, 17, an19 LT at $200 \mathrm{hPa}$. Black contours indicate the delimitation of the countries and the Rio Santa watershed.... 52

Figure 4.18 - DJFM averaged horizontal wind speed (color shaded, $\mathrm{m} \mathrm{s}^{-1}$ ) as well as wind direction (arrows, $\mathrm{m} \mathrm{s}^{-1}$ ) from WRF6 for 13, 15, 17, an19 LT at $500 \mathrm{hPa}$. Black contours indicate the delimitation of the countries and the Rio Santa watershed. 53

Figure 4.19 - DJFM averaged horizontal wind speed (color shaded, $\mathrm{m} \mathrm{s}^{-1}$ ) as well as wind direction (arrows, $\mathrm{m} \mathrm{s}^{-1}$ ) from WRF6 for 13, 15, 17, an19 LTat $850 \mathrm{hPa}$. Black contours indicate the delimitation of the countries and the Rio Santa watershed. 54

Figure 4.20 - DJFM averaged horizontal wind speed (color shaded, $\mathrm{m} \mathrm{s}^{-1}$ ) as well as

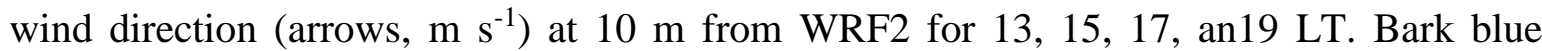
contours show 500 and 3500 m orography limits. Delimitation of the coastline and the Rio Santa watershed are indicated in thin black line 57

Figure 4.21 - Vertical cross-section of zonal and vertical (x 10) winds (arrows, $\mathrm{m} \mathrm{s}^{-1}$ ) and specific humidity (color, $\mathrm{g} \mathrm{kg}^{-1}$ ) for the times 13, 15, 17, and 19 LT obtained from WRF2 at $8.66^{\circ} \mathrm{S}$ (north section). 59

Figure 4.22 - Vertical cross-section of zonal and vertical (x 10) winds (arrows, $\mathrm{m} \mathrm{s}^{-1}$ ) and cloud water mixing ratio (color, $\mathrm{g} \mathrm{kg}^{-1}$ ) for the times $13,15,17$, and $19 \mathrm{LT}$ obtained from WRF2 at $8.66^{\circ} \mathrm{S}$ (north section). 60 
Figure 4.23 - Vertical cross-section of zonal and vertical (x 10) winds (arrows, $\mathrm{m} \mathrm{s}^{-1}$ ) and specific humidity (color, $\mathrm{g} \mathrm{kg}^{-1}$ ) anomalies (time-step mean minus the daily average) for $13,15,17$, and $19 \mathrm{LT}$ from WRF2 at latitude $8.66^{\circ} \mathrm{S}$ (north section) 61

Figure 4.24 - Vertical cross-section of zonal and vertical (x 10) winds (arrows, $\mathrm{m} \mathrm{s}^{-1}$ ) and cloud water mixing ratio (color, $\mathrm{g} \mathrm{kg}^{-1}$ ) for the times 13, 15, 17, and $19 \mathrm{LT}$ obtained from $\mathrm{WRF} 2$ at $9.15^{\circ} \mathrm{S}$ (center section) and between $78.2^{\circ}-76.8^{\circ} \mathrm{W}$ of longitude. 62

Figure 4.25 - Vertical cross-section of zonal and vertical (x 10) winds (arrows, $\mathrm{m} \mathrm{s}^{-1}$ ) and specific humidity (color, $\mathrm{g} \mathrm{kg}^{-1}$ ) anomalies (time-step mean minus the daily average) for $13,15,17$, and $19 \mathrm{LT}$ from WRF2 at latitude $9.15^{\circ} \mathrm{S}$ (central section) and between $78.2^{\circ}$ $76.8^{\circ} \mathrm{W}$ of longitude.

Figure 4.26 - Vertical cross-section of zonal and vertical (x 10) winds (arrows, $\mathrm{m} \mathrm{s}^{-1}$ ) and cloud water mixing ratio (color, $\mathrm{g} \mathrm{kg}^{-1}$ ) for the times 13, 15, 17, and $19 \mathrm{LT}$ obtained from $\mathrm{WRF} 2$ at $9.75^{\circ} \mathrm{S}$ (south section) and between $78.1^{\circ}-76.6^{\circ} \mathrm{W}$ of longitude. 64

Figure 4.27 - Vertical cross-section of zonal and vertical (x 10) winds (arrows, $\mathrm{m} \mathrm{s}^{-1}$ ) and specific humidity (color, $\mathrm{g} \mathrm{kg}^{-1}$ ) anomalies (time-step mean minus the daily average) for $13,15,17$, and $19 \mathrm{LT}$ from WRF2 at latitude $9.75^{\circ} \mathrm{S}$ (south section) and between $78.1^{\circ}-$ $76.6^{\circ} \mathrm{W}$ of longitude.

Figure 4.28 - Vertical cross-section of meridional and vertical (x 10) winds (arrows, $\mathrm{m} \mathrm{s}^{-1}$ ) and cloud water mixing ratio (color, $\mathrm{g} \mathrm{kg}^{-1}$ ) for the times 13, 15, 17, and $19 \mathrm{LT}$ obtained from WRF2 starting at $8.70^{\circ} \mathrm{S}-77.98^{\circ} \mathrm{W}$ to $9.52^{\circ} \mathrm{S}-77.58^{\circ} \mathrm{W}$. 66

Figure 4.29 - Cross-section of meridional and vertical (x 10) winds (arrows, $\mathrm{m} \mathrm{s}^{-1}$ ) and specific humidity (color, $\mathrm{g} \mathrm{kg}^{-1}$ ) anomalies (time-step mean minus the daily average) for the times $13,15,17$, and $19 \mathrm{LT}$ obtained from WRF2 starting at $8.70^{\circ} \mathrm{S}-77.98^{\circ} \mathrm{W}$ to $9.52^{\circ} \mathrm{S}$ $77.58^{\circ} \mathrm{W}$

Figure 5.1 - Schematic diagram of the main circulation from model outputs at (a) 13, (b) 16, and (c) 19 LT. Blue dashed zones correspond to precipitation maxima. Light bluegreen arrows indicate vertically-integrated moisture flux, thin light blue arrows are surface moisture flux and thin dark blue arrows are surface winds. .70

Figure A.8.1 - DFJM precipitation mean (mm/day) from CMORPH to one-hour time step mean. Brown contours show 500 and 3500 m orography limits. Delimitation of the Rio Santa Basin watershed and the coastline are indicated in bold black lines. .81 
Figure A.8.2 - DJFM averaged horizontal wind direction (arrows, $\mathrm{m} \mathrm{s}^{-1}$ ) as well as anomalous specific humidity (color shaded, $\mathrm{g} \mathrm{kg}^{-1}$ ) from WRF2 for 13, 15, 17, an19 LT at $700 \mathrm{hPa}$. Black contours indicate the delimitation of the countries and the Rio Santa watershed. .82

Figure A.8.3 - DJFM averaged horizontal wind direction (arrows, $\mathrm{m} \mathrm{s}^{-1}$ ) as well as anomalous specific humidity (color shaded, $\mathrm{g} \mathrm{kg}^{-1}$ ) from WRF2 for 13, 15, 17, an19 LT at $850 \mathrm{hPa}$. Black contours indicate the delimitation of the countries and the Rio Santa watershed. .83

Figure A.8.4 - Vertical cross-section of zonal and vertical (x 10) winds (arrows, m s ${ }^{1}$ ) and specific humidity (color, $\mathrm{g} \mathrm{kg}^{-1}$ ) for the times 13, 15, 17, and $19 \mathrm{LT}$ obtained from WRF2 at $9.15^{\circ} \mathrm{S}$ (central section). .84

Figure A.8.5 - Vertical cross-section of zonal and vertical (x 10) winds (arrows, m s ${ }^{1}$ ) and specific humidity (color, $\mathrm{g} \mathrm{kg}^{-1}$ ) for the times 13, 15, 17, and $19 \mathrm{LT}$ obtained from WRF2 at $8.66^{\circ} \mathrm{S}$ (south section). .85

Figure A.8.6 - Vertical cross-section of meridional and vertical (x 10) winds (arrows, $\mathrm{m} \mathrm{s}^{-1}$ ) and specific humidity (color, $\mathrm{g} \mathrm{kg}^{-1}$ ) for the times 13, 15, 17, and $19 \mathrm{LT}$ obtained from $\mathrm{WRF} 2$ starting at $8.70^{\circ} \mathrm{S}-77.98^{\circ} \mathrm{W}$ to $9.52^{\circ} \mathrm{S}-77.58^{\circ} \mathrm{W}$. .86 


\section{LIST OF TABLES}

Table 3.1 - Characteristics of the WRF simulations at the three different spatial grid spacings.

Table 3.2 - Physical parameterizations used in the sensitivity WRF simulation tests.

Table 3.3 - Names and the selected physical parameterization used in each WRF experiment.

Table 3.4 - List of in situ rainfall stations from UNASAM and SENAMHI. * indicates stations from the same positions.

Table 4.1 - Statistics (MB - mean bias, RMSE - root mean square error, MAE - mean absolute error) for March mean precipitation (mm/day) obtained from the different WRF runs compared to all stations 33

Table 4.2 - Statistics (Bias) for DJFM mean precipitation (mm/day) obtained from TRMM3B42, CMORPH, CHIRPS, PISCO data, and WRF simulations compared to all stations shown in Figure 4.9. 


\section{LIST OF ABBREVIATIONS}

BH: Bolivian High

CL: Chaco Low

GCM: Global Climate Model

ITCZ: Intertropical Convergence Zone

SAMS: South American Monsoon System

SALLJ: South American Low-level jet

SCAZ: South Atlantic Convergence Zone

SPA: South Pacific Anticyclone

RCM: Regional Climate Model

WRF: Weather Research and Forecasting Model

WRF6: WRF output at $6 \mathrm{~km}$

WRF2: WRF output at $2 \mathrm{~km}$ 


\section{Introduction}

The Andes mountain range is the most important topographic feature in South America, extending from Colombia to the southern tip $\left(10^{\circ} \mathrm{N}-53^{\circ} \mathrm{S}\right)$ of the continent, with a maximum altitude of $6961 \mathrm{~m}$ above sea level and width of less than $200 \mathrm{~km}$ except at subtropical latitudes. In the central part of the Andes $\left(15^{\circ}-22^{\circ} \mathrm{S}\right)$, a region is divided into two mountain ranges that are known as the Altiplano, with a width of $250 \mathrm{~km}$ and an average height of $3800 \mathrm{~m}$. The presence of the Andes has a strong impact on circulation for mesoscale phenomena and synoptic scale (e.g. Garreaud, 1999, 2009). On the west side of the Andes, the presence of the South Pacific Anticyclone (SPA) establishes dry and stable conditions of high subsidence. On the other hand, the status of high humidity in the low and medium levels of the troposphere predominate on the east side (e.g. Garreaud, 1999, 2009). In the austral summer (December-January-February, DJF), the South Pacific Ocean provides moisture for precipitation over the latitudinal tip of South America. Whereas, the North Atlantic Ocean is a large source of moisture for precipitation over the tropics of South America (Gimeno et al., 2010). During this season, the surface wind has a strong northward component associated with the presence of the SAP along most of the west coast of South America (Romatschke \& Houze, 2010). On the coast, an extended sea-breeze is created due to diurnal solar heating of the coastal land surfaces (Enfield, 1981; Takahashi, 2012) although these winds do not pass over the Andes, leaving without effect on the convection on the east side (Romatschke \& Houze, 2010). The Andes are influenced by tropical and extratropical upper-level large-scale circulation because of their extension over all of South America. At low latitudes $( \pm 15$ of latitude) the circulation is dominated by the easterly winds while in subtropical and extratropical latitudes by westerly winds (Garreaud, 2009).

In the South American summer, the upper-level $(200 \mathrm{hPa})$ circulation is dominated by the presence of the large anticyclonic circulation called Bolivian High (BH), which was first identified by Gutman and Schwerdtfeger (1965) and Virji (1981). It is centered near at $15^{\circ} \mathrm{S}$ and $65^{\circ} \mathrm{W}$ (Vera et al., 2006) and some studies suggest that its intensification and

southward movement are associated with intense precipitation events (e.g. Aceituno \& 
Montecinos, 1993; Lenters \& Cook, 1999). Numerical studies suggest that the BH results of the diabatic warming over the Amazon basin (Figueroa et al., 1995; Lenters \& Cook, 1999). At low levels, the low pressure called Chaco Low (CL) together with the $\mathrm{BH}$ are generated as a regional response of the tropospheric circulation by the strong convective heating in the Amazon (Vera et al., 2006). In addition, the CL is intensified by the Andes (Gandu \& Silva Dias, 1998). The presence of the South Atlantic Convergence Zone (SCAZ) is a distinctive feature (Kodama, 1992) and indicator of the mature phase of the South American Monsoon System (SAMS) (Marengo et al., 2012; Vera et al., 2006). In addition, this phase is associated with deep convection over the Amazon. In this period, a large amount of moisture is transported from the tropical Atlantic Ocean, where the Intertropical Convergence Zone (ITCZ) is organizing deep convection between $5^{\circ}$ to $8^{\circ} \mathrm{N}$ (Zhou \& Lau, 1998), to the Amazon basin (Vera et al., 2006) by the trade winds. This transport increases the moisture in the planetary boundary layer and the temperature at the top of the layer, favoring convection in tropical South America (Liebmann \& Marengo, 2001; Marengo et al., 2001). The northeasterly trade winds suffer a deflection when encountering the Andes and turn to the north/northwesterly, flowing and tranporting moisture southward in the eastern side of the Andes (Marengo et al., 2002). In several days, this flow reaches high wind speeds at low levels, resulting in the South American Low-level jet (SALLJ). The SALLJ intensifies the meridional moisture transport in the eastern side of the tropical Andes (Marengo et al., 2004), allowing an important transfer of energy and moisture from tropical to subtropical zones of South America (Berbery \& Barros, 2002). The interaction of the north/northwest meridional flow with the eastern flanks of the Central Andes is associated with the formation of deep precipitation nuclei "hotspots" (Espinoza et al., 2015). The precipitation in the Tropical Andes during the austral summer is due to the development of deep convective storms over the mountain range (Garreaud, 2009). In the Altiplano, this season is distinguished with the destabilization of the local troposphere, by intense surface heating and the presence of stronger-than-normal upper-level easterly winds that favor the transport of moist air from the interior of the continent. In addition, the rainy episodes are associated with intensifying and displaced southward of the BH (Garreaud, 1999, 2009; Lenters \& Cook, 1999).

As mentioned, there are several studies showing the influence of the Andes on largescale circulation over the South America. In contrast, the interactions of local (valley- 
mountain circulation) with regional processes associated with the diurnal cycle of precipitation have not yet been properly explored over the tropical Andes (Junquas et al., 2018). According to Poveda (Poveda et al., 2005), the presence of the Andes with intraAndean valleys, establish the local orography that characterizes the atmospheric circulation linked with deep convection and associated with intense rainfall. The high values of precipitation in the Ecuadorian Andes, are due to due to enhanced orographic rainfall and the permanent drizzle from orographic clouds (Garreaud, 2009). In subtropical latitudes, the presence of the Andes Mountain Range and solar radiation are the trigger mechanisms for convection. Thereby, they modulate both the spatial distribution of the precipitation and its intensity (García-Ortega et al., 2009). In this way, the Andes influence the local circulation that is associated with the development of precipitation. Consequently, it is important to conduct studies focused on this topic since several of the orographic effects in precipitating clouds occur near the less studied mountain ranges in the tropics and subtropics (Houze, 2012). In particular, to understand the physical mechanisms controlling rainfall is essential in some specific regions of the tropical Andes, such as the Rio Santa basin. This basin has an extension of $11910 \mathrm{~km}^{2}$ and it is located in the central coast of Peru (limited by $10.23^{\circ}-7.97^{\circ} \mathrm{S}$ and $78.65^{\circ}-77.17^{\circ} \mathrm{W}$ ) in the department of Ancash. It is part of the Pacific hydrographic region bounded in its western side by the Cordillera Negra (mountainous chain lacking glaciers) and in eastern by Cordillera Blanca (largest glacial chain of Peru), composing the Occidental Cordillera. The Santa River drains into the Pacific at the height of the city of Chimbote and is parallel to the Marañón valley, which discharges into the Atlantic (Vignon, 2002). In this way, the Amazon is located in the east of the Cordillera Central and to the west of the Occidental Cordillera lies the Coast. The Cordillera Blanca, which represent the largest concentration of Tropical Glaciers in the world, constitutes approximately $35 \%$ of the Peruvian Glaciers (Zapata et al., 2008). Glaciers in the dry season (May-September) allow the Santa River to maintain a relatively stable flow, favoring the agriculture and the production of electrical energy (such as the hydropower station of El Cañon del Pato; Vignon, 2002). However, previous studies revealed a retreat of glaciers in the last five decades (e.g. Georges, 2004; Kaser et al., 1990; Vuille et al., 2008). It is confirmed recently by Condom et al. (2012), who observes through satellite images the retreating of the Cordillera Blanca. Vuille et al. (2008) discussed that the interannual variability of precipitation is the most 
significant variable associated with the fluctuations of the mass balance of the Glacier. This is observed in the relationship between mass balance variations and local- to regional-scale precipitation variability. On the other hand, Kaser et al. (1990) pointed as principal factor, in the seasonality and distribution of precipitation over the Cordillera Blanca, the positioning of the ITCZ which brings southeasterly moist air masses towards the basin, organizing the rainfall in the watershed and over the most elevated areas. In this way, the importance of the study of the Cordillera Blanca, as well as the precipitation variable both locally and regionally, is evident.

Some tools to evaluate the previously discussed atmospheric processes are the atmospheric numerical models and the reanalyses. However, both global climate models (GCMs) and reanalyses do not have yet spatial resolution to represent local scale processes in the tropical Andes. Therefore, the downscaling thecnique using regional climate models (RCMs), such as model Weather Research and Forecasting (WRF), has been used by previous studies on the Andes region (e.g. Junquas et al., 2016; Mejía \& Douglas, 2006; Moya-Álvarez et al., 2018; Ochoa-Sánchez et al., 2014; Spiga et al., 2008), but few on the Cordillera Blanca (e.g. Mourre et al., 2016) and focused on local processes (e.g. Junquas et al., 2018). The WRF has different options of physical parameterizations such as microphysics, convection, planetary boundary layer, radiation, soil surface among others (Skamarock et al., 2008). In this way, it is possible to configure the model to simulate local phenomena, such as the formation of convective nuclei associated with intense rainfall in the Andes (Garreaud, 1999). In addition, the WRF outputs may have high spatial and temporal resolutions, which help to reconstruct the tri-dimensional structure of atmosphere in a region of complex topography with low density of observed data (Garreaud, 2009).

The main objective of the present research is to understand the combination of local and regional mechanisms associated with the precipitation diurnal cycle over tropical Andes Mountain using the WRF model. Thus, the following specific objectives will be addressed:

- Evaluate the sensitivity of different WRF setups in simulating the main features of observed precipitation; 
- Validate the WRF model performance in simulating the observed (rain gauge observations and satellite estimates) precipitation;

- Identify the local-regional scales processes associated with the precipitation diurnal cycle over the Rio Santa Basin. 


\section{Literature Review}

\subsection{Valley-Mountain Circulations}

\subsubsection{Diurnal Mountain Winds}

The valley-mountain valley circulations can be understood as a combination of local and mesoscale processes. According to Wallace and Hobbs (2006), during the day the sun warms the sides of mountains, the air ascends to generate anabatic wind (valley wind ) until the two winds on each side of mountain meet and possibly form cumulus clouds depending on the availability of moisture (Fig. 2.1.a). During the night, the sides of the mountain are cooled faster by longwave radiation, and the cold air sinks as katabatic winds (mountain winds). The cooled air converges on the valley (cold pool) generating fog. However, if the downslope air does not descend until the bottom of the valley it stays where the buoyancy is neutral (Fig. 2.1.b).
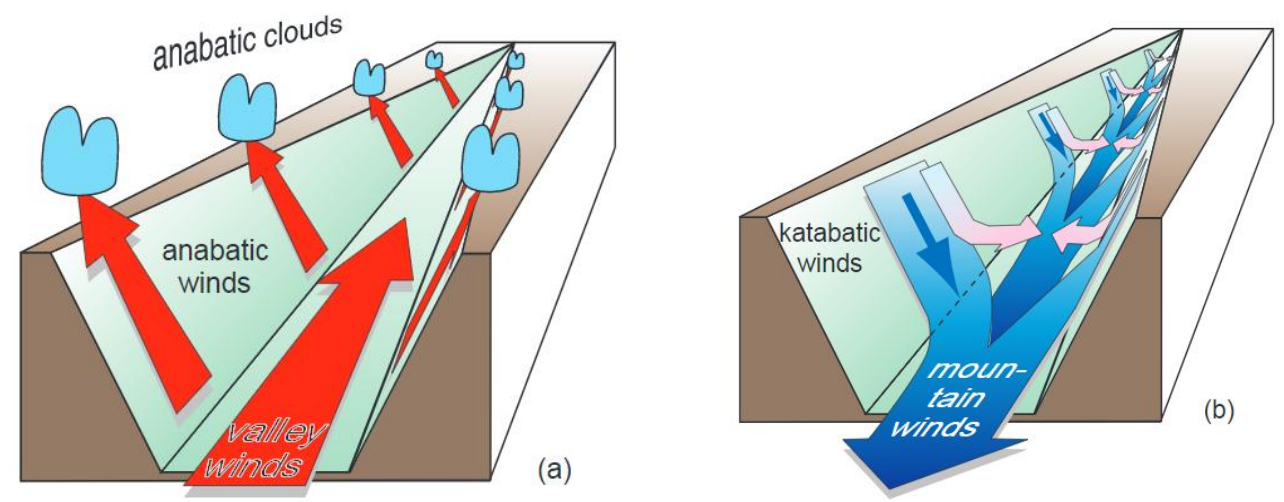

Figure 2.1 - (a) Anabatic flow conditions during the day through the valley associated with the wind of the valley. (b) Conditions of katabatic flow. Source: Wallace and Hobbs (2006). 
As previously commented, the horizontal temperature difference produces diurnal mountain winds. The winds near surface blow from areas with lower temperatures and higher pressures toward areas with higher temperatures and lower pressures. After understanding how valley-mountain circulation works, three mountain wind systems (Fig. 2.2) are identified by Whiteman (2000):

In the first, the upslope winds and downslope winds are driven by horizontal temperature contrasts between the air over the valley sidewalls and the air over the center of the valley. In the second, the up-valley winds and down-valley winds are driven along a valley's axis or between the air in a valley and the air over the adjacent plain. Finally, the mountain-plain wind system results from horizontal temperature differences between the air over a mountain massif and the air over the surrounding plains.

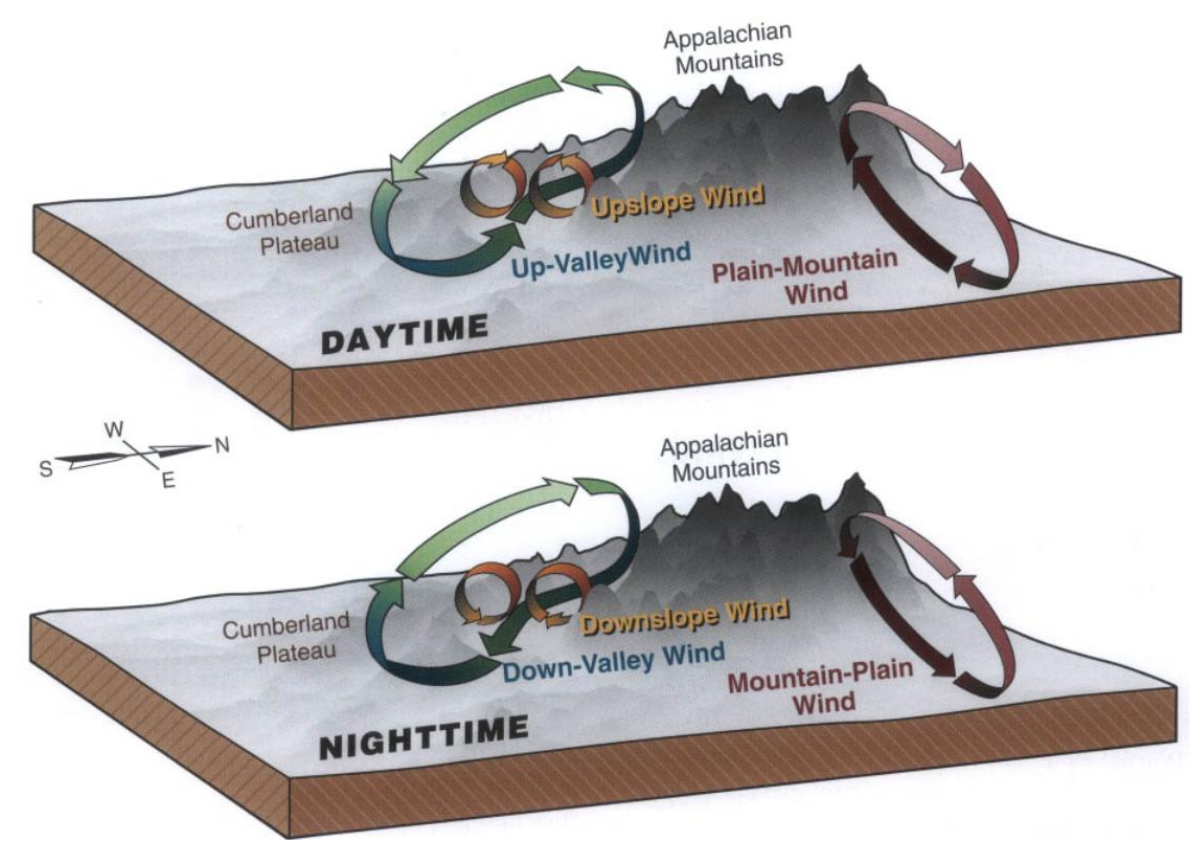

Figure 2.2 - Three interacting wind systems are found over mountainous terrain (the Appalachian Mountains). Source: Whiteman (2000). 


\subsubsection{Terrain-Forced Flows}

The Venturi or Bernoulli Effect defines the acceleration through a terrain constriction. It happens when winds pass through a terrain constriction and strengthen (Fig. 2.3). Thereby, the flow speed increases when the cross-section of the flow narrows and decreases when the cross-section widens.

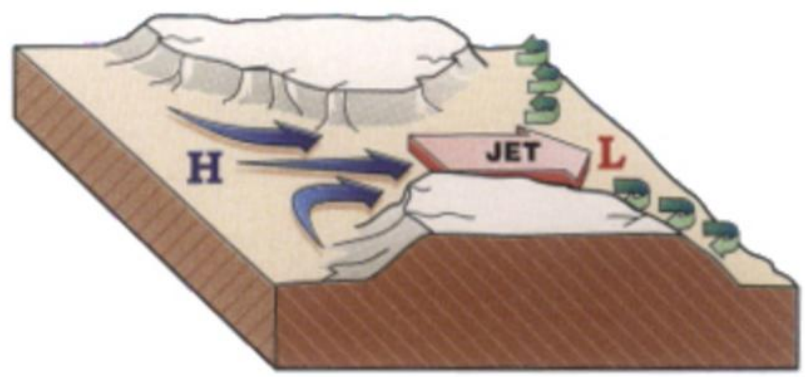

Figure 2.3 - The Venturi effect creates a jet to create as winds pass through a terrain constriction and strengthen. Source: Whiteman (2000).

In other words the thermally conducted circulations begin with the development of the temperature gradient as a function of differential solar heating of the earth's surface during the day and longwave radiative cooling at night; consequently generates a pressure gradient which in diurnal conditions obeys anabatic winds, and during the night the katabatic winds.

\subsection{Orographic effect on precipitation}

The mountains have an important role in the position, intensity, and timing of convective precipitation (Houze, 1993). Since the earth's topography is a static variable, the precipitation is attributable to convective clouds, frontal systems, or tropical cyclones (Houze, 2012). The orographic precipitation is described as the rain and/or snow caused by the flow over the complex terrain. This flow can be affected by three factors, the stability and 
speed of the air approaching to the mountains, and the topographic characteristics of the terrain (Whiteman, 2000). Under stable conditions, it is more difficult to lift the air. As a result, the air circulates around the slopes of the mountains. The stable layer air can be divided by air flowing over the mountain barrier and air splitting upwind of the mountain, flowing around the barrier and converging on the leeward side (Fig. 2.4). According to Houze (2012), the spatial variability of precipitation over complex terrain depends on three principal factors such as microphysics of particles growth, the dynamical behavior of the flow, and the thermodynamics of moist air.

The microphysics processes have an important effect on the condensation associated with the distribution of precipitation (Roe, 2005). For example, there are different possibilities of interaction between cloud ice and cloud water particles to form precipitation. Thus, the growth and evaporation exchanges of the latent heating with the surrounding air have an important influence on the airflow. The microphysical time scales combined with the width of the terrain and the characteristics of the airflow determine the zones where precipitation will fall out (Roe, 2005).

The airflow dynamics have two main cases. The first case refers to an unstable flow when convective precipitation is triggered for the oncoming air raises crossing over the mountain. Otherwise, the stable flow is influenced by the strength of the cross-barrier component of the upstream airflow, the degree of the thermodynamic stability of oncoming flow, and the height of the terrain barrier. Finally, the presence of clouds over the mountain is associated with the vapor pressure that decreased exponentially with temperature and height. The precipitation is greater on the lower levels of the terrain on account of the interaction with microphysical and dynamical trends make higher mountains drier than the lower. 


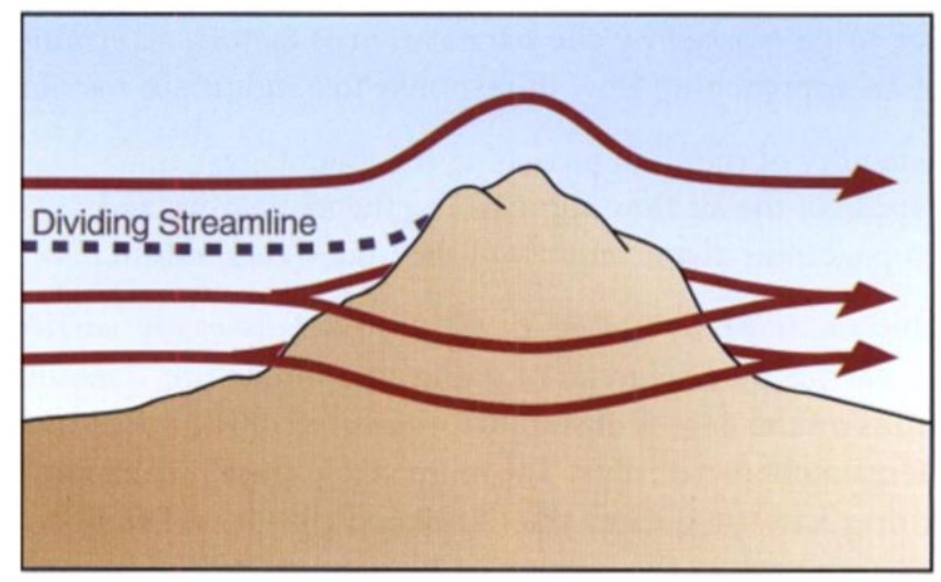

Figure 2.4 - The dividing streamline height is the height of the boundary between low-level air, which splits to flow around the barrier, and upper-level air, which is carried over the barrier (Source: Whiteman, 2000).

According to Roe (2005), based on the observations and models there are predetermined mechanisms controling orographic precipitation. For a better understanding, these can be evaluated independently. However, more than one mechanism may be present in the development of orographic precipitation. The simplest mechanism of orographic precipitation is the upslope ascent windward, which causes cooling in the air column favoring condensation and later precipitation (Fig. 2.5.a). In contrast, the descent leeward leads to heating and drying, which consequent inhibiting of precipitation. In the another case, the atmosphere is very stable and the flow is not intense enough for the air to rise above the mountain so the flow is blocked (Fig. 2.5.b). This blocking causes a deviation or concentration of the flow, the latter encourages the ascent, intenfying the lifting associated with precipitation. The processes of melting and evaporation of the precipitation cool the surrounding air, causing a strong subsident flow over the valley (Fig. 2.5.c). Another interaction of the airflow with the orography is when it diverges windward and converges leeward, also denominated like zone of convergence, causing precipitation (Fig. 2.5.d). In unstable atmospheric conditions, convection takes the air above of the level of free convection (a condition where the density of the air parcel is smaller than the environment) and continues to develop vertically (Fig. 2.5.e). In effect, the condensation rate is intensified, producing a greater quantity of super-cooled cloud water droplets, leading to riming onto ice particles, being the fall-out of particles more efficient in the precipitation. Another response 
to the presence of complex orography is the heating of the slopes, causing storms in the afternoon (Fig. 2.5.f). The last mechanism is called "seeder-feeder", which consists in the presence of a large-scale cloud (the seeder) positioned below another cloud (the feeder), which results by the rise of air on the hill (Fig. 2.5.g). Consequently, the precipitation falling from the seeder cloud increases the moisture of the feeder cloud, either by coalescence or by riming, which increases the precipitation.

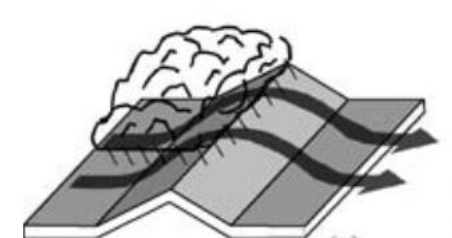

(a)

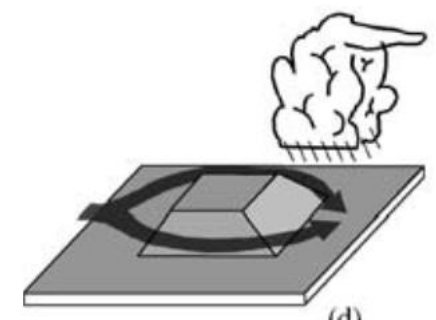

(d)

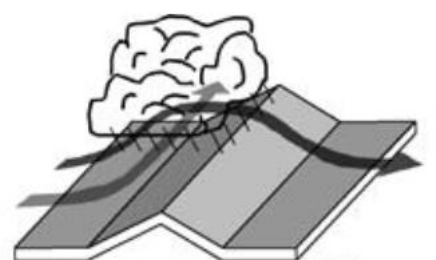

(b)

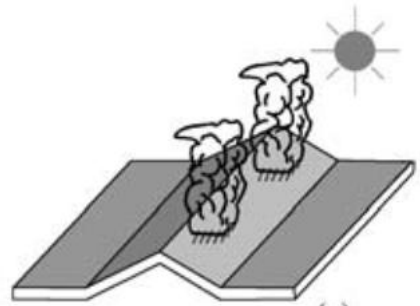

(e)

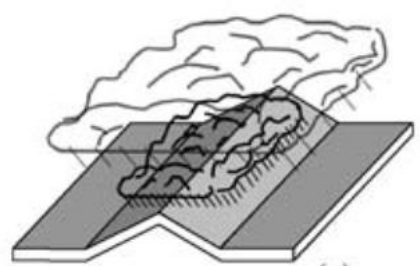

(g)

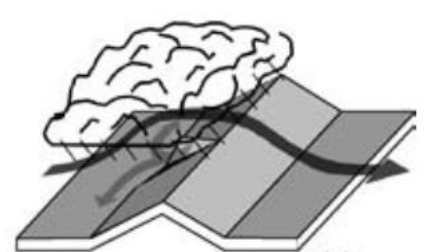

(c)

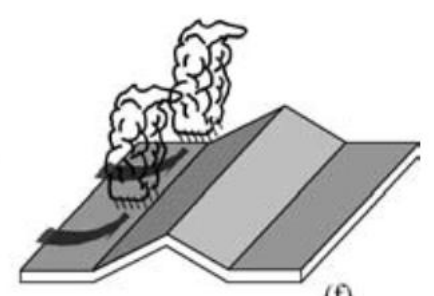

(f)

Figure 2.5 - The dividing streamline height is the height of the boundary between low-level air, which splits to flow around the barrier, and upper-level air, which is carried over the barrier (Source: Roe, 2005).

\subsection{Regional climate modeling over complex topography}

Once seen the orographic effect in precipitation, it is necessary to identify the physical and dynamic atmospheric features governing each region of complex topography. Therefore, the use of regional climate models (RCMs) is key to investigate the regional and local 
processes controlling the precipitation in the fine spatial resolution simulations. The focus is on the simulations over tropical Andes since it is the main of interest. However, there are other complex topography regions such as the Colorado Rockies (Tripoli \& Cotton, 1989) and the Tibetan Plateau (Tang \& Reiter, 1984) with intense precipitation events.

RCMs simulations on complex topography are of great utility for the understanding atmospheric processes, which helps to improve the weather forecasting (e.g. Moya-Álvarez et al., 2018; Yáñez-Morroni et al., 2018) and the study of climatology (e.g. da Rocha et al., 2009; Junquas et al., 2018; Mourre et al., 2016; Ochoa-Sánchez et al., 2014). The study of Smiatek et al. (2009) over the European Alps shows that the RCMs such as RegCM (Regional Climate Model), REMO (REgional MOdel), HIRHAM (HIgh Resolution HAmburg Climate Model), COSMO-(Consortium for Small-Scale Modeling) CLM (COSMO in Climate Mode), and WRF (Weather Research and Forecasting) are able to simulate adequately the monthly climatology of temperature and precipitation. Second Smiatek et al. (2009), to obtain better results in simulating precipitation it is necessary to improve the performance of the RCMs by running high-resolution experiments with non-hydrostatic core since it allows reaching finer grid spacing $(\sim 10 \mathrm{~km})$. In contrast, the GCMs, which fail to reach similar spatial grid spacing, have an inaccuracy in the representation of the orography and the soil coverage as well, which limit the representation of the observed mesoscale processes.

In the Central Andes, Moya-Álvarez et al. (2018) suggests that WRF, independently of setups chosen, overestimates the precipitation in the Tropical Andes compared with the TRMM3B42 product. When WRF is compared with the data of TRMM3B42 and TRMM2A25 products, it shows an adequate representation of the spatial distribution of precipitation over the Central Andes and the diurnal cycle, respectively. However, there is a strong overestimation of rainfall on the peaks of the Andes as found by Junquas et al. (2018). The diurnal cycle of precipitation is a point of great importance, and little explored according to da Rocha et al. (2009), because it affects the energy budget and the regional circulation, with consequences in the climatic characteristics of a region. Identifying the synoptic systems associated with diurnal cycle and their interaction with orography are vital for understanding how atmospheric circulation influences the rainfall variability (Junquas et al., 2018). Therefore, the use of RCMs such as the WRF is a possible resource to study these processes. 


\section{Data and methodology}

\subsection{Model and experiments}

The simulations of the climate conditions in the Rio Santa Basin during the rainy season months (DJFM) applied the Weather Research and Forecasting (WRF) model, version 3.8.1, considering the Advanced Research WRF (ARW) core. The ARW solves the compressible and nonhydrostatic Euler equations in a terrain-following vertical coordinate (Skamarock et al., 2008).

The analysis of WRF simulations is divided into two parts. The first consists in evaluating different parameterization schemes to identify the most acceptable setup to describe the observed diurnal cycle of precipitation during March 2013 at 5km (WRF5) of grid spacing. In the second, once identified an acceptable configuration, a nesting simulation, with 6km (WRF6) and 2km (WRF2) of grid spacing's, is carried out for the period from December 2012 to March 2013 (summer season). Table 3.1 resumes the principal features of the simulations.

Table 3.1 - Characteristics of the WRF simulations at the three different spatial grid spacings.

\begin{tabular}{|lcc|c|}
\hline & WRF5 & D01 (WRF6) & D02 (WRF2) \\
\hline Domain & Tropical Andes & Tropical Andes & Rio Santa region \\
\hline Configuration & Regional Simulation & Regional simulation & One-way nesting \\
\hline Horizontal grid spacing $(\mathrm{km})$ & $\mathbf{5}$ & $\mathbf{6}$ & $\mathbf{2}$ \\
\hline Number of grid points & $\mathbf{4 5 2 x 4 7 2}$ & $\mathbf{3 9 1 x 3 9 7}$ & $\mathbf{1 8 7 x 1 7 2}$ \\
\hline Vertical resolution & $\mathbf{3 8}$ sigma levels & $\mathbf{3 8}$ sigma levels & $\mathbf{3 8}$ sigma levels \\
\hline Forcing & ERA5 & ERA5 & WRF6 \\
\hline Run time step (s) & $\mathbf{3 0}$ & $\mathbf{1 2}$ & $\mathbf{4}$ \\
\hline Output time resolution $(\mathrm{h})$ & $\mathbf{1}$ & $\mathbf{2 1}$ & $\mathbf{1}$ \\
\hline Start/end date & $\mathbf{3 1}$ March 2013 & $\mathbf{3 1}$ March 2013 & $\mathbf{3 1}$ March 2013 \\
\hline
\end{tabular}


How mentioned, the first part is making sensitivity tests of different WRF parameterizations over one domain with $5 \mathrm{~km}$ of horizontal grid spacing. This domain covers the Tropical Andes region and the simulations are for March 2013, which is the month with high accumulated precipitation in the Rio Santa basin (Condom et al., 2011). Table 3.1 describes the different experimental setups, while Table 3.2 presents the physical parameterizations together with the appropriated references.

Table 3.2 - Physical parameterizations used in the sensitivity WRF simulation tests.

\begin{tabular}{|c|c|c|}
\hline & Parameterization & Reference \\
\hline \multirow[t]{2}{*}{ Planetary boundary layer } & $\begin{array}{l}\text { Yonsei University with wind } \\
\text { topographic correction (option } \\
\text { 1) }\end{array}$ & Hong et al. (2006) \\
\hline & $\begin{array}{l}\text { Mellor-Yamada Nakanishi and } \\
\text { Niino Level } 2.5 \\
\text { (MYNN2) }\end{array}$ & Nakanishi \& Niino (2006) \\
\hline \multirow[t]{2}{*}{ Surface layer } & Similarity theory & Paulson (1970) \\
\hline & MYNN & \\
\hline Land Surface & $\begin{array}{l}\text { Noah-MP (multi-physics) with } \\
\text { precipitation partitioning } \\
\text { between snow and rain (option } \\
\text { 2) }\end{array}$ & $\begin{array}{l}\text { Niu et al. (2011); (Yang et al., } \\
\text { 2011) }\end{array}$ \\
\hline \multirow{3}{*}{$\begin{array}{l}\text { Cumulus } \\
\text { parameterization }\end{array}$} & Grell-Devenyi & Grell \& Devenyi (2002) \\
\hline & Betts-Miller-Janjic & $\begin{array}{l}\text { Betts, 1986; Betts \& Miller, } \\
\text { 1986; Janjić, } 1994\end{array}$ \\
\hline & Grell-Freitas & Grell \& Freitas (2014) \\
\hline \multirow[t]{2}{*}{ Microphysics } & Thompson & Thompson et al. ( 2008) \\
\hline & Goddard & Tao et al. (1989) \\
\hline \multirow[t]{3}{*}{ Radiation } & Longwave:Rapid & Iacono et al. (2008) \\
\hline & Transfer Model (RRTM) & \\
\hline & Shortwave: Dudhia scheme & Dudhia (1988) \\
\hline
\end{tabular}

Table 3.3 presents the selected physical parameterization used in each experiment. From Table 3.3 it is clear that all WRF sensitivity experiments used the same radiation (RRTM for longwave; Iacono et al., 2008 and Dudhia for shortwave; Dudhia 1988) and land surface Noah-MP (multi-physics) (Niu et al., 2011; Yang et al., 2011) schemes described in 
Table 3.2. The Noah-MP is an extended version of the Noah land surface model, which has the option of the partitioning of precipitation into rainfall and snowfall (option 2) using the Biosphere-Atmosphere Transfer Scheme. In this option, if the air temperature is lower than the freezing point plus $2.2 \mathrm{~K}$, the precipitation is assumed as snowfall. Otherwise, it is rainfall.

Table 3.3 - Names and the selected physical parameterization used in each WRF experiment.

\begin{tabular}{|c|c|c|c|c|c|c|}
\hline & EXP1CT & EX2CT & EXP1GF & EXP2GF & EXP2NC & EXP2T \\
\hline \multirow[t]{2}{*}{ PBL } & Yonsei University & & & & & \\
\hline & Mellor-Yamada & & & & & \\
\hline \multirow[t]{2}{*}{ Surface layer } & MM5 similarity & & & & & \\
\hline & MYNN & & & & & \\
\hline \multirow{4}{*}{$\begin{array}{l}\text { Cumulus } \\
\text { scheme }\end{array}$} & Grell-Devenyi & & & & & \\
\hline & Betts-Miller-Janjic & & & & & \\
\hline & Grell-Freitas & & & & & \\
\hline & No cumulus scheme & & & & & \\
\hline \multirow[t]{2}{*}{ Microphysics } & Thompson & & & & & \\
\hline & Goddard & & & & & \\
\hline
\end{tabular}

After fixed these three parameterizations, the sensitivity simulations considered two main configurations. The first, the control (Table 3.3), named EXP1CT, uses Yonsei University scheme (Hong et al., 2006) as planetary boundary layer parameterization including the option of topography correction for surface wind. The surface layer is specified by the MM5 scheme (Paulson, 1970) that uses a convective velocity (Beljaars, 1995) to improve the surfaces fluxes of heat and moisture. The Grell-Devenyi (Grell \& Dévényi, 2002) scheme is responsible for the sub-grid scale effects of the deep and shallow convective clouds, which considers the convective available potential energy (CAPE), low-level vertical velocity, or moisture flux convergence as dynamic control closing. While Thompson et al. (2008) scheme is used to solve explicitly water vapor, clouds, and precipitation processes. This scheme differs from the others since the snow size distribution depends on both ice water content and temperature. All these schemes are chosen following Mourre et al., (2016) 
that analyzed WRF simulations over the Rio Santa basin. The experiment called as EXP1GF is based on EXP1CT (Table 3.3), but changing cumulus scheme to Grell-Freitas (Grell \& Freitas, 2014).

The experiment EXP2CT uses Mellor-Yamada Nakanishi and Niino Level 2.5 (MYNN2) (Nakanishi \& Niino, 2006) as the planetary boundary layer parameterization in conjunction with the MYNN surface layer scheme (Table 3.3). The cumulus parameterization is Betts-Miller-Janjic scheme, with modifications of the triggering mechanism to improve its performance for higher horizontal resolutions The Goddard scheme (Tao et al., 1989) describes the microphysics parameterization with options to solve the contrast between graupel and hail, and new techniques for saturation adjustment. EXP2CT's setup follows suggestions of the supervisor. The sensitivity run EXP2GF (Table 3.3) is similar to EXP2CT, except for changing the cumulus scheme by Grell-Freitas (called). The experiment EXP2NC (Table 3.3) is also similar to EX2CT but it deactivates the cumulus parameterization to demonstrate the model skill to explicitly simulate convective clouds. Further, the last sensitivity run (Table 3.3), referred as EXP2T, selects Thompson et al. (2008) scheme as microphysics parameterization in association with Betts-Miller-Janjic convective scheme.

Once tested the different parameterizations combination, one was chosen to simulate the moist period from December 2012 to March 2013. The simulations starts on November 21 at 00:00 UTC, being the first 10 days considered as a spin-up period, and they used the one-way nesting method. That is, the parent domain (D01) is simulated and after provides the initial and border conditions to the child domain (D02). D01 cover all Tropical Andes region (Fig. 3.1.a) at $6 \mathrm{~km}$ (WRF6) of grid spacing, while D02 is focused in the area of the Rio Santa Basin (Fig. 3.1.b) at 2 km (WRF2) of grid size. The details of these simulations are presented in Table 3.1, while the parameterizations are the same of EXP2CT for D01 (Table 3.3) for D02 the cumulus parametrization is deactivated. 
(b)

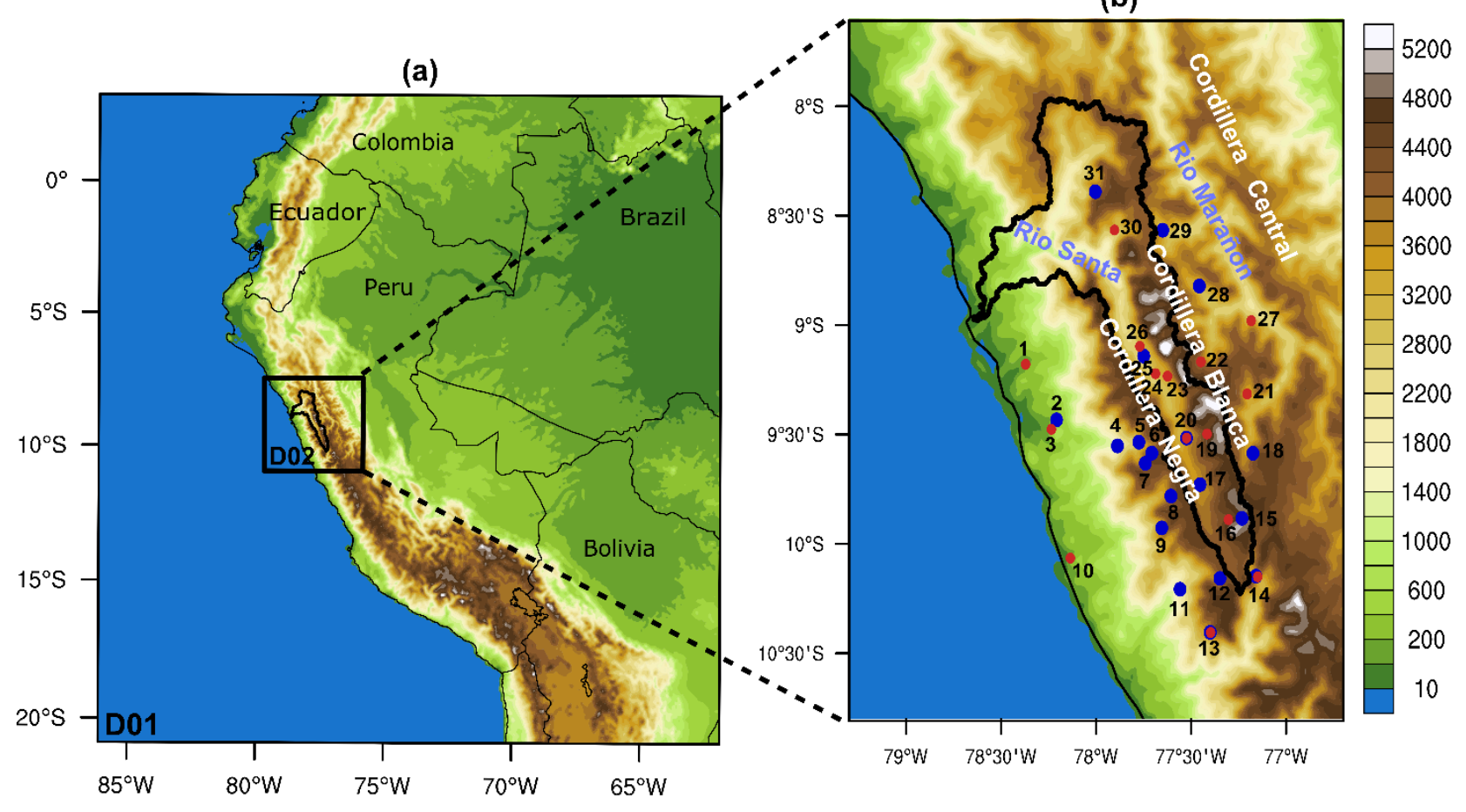

Figure 3.1 - (a) WRF domains for the $6 \mathrm{~km}$ (D01) and $2 \mathrm{~km}$ (D02) grid spacing simulations. (b) Location of the upper Santa watershed. Color dots indicate the meteorological station position. Blue and orange dots correspond to SENAMHI and UNASAM stations respectively.

\subsection{Observational and estimated dataset}

\subsubsection{Reanalysis and topography}

The WRF model is driven by ERA5 dataset to make a regional simulation. The ERA5 is another product of the European Centre for Medium-Range Weather Forecasts (ECMWF) atmospheric reanalysis of the global climate. ERA5 provides hourly data from 1950 to the present with a grid size of $30 \mathrm{~km}$ and resolve the atmosphere processes using 137 levels from the surface up to a height of $80 \mathrm{~km}$. The high resolution of ERA5 allows saving computation resource to make a regional simulation with a high horizontal resolution without many nesting domains. According to Hofer et al. (2012), the ERA-interim reanalysis has a high skill such as air temperature predictor in the Cordillera Blanca. But some studies show that the use of the National Center for Environmental Prediction (NCEP) Final Analyses (FNL) 
Global Forecast System (GFS) is usually common to drive WRF to make regional simulation over this region (e.g. Hierro et al., 2013; Mourre et al., 2016; Moya-Álvarez et al., 2018; Yáñez-Morroni et al., 2018). The present research also tests the skill of ERA5 through WRF to simulate the atmospheric conditions in the Cordillera Blanca, Knowing the advantage of using ERA product previous mentioned.

It is necessary to clarify that the elevation dataset used by WRF is for default from the United States Geological Survey (USGS) GTOPO30. It was changed by Shuttle Radar Topographic Mission (SRTM) at 90m dataset because in recently studies (Junquas et al., 2018; Mourre et al., 2016; Moya-Álvarez et al., 2019; Posada-Marín et al., 2018) is observed that this change improve the real characteristic of topography in high-resolution simulations.

\subsubsection{In-Situ Precipitation Data}

The precipitation data of weather stations from Peruvian National Meteorology and Hydrology Service (SENAMHI) is available daily throughout Peru. The weather stations cover the large Tropical Andes region but in this work, are focused on the Santa basin. The method to calculate the daily rainfall amount is measured twice at 07 and 19 local time (LT), but the 07 LT measurement is considered to the previous day. For this research, also are available the meteorological stations from the Universidad Nacional Santiago Antúñez de Mayolo (UNASAM) of Huaraz, which provide hourly rainfall data (Table 3.4). These datasets (Fig. 3.1 b) were used by Mourre et al. (2016), which employed a rigorous quality control for SENAMHI data and compared precipitation amounts reported by stations located in the same area, removing incorrect values for UNASAM data. 
Table 3.4 - List of in situ rainfall stations from UNASAM and SENAMHI. * indicates stations from the same positions.

\begin{tabular}{|c|c|c|c|c|c|}
\hline UNASAM N & Name & Lat. & Lon. & Alt. (m) & Freq. \\
\hline 1 & Nepena & -9.18 & -78.37 & 125 & hourly \\
\hline 3 & Casma & -9.48 & -78.24 & 133 & hourly \\
\hline 10 & Huarmey & -10.06 & -78.14 & 18 & hourly \\
\hline $13 *$ & Ocros & -10.41 & -77.40 & 3268 & hourly \\
\hline $14^{*}$ & Chiquian & -10.15 & -77.15 & 3405 & hourly \\
\hline 16 & Pasto Ruri & -9.89 & -77.30 & 4145 & hourly \\
\hline 19 & Quillcayhuanca & -9.50 & -77.42 & 3850 & hourly \\
\hline $20 *$ & Shancayan & -9.52 & -77.52 & 3091 & hourly \\
\hline 21 & Purhuay & -9.31 & -77.21 & 3480 & hourly \\
\hline 22 & Chacas & -9.17 & -77.45 & 3770 & hourly \\
\hline 23 & Shilla & -9.23 & -77.62 & 3040 & hourly \\
\hline 24 & Tingua & -9.22 & -77.69 & 2500 & hourly \\
\hline 26 & Canasbamba & -9.10 & -77.77 & 2350 & hourly \\
\hline 27 & San Nicolas & -8.98 & -77.18 & 2786 & hourly \\
\hline 30 & Corongo & -8.57 & -77.90 & 3172 & hourly \\
\hline SENAMHI N & Name & Lat. & Lon. & Alt. (m) & Freq. \\
\hline 2 & Buena Vista & -9.43 & -78.21 & 213 & daily \\
\hline 4 & Chacchan & -9.54 & -77.78 & 2266 & daily \\
\hline 5 & Pira & -9.59 & -77.71 & 3625 & daily \\
\hline 6 & Cajamarquilla & -9.63 & -77.74 & 3286 & daily \\
\hline 7 & Pariacoto & -9.55 & -77.89 & 1312 & daily \\
\hline 8 & Aija & -9.78 & -77.61 & 3508 & daily \\
\hline 9 & Malvas & -9.93 & -77.66 & 2979 & daily \\
\hline 11 & Chamana & -10.21 & -77.56 & 1260 & daily \\
\hline 12 & Mayorarca & -10.16 & -77.35 & 3335 & daily \\
\hline $13^{*}$ & Ocros & -10.40 & -77.40 & 3249 & daily \\
\hline $14^{*}$ & Chiquian & -10.15 & -77.16 & 3386 & daily \\
\hline 15 & Milpo & -9.88 & -77.23 & 4400 & daily \\
\hline 17 & Recuay & -9.73 & -77.45 & 3431 & daily \\
\hline 18 & Chavin & -9.59 & -77.18 & 3140 & daily \\
\hline $20 *$ & SantiagoAntunezDeMayolo & -9.52 & -77.52 & 3079 & daily \\
\hline 25 & Yungay & -9.14 & -77.75 & 2466 & daily \\
\hline 28 & Pomabamba & -8.82 & -77.46 & 2985 & daily \\
\hline 29 & Sihuas & -8.57 & -77.65 & 2716 & daily \\
\hline 31 & Cabana & -8.39 & -78.00 & 3364 & daily \\
\hline
\end{tabular}




\subsubsection{Gridded data}

The daily rainfall analysis from Climate Hazards Group InfraRed Precipitation with Station data (CHIRPS; Funk et al. 2015) version 2.0 is used. It covers the continental parts of the globe between $50^{\circ} \mathrm{N}$ to $50^{\circ} \mathrm{S}$ and is available from 1981 to the present. CHIRPS incorporate $0.05^{\circ}$ resolution satellite imagery with in-situ station data to create gridded daily rainfall analysis. Another gridded observed data is the Peruvian Interpolated data of the SENAMHI's Climatological and hydrological Observations (PISCO) version 2.0 using the Climate Hazards Precipitation Climatology (CHPClim) and the Tropical Rainfall Measuring Mission (TRMM) 2A25 dataset. The fine horizontal grid spacing ( $\sim 5 \mathrm{~km})$ of PISCO data is useful to validate WRF in Andes regions how is demonstrated by Moya-Álvarez et al. (2018).

Tropical Rainfall Measuring Mission (TRMM) 3B42 version 7, hereafter TRMM3B42 (Huffman et al., 2007; Kummerow et al., 2000), product incorporates high quality (HQ)/infrared (IR) precipitation estimations and root-mean-square (RMS) precipitation-error estimates. This data covers from $50^{\circ} \mathrm{N}$ to $50^{\circ} \mathrm{S}$ and all longitudes in a regular grid with of $0.25^{\circ}$ of latitude by longitude available each 3 hours. TRMM have been used in many studies to analyze the spatial pattern of Andes rainfall (e.g. Condom et al., 2011; Junquas et al., 2018; Mourre et al., 2016; Moya-Álvarez et al., 2018; Ochoa-Sánchez et al., 2014). Finally, the National Oceanic and Atmospheric Administration (NOAA) CPC Morphing Technique (CMORPH, Joyce et al., 2004) generates global precipitation analyses at very high spatial $(8 \mathrm{~km})$ and temporal (30 minutes) resolutions. CMORPH incorporates

precipitation estimates derived from low orbit satellite microwave observations exclusively, which is obtained only from geostationary satellite IR data. 


\subsection{Statistical analysis}

According to Wilks (2006) we can describe the next statistic verification:

The mean bias $(\mathrm{MB})$ compares the simulated and observed averages and allows understanding if there is underestimation or overestimation of the observation by the simulation. MB is calculated as:

$$
M B=\frac{1}{N} \sum_{i=1}^{N_{d}} \sum_{j=1}^{N_{s}}\left(P e_{i, j}-P o_{i, j}\right)
$$

where $P e_{i, j}$ is the daily precipitation at point $i$ for day $d$ simulated by WRF simulations, $P o_{i, j}$ the corresponding observed daily rainfall, $N_{d}$ is the number of days studied, $N_{S}$ is the number of stations, and $N$ is the number of grid points $\left(N_{S} * N_{d}\right)$.

The Root-mean squared error (RMSE) is another way to express the mean squared error (MSE) that describes spatially averaging the individual squared differences precipitation estimated and measured daily rainfall.

$$
R M S E=\sqrt{\frac{1}{N} \sum_{i=1}^{N_{d}} \sum_{j=1}^{N_{s}}\left(P e_{i, j}-P o_{i, j}\right)^{2}}
$$


The Mean Absolute Error (MAE) is the average of the absolute values of the difference between simulated and measured daily rainfall.

$$
M A E=\frac{1}{N} \sum_{i=1}^{N_{d}} \sum_{j=1}^{N_{s}}\left|P e_{i, j}-P o_{i, j}\right|
$$

\subsection{Diurnal cycle precipitation analysis}

In the present research, there is a great interest in to understand the model ability to adequately represent the diurnal cycle of rainfall in a more qualitative than quantitative analysis. Hence, hourly precipitation is represented as percentages, following the equation:

$$
\operatorname{prep}(\%)=\frac{P e_{\text {hour }}}{P e_{\text {day }}} * 100 \%
$$

prep (\%): Percentage of precipitation for each hour;

$P e_{\text {hour }}:$ Mean precipitation each hour;

$P e_{d a y}:$ Accumulated rainfall during 24 hours or daily rainfall. 


\section{Results and Discussions}

\subsection{Sensitivity test}

\subsubsection{General circulation}

How was described in chapter 2 the ERA5 is used to force WRF simulations and it also used to represent the observed circulation over the simulation domain. Figure 4.1 shows the ERA5 wind at 850h, 500 and $200 \mathrm{hPa}$ for March 2013.

At upper-level (200 hPa; Fig. 4.1.a), strong easterly winds cross the north of Peru from Amazon towards the Pacific Ocean, where it is noted a southern deviation in anticyclonic sense characterizing the presence of the Bolivian High, which dominates the circulation. At this level, the northeasterly wind changes to the northwesterly/westerly and intensifies from the Pacific Ocean to northern Chile and southern Bolivia. In the middle levels ( $500 \mathrm{hPa}$; Fig. 4.1.b), the presence of easterly winds dominates circulation throughout Peru, being consistent with the predominant circulation in upper-level, and over the southwestern part it is noted the presence of subtropical anticyclone. At low level ( $850 \mathrm{hPa}$; Fig. 4.1.c), the northeasterly trade winds are intense in north of Brazil but decrease as entering northern Peru. The low-level northwesterly flowing east of the Andes has weak intensity. However, being an average, there could be days that this flow develops the known South America low level jet (SALLJ) (Marengo et al., 2004). In addition, a cyclonic flow is observed over the Pacific Ocean between the latitudes of $10^{\circ}$ and $15^{\circ} \mathrm{S}$. 
(a) $200 \mathrm{hPa}$

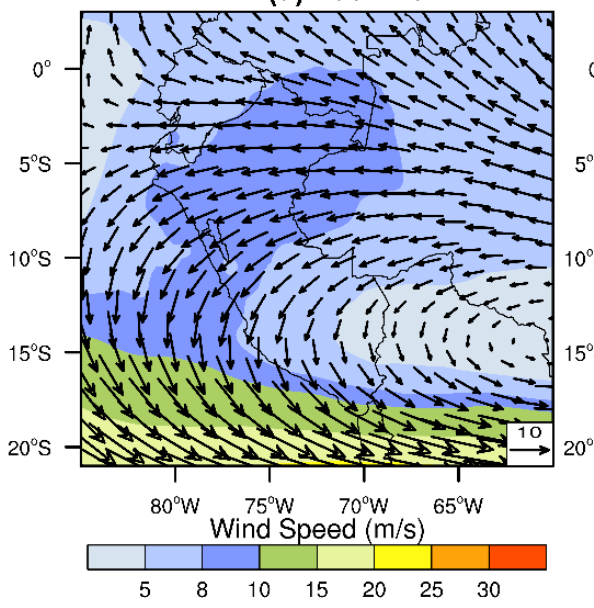

(b) $500 \mathrm{hPa}$

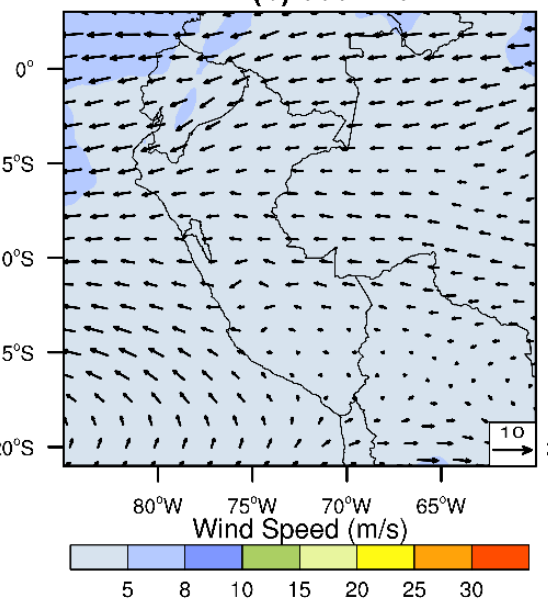

(c) $850 \mathrm{hPa}$

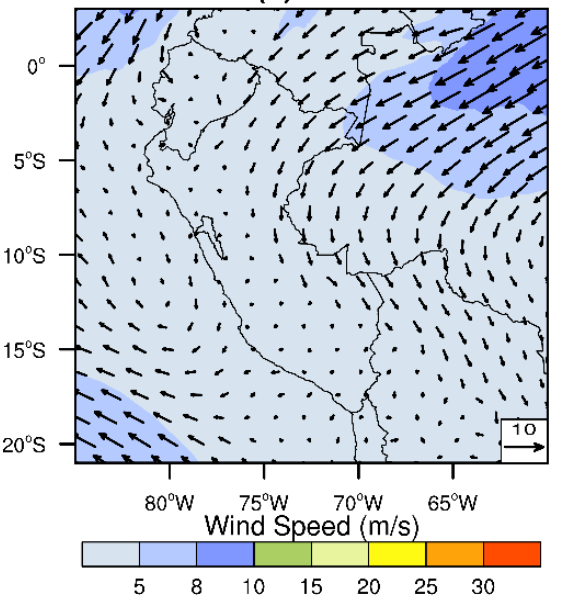

Figure 4.1 - Averaged horizontal wind speed (color shaded, $\mathrm{m} \mathrm{s}^{-1}$ ) as well as wind vectors (arrows, $\mathrm{m} \mathrm{s}^{-1}$ ) from ERA5 data in March at: (a) 200hPa, (b) $500 \mathrm{hPa}$ and (c) $850 \mathrm{hPa}$.

The average circulation of the ERA5 (Fig. 4.1) will be used to compare with WRF6 sensitivity experiments. At upper level (200 hPa; Fig. 4.2), EXP1CT and EXP1GF show a similar pattern of wind circulation, with the difference of the slightly stronger winds in most of the north of Peru simulated by EXP1GF. This occurs when only the cumulus scheme was changed (Grell-Freitas scheme, Table 3.3). In the EXP2CT and EXP2GF experiments, the differences are greater than in the previous comparison. EXP2GF presents stronger winds in the border of Peru with Brazil, which evidences the greater difference in circulation as a result of only changing the cumulus scheme from Betts-Miller-Janjic to Grell-Freitas (Table 3.3). EXP2NC has a similar circulation of EXP2CT, only presenting small differences related with the weaker winds in Pacific Ocean region. The difference between EXP2CT with its control (EXP2CT) is the greater intensity of wind over the Pacific region that also influences the continental zone where the basin under study is located. The change of the microphysics scheme from Goddard (EXP2CT and EXP2NC) to Thompson (EXP2T) implies in greater intensity of the wind in the region of changing the direction of flow from east to north, associated with BH. Among the EXP1CT and EXP2CT simulations, the one that shows the greatest similarity with the ERA5 data is EXP2CT. It has the core of the BH centered in similar position of ERA5 $\left(15^{\circ} \mathrm{S}\right.$ and $\left.60^{\circ} \mathrm{W}\right)$ and more zonal winds also as ERA5. On the other hand, EXP1CT shows the BH core northward displaced $\left(14^{\circ} \mathrm{S}\right)$, stronger winds over most of 
domain and winds with a greater meridional component than ERA5. More intense $200 \mathrm{hPa}$ winds than ERA5 are also simulated by the EXP1GF, EXP2GF and EXP2T (Fig. 4.2).

At the $500 \mathrm{hPa}$ level (Fig. 4.3), EXP1CT shows the entrance of easterly winds with a short-wave undulation over Amazon, which contrasts with the predominant easterly winds of ERA5 (Fig. 4.1.b). The more zonal winds simulated by EXP2CT (Fig. 4.3.b) has greater similarity with the circulation of the ERA5. The circulation of the EXP1GF does not differ greatly of EXP1CT. In the same way, the difference is minimal for the EXP2GF and EXP2NC compared with EXP2CT, while EXP2T shows a stronger incoming flow along the north of the Amazon and Peru.

At low levels, EXP1CT and EXP1GF simulate a northeasterly wind over Amazon perpendicular to the east side of the Andes mountain range (Fig. 4.4), which is not observed in ERA5 (Fig. 4.1.c). The simulated perpendicular flow does not turn to northwesterly as shown in ERA5. In contrast, in EXP2CT, EXP2GF, EXP2NC, and EXP2T simulate weak northeasterly winds over Amazon turnings to northwesterly near the eastern of the Andes, and then follow the eastern slope of the Andes to the south as in ERA5. Near the shore, over the Pacific Ocean, are simulated anticyclonic $\left(\sim 11^{\circ} \mathrm{S}\right)$ and cyclonic $\left(\sim 17^{\circ} \mathrm{S}\right)$ small-scale flows by all experiments derived from the EXP2CT with exception of EXP2T. The experiments EXP1CT and EXP1GF simulate a northwesterly flow parallel to the Peruvian coast northward of $14 \mathrm{oS}$. There are not much differences of circulation between the EXP1CT and the EXP1GF, only in the intensity of northeasterly flow in northernmost part of Amazon. The main difference between EXP1CT and EXP2CT is in the flow direction in eastern side of the Andes. The EXP2CT simulated flow has larger an agreement with ERA5 showing the correct turning of the wind from northeasterly to northwesterly, while in EXP1CT the intercept perpendicularly the mountain. Other difference occurs over the ocean where EXP1CT shows northeasterly winds parallel to the northern Peruvian coast, while EXP2CT simulates two small-scale vortices in cyclonic and anticyclonic senses.

As previously shown, the ERA5 BH is near its climatological center described by Vera et al. (2006), which is better simulated by EXP2CT experiment. In addition, at low levels $(850 \mathrm{hPa})$, the northwesterly flow in eastern side of the Andes in ERA5 coincides with previous studies of austral summer circulation in the region (e.g. Marengo et al., 2012, 2004; 
Romatschke \& Houze, 2010; Vera et al., 2006). However, there is still some uncertainty about the circulation in Pacific, where a deeper investigation is still lacking. As expected, WRF runs present differences related with wind direction with consequent differences in the wind speed. However, the circulations at low, middle and upper levels simulated by EXP2CT have greater similarity with the ERA5, mostly which one related with northwesterly flow in eastern side of Andes at low levels. In addition, among the experiments, the change from Goddard to the Thompson microphysics resulted in greater influence on the circulation than the change of the Grell-Freitas cumulus scheme 
(a) EXP1CT

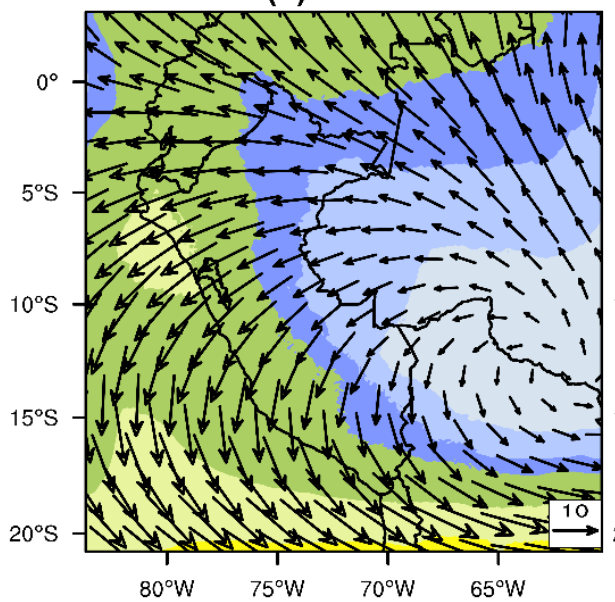

(c) EXP1GF

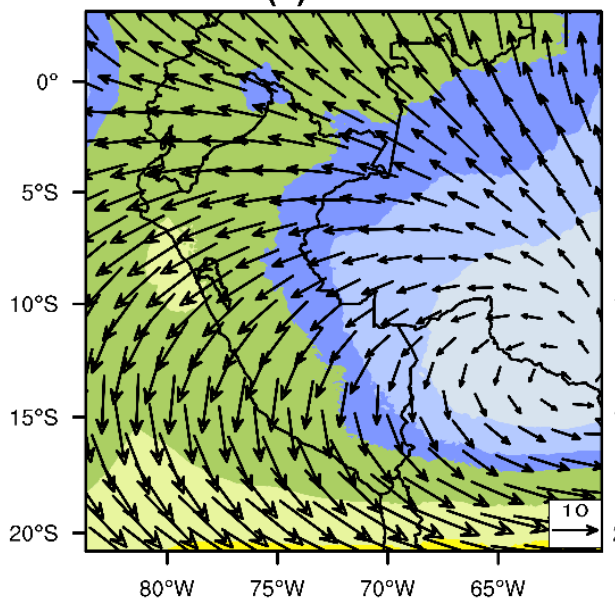

(e) EXP2NC

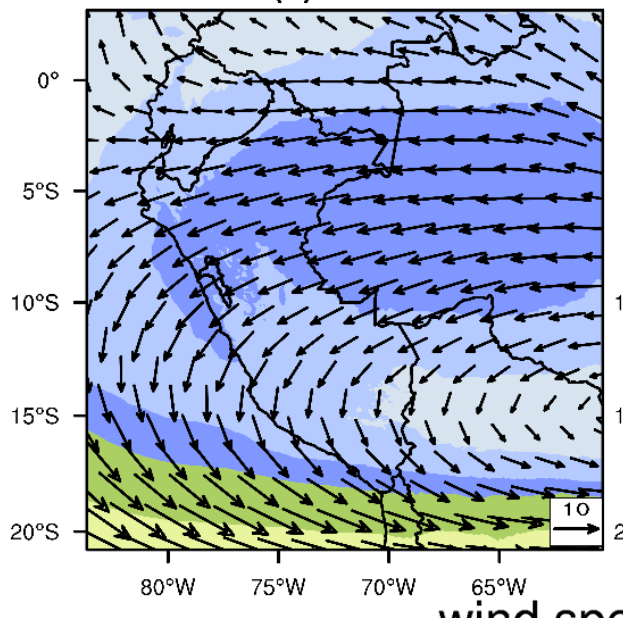

(b) EXP2CT

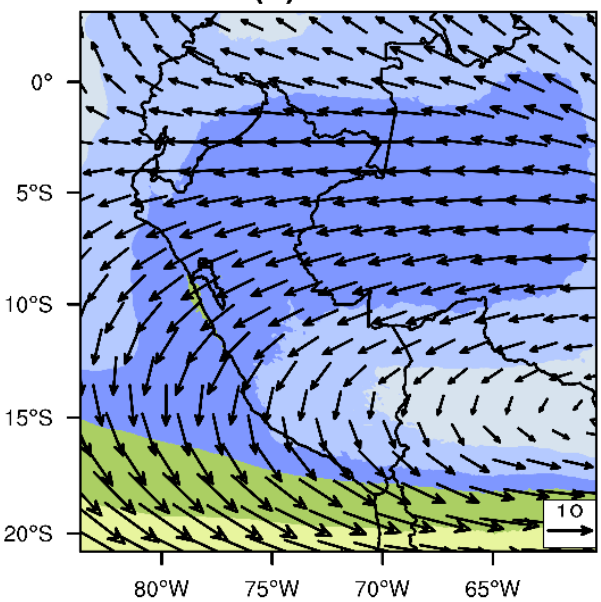

(d) EXP2GF

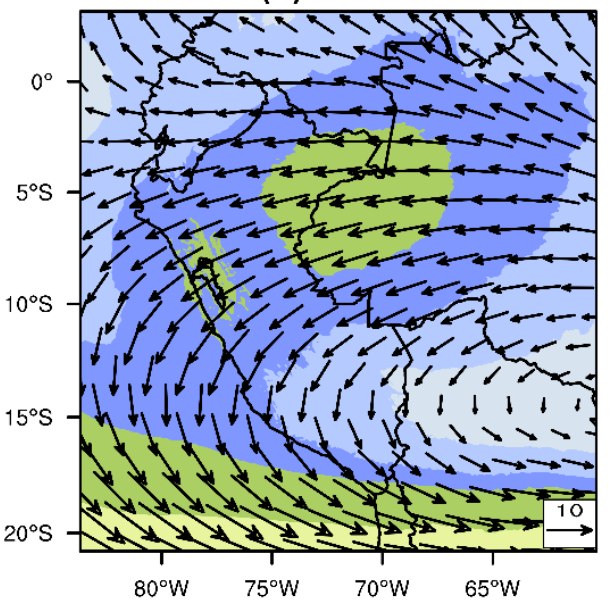

(f) EXP2T
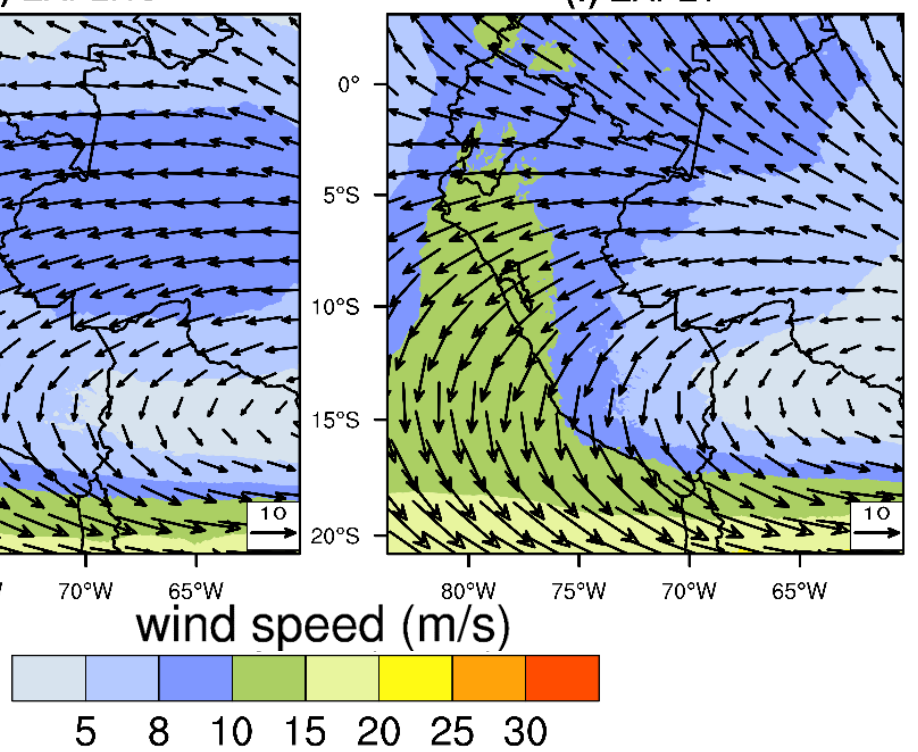

Figure 4.2 - Averaged for March 2013 of horizontal wind speed (color shaded, $\mathrm{m} \mathrm{s}^{-1}$ ) and wind vectors (arrows, $\mathrm{m} \mathrm{s}^{-1}$ ) at 200hPa from WRF simulations: (a) EXPC1T, (b) EXP2CT, (c) EXP1GF, (d) EXP2GF, (e) EXP2NC, (f) EXP2CT. 
(a) EXP1CT

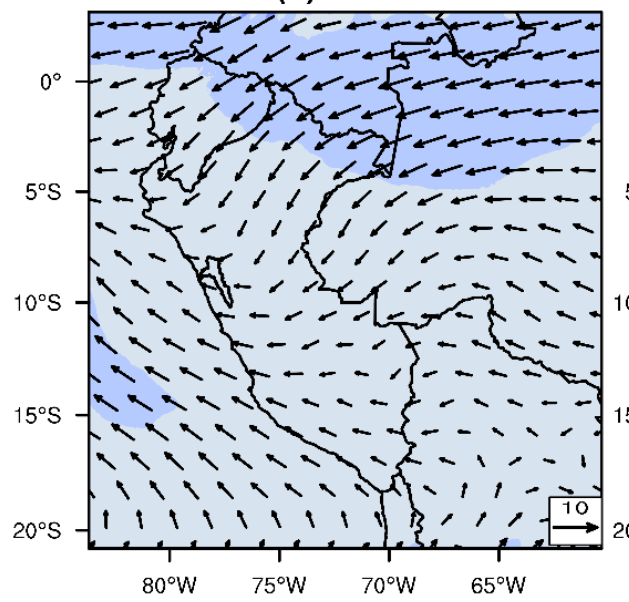

(c) EXP1GF

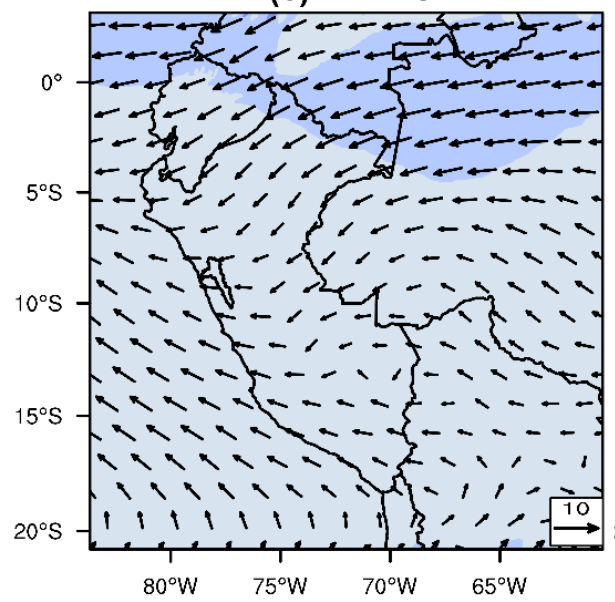

(e) EXP2NC

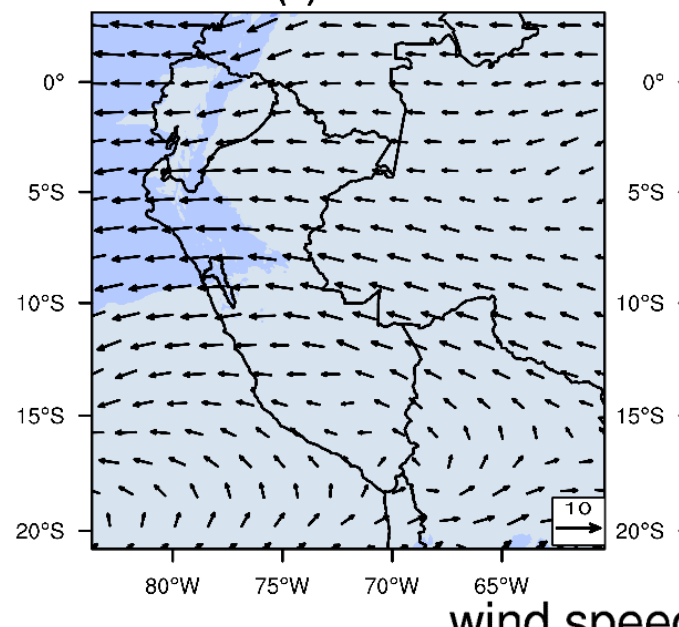

(b) EXP2CT

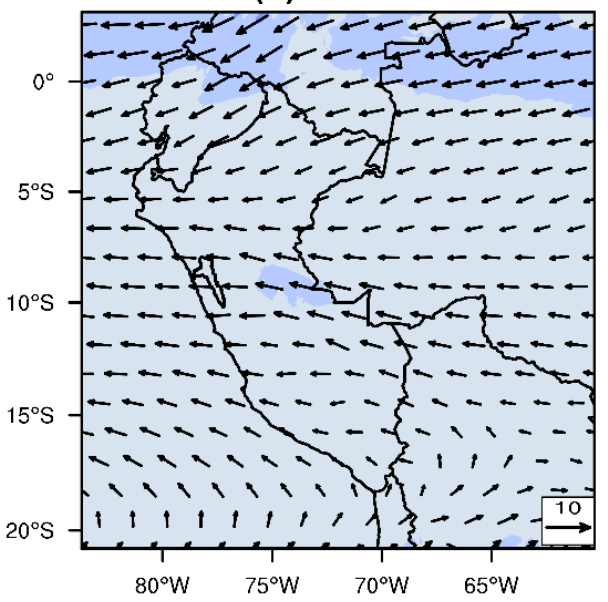

(d) EXP2GF

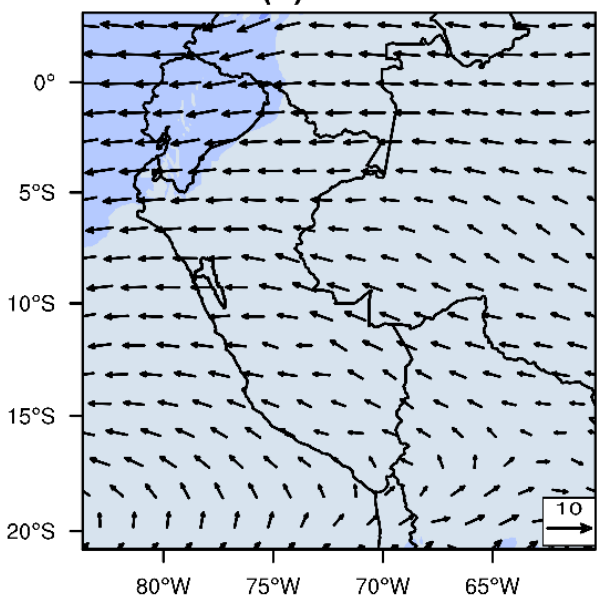

(f) EXP2T

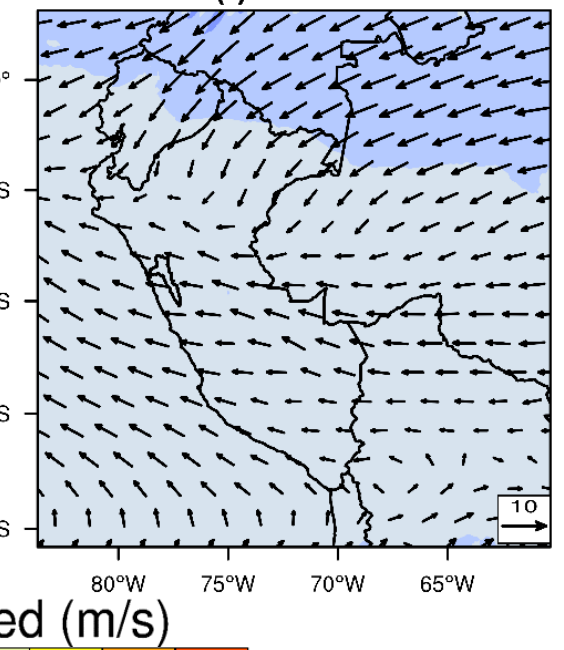

$\begin{array}{lllllll}5 & 8 & 10 & 15 & 20 & 25 & 30\end{array}$

Figure 4.3 - Averaged for March 2013 of horizontal wind speed (color shaded, $\mathrm{m} \mathrm{s}^{-1}$ ) and wind vectors (arrows, $\mathrm{m} \mathrm{s}^{-1}$ ) at 500hPa from WRF simulations: (a) EXPC1T, (b) EXP2CT, (c) EXP1GF, (d) EXP2GF, (e) EXP2NC, (f) EXP2CT. 
(a) EXP1CT

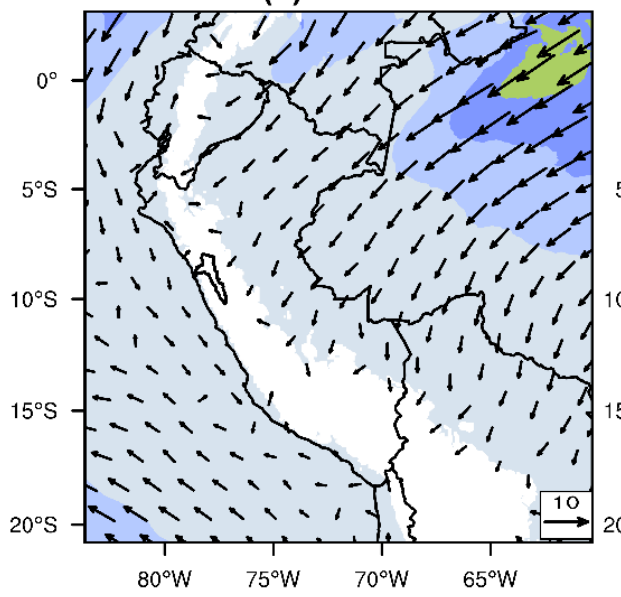

(c) EXP1GF

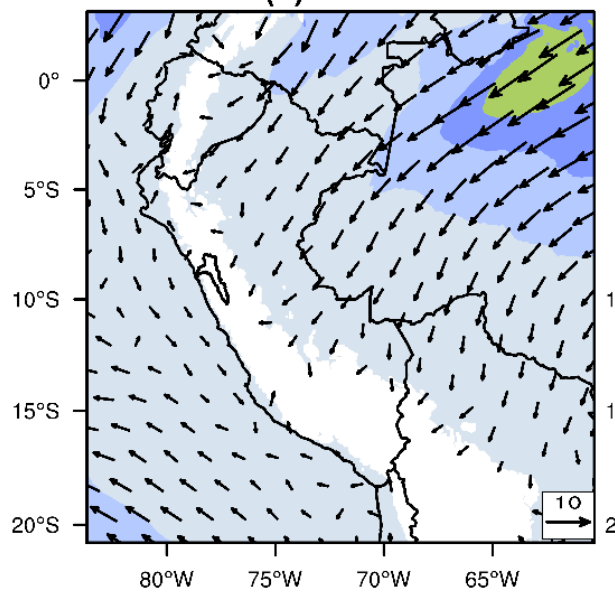

(e) EXP2NC

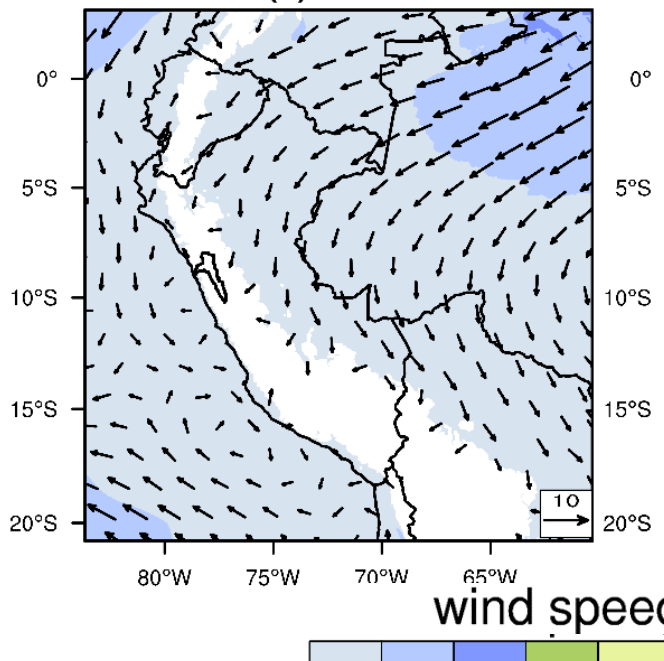

(b) EXP2CT

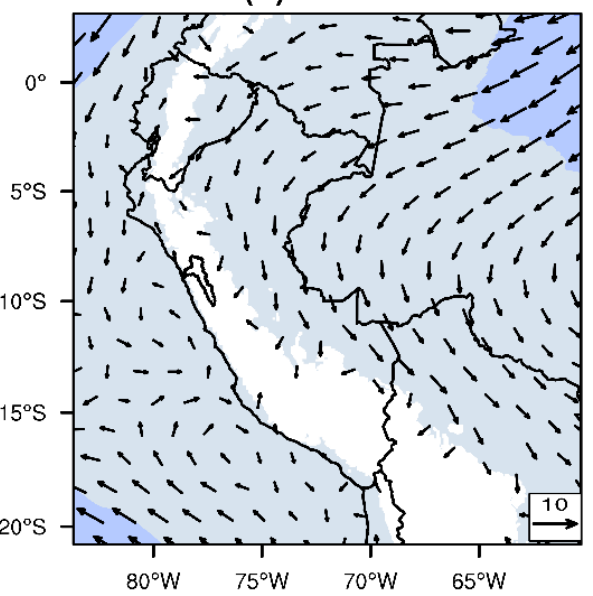

(d) EXP2GF

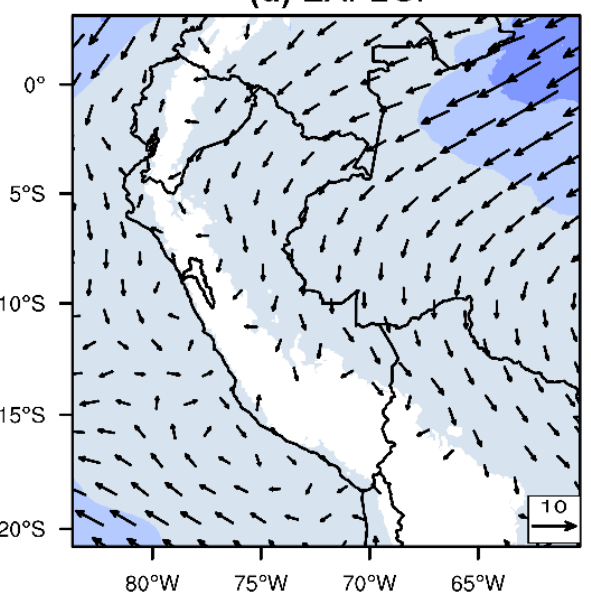

(f) EXP2T

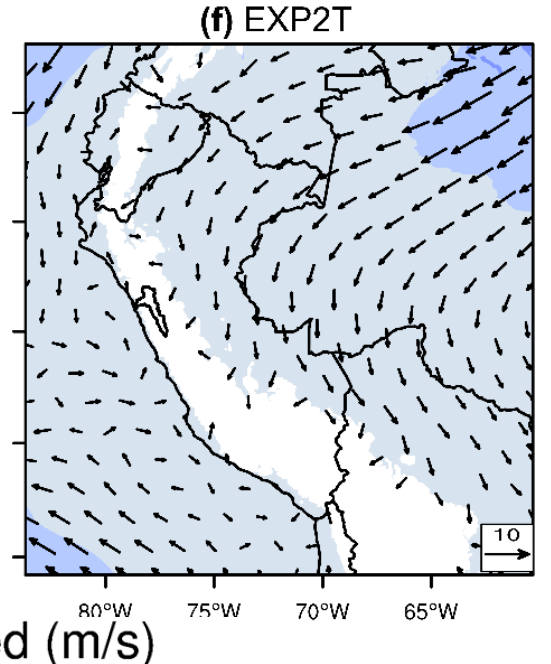

$\begin{array}{lllllll}5 & 8 & 10 & 15 & 20 & 25 & 30\end{array}$

Figure 4.4 - Averaged for March 2013 of horizontal wind speed (color shaded, $\mathrm{m} \mathrm{s}^{-1}$ ) and wind vectors (arrows, $\mathrm{m} \mathrm{s}^{-1}$ ) at $850 \mathrm{hPa}$ from WRF simulations: (a) EXPC1T, (b) EXP2CT, (c) EXP1GF, (d) EXP2GF, (e) EXP2NC, (f) EXP2CT. 


\subsubsection{Spatial variability of precipitation}

The spatial distribution of the precipitation (Fig. 4.5) has differences between the analyzed data (CHIRPS, PISCO, TRMM3B42, and CMORPH). For instance, in PISCO precipitation is more and less intense, respectively, in the valley and in the mountains of the Santa River basin, in contrast to CHIRPS, TRMM3B42, and CMORPH that show less and more amount of precipitation, respectively, in the valley and in the Cordillera Blanca. Considering these inconsistencies between these analyzes, we base our confidence in the Mourre et al. (2016) study, which using local stations found for the same area large amount of rainfall in the mountains than in the valley of the Santa River basin. With this in mind, it can be noted that all WRF runs overestimate the rainfall in eastern of the Andes, over the Amazon side. The simulated precipitation over the mountain ranges has marked contrasts between the different parameterization schemes used. However, similarities may be found in some experiments. For example, there is great similarity between EXP1CT and EXP1GF in reproducing similar spatial pattern of rainfall, although the former simulates great amount of precipitation in the coast. The change of the cumulus scheme from Grell-Devenyi to GrellFreitas in EXP2GF helps to decrease the precipitation over the two mountain ranges. This occurs also in EXP2CT that uses Betts-Miller-Janjic scheme. However, over the Amazon region EXP2GF simulates greater amount of precipitation as also noted in EXP1CT and EXP2T. In common, these three experiments use the Thompson microphysics scheme.

In the EXP2NC, the intensity of precipitation decreases over both the valley and the Andes region, revealing that by disabling the cumulus parameterization not only deep but also shallow rainfall clouds are restricted. The change in the microphysical scheme from Goddard in EXP2CT to Thompson in EXP2T contributes to increase the amount of rainfall in the entire basin, including over the Amazonian and coastal regions, eastern and western sides of the basin respectively.

Since the different analysis products have different spatial pattern of the precipitation patterns, it difficult to establish which of them is the more precise reference to compare with the WRF simulations. All simulations the rainfall over the valley is lower than over the mountains of the basin, as was also found (Mourre et al., 2016). 
(a) CHIRPS

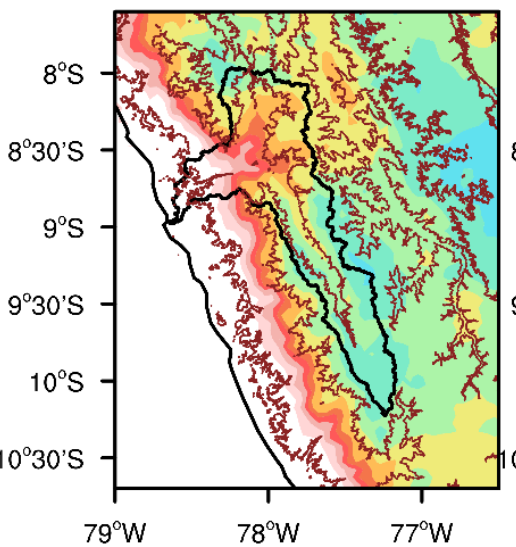

(f) EXP2CT
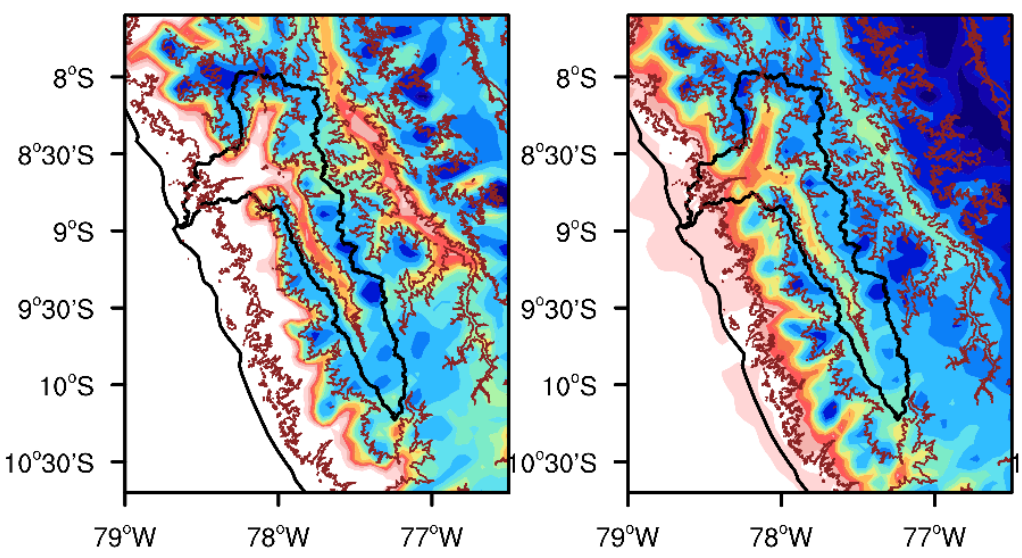

(c) TRMM3B42

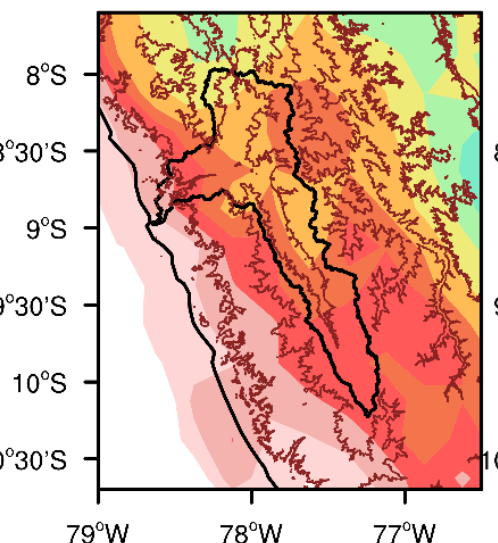

(h) EXP2GF

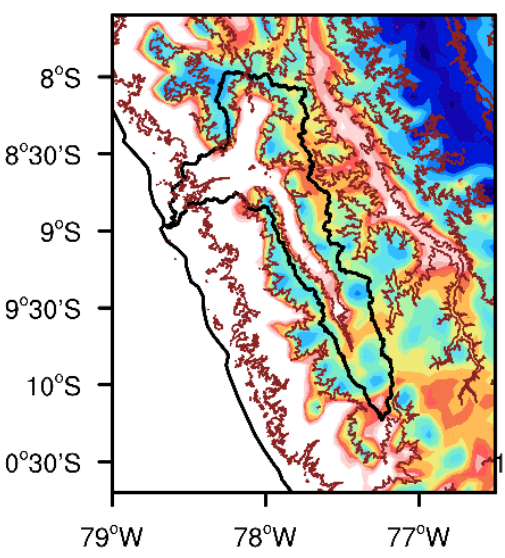

(d) $\mathrm{CMORPH}$

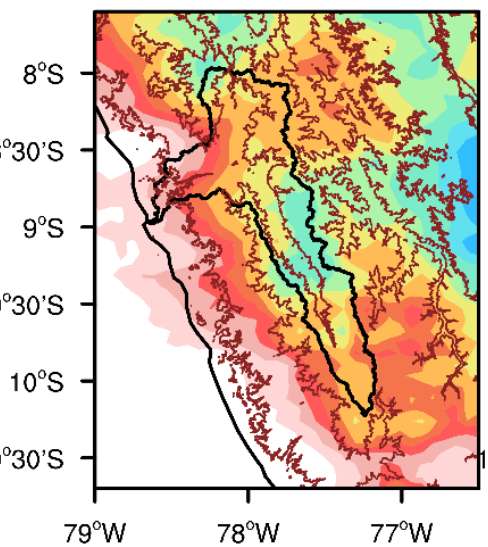

(i) EXP2NC

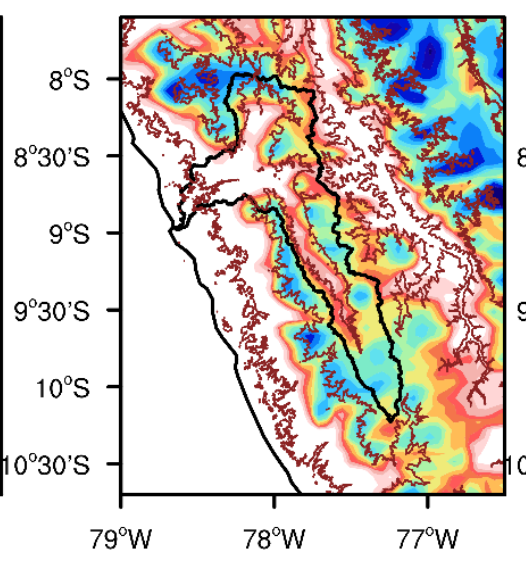

(e) EXP1CT

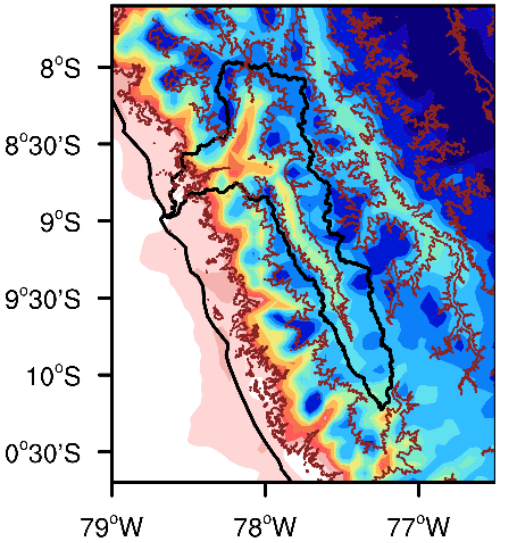

(j) EXP2T

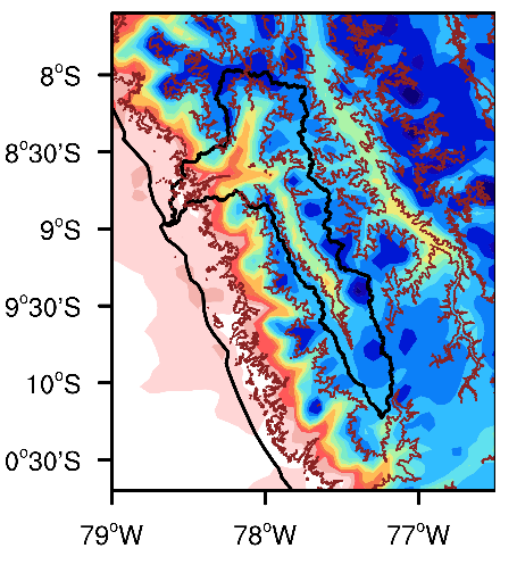

precipitation (mm/day)

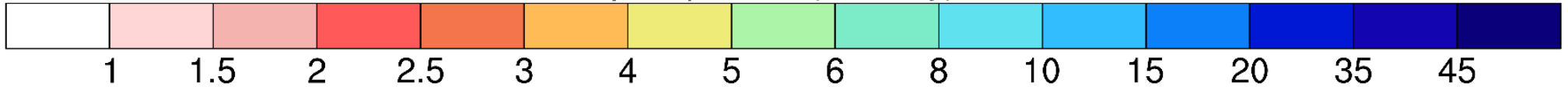

Figure 4.5 - March precipitation (mm day ${ }^{-1}$ ) mean from (a) CHIRPS, (b) PISCO, (c) TRMM3B42, (d) CMORPH data and WRF simulations (e) EXP1CT, (f) EXP2CT, (g) EXP1GF, (h) EXP2GF (i) EXP2NC, and (j) EXP2T run. Brown contours show 500 and 3500 m orography limits. 
The accumulated precipitation for March observed by the meteorological stations shows a clear contrast between the stations in western (near the coast) and the stations inside and eastern of the basin (Fig. 4.6). According to the punctual meteorological stations, western of the basin precipitation is weaker than in those in eastern side. All WRF runs simulate this contrast, with exception of EXP2NC. This could be due to the cumulus parameterization deactivation in the EXP2NC, which would result in weaker vertical motions and absence of deep convective clouds and more intense rainfall. In addition, no simulation represents the heavy rainfall inside the basin, i.e., no WRF experiment stands out the others. However, it is important to mention that unlike EXP1CT and EXP1GF, which overestimate precipitation eastward of the basin, in the experiments derived from EXP2CT the precipitation amounts are closer to the punctual observations.
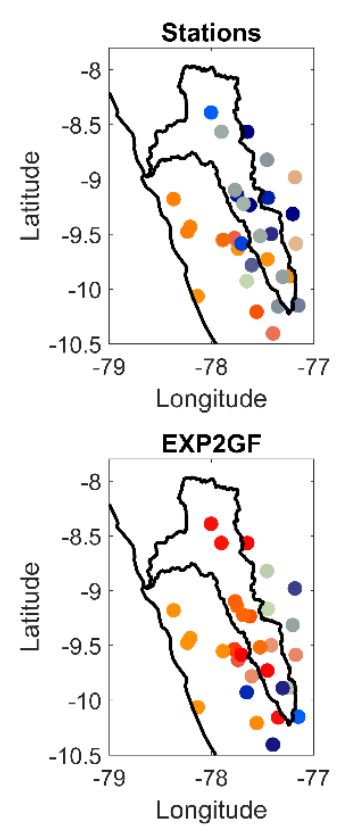

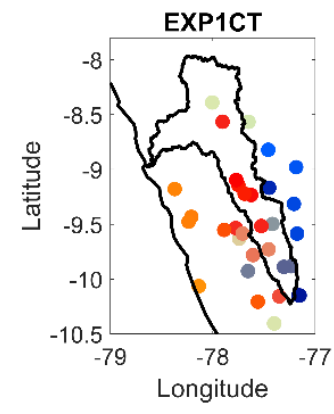

EXP2NC

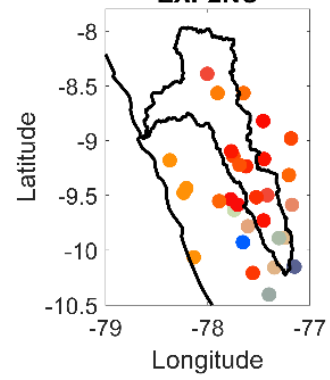

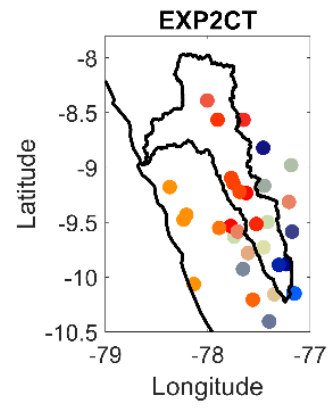

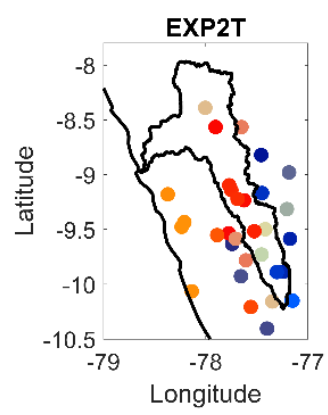

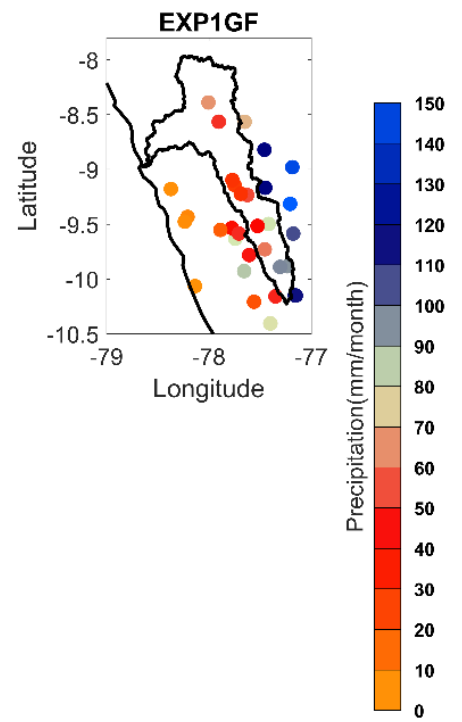

Figure 4.6 - Color dots indicate accumulated precipitation $(\mathrm{mm} / \mathrm{month})$ amounts at in situ stations and WRF runs. Delimitation of the Rio Santa Basin watershed is indicated in bold black lines. The coastline is also indicated in black.

The table 4.1 summarizes the results of the calculated statistics. Among the WRF runs, EXP2CT is the experiment that least overestimates precipitation compared to meteorological stations (4.6 mm/day) with a MB of $1.8 \mathrm{~mm} / \mathrm{day}, \mathrm{RMSE}$ of $9.0 \mathrm{~mm} / \mathrm{day}$, and MAE of $5.6 \mathrm{~mm} /$ day, while EXP2NC is the one that underestimates less precipitation with a $\mathrm{MB}$ of $-0.8 \mathrm{~mm} /$ day, RMSE of $7.4 \mathrm{~mm} /$ day, and MAE of $4.7 \mathrm{~mm} /$ day. In contrast, EXP2T 
shows a failure to simulate precipitation amounts with an MB of $5.4 \mathrm{~mm} / \mathrm{day}$, RMSE of 10.8 $\mathrm{mm} /$ day, and MAE of $7.5 \mathrm{~mm} /$ day.

Table 4.1 - Statistics (MB - mean bias, RMSE - root mean square error, MAE - mean absolute error) for March mean precipitation ( $\mathrm{mm} /$ day) obtained from the different WRF runs compared to all stations

\begin{tabular}{lllll}
\hline Experiments & Mean & MB & RMSE & MAE \\
\hline EXP1CT & 9.2 & 4.5 & 10.2 & 6.8 \\
EXP2CT & 6.7 & 1.8 & 9.0 & 5.6 \\
EXP1GF & 8.3 & 3.5 & 9.0 & 6.0 \\
EXP2GF & 3.5 & -1.1 & 6.4 & 4.1 \\
EXP2NC & 4.0 & -0.8 & 7.4 & 4.7 \\
EXP2T & 10.5 & 5.4 & 10.8 & 7.5 \\
\hline
\end{tabular}

\subsubsection{Diurnal cycle of precipitation}

In the mean diurnal cycle of precipitation in March (Fig. 4.7), the main rainfall amount is captured between 15 and 19 local hours, indicating that principal processes happen during this period. With this in mind, it is necessary from an adequate WRF simulation the skill to reproduce the rainfall diurnal cycle to understand the dynamics processes associated.

Beginning with EXP1CT and EXP1GF. They show strong unrealistic precipitation in the early hours of the day at meteorological stations above the valley (Canasbamba, Corongo, Quillcayhuanca, Shancayan, Shilla, and Tingua). These experiments demonstrate the similar capacity to trigger rainfall of the cumulus schemes of Grell-Devenyi and Grell-Freitas. In contrast, EXP2CT and EXP2GF show a great difference in the patterns of the diurnal cycle. Thereby the change of cumulus scheme from the Betts-Miller-Janjic to Grell-Freitas has great influence than in the previous case. Moreover, EXP2GF and EXP2NC simulate intense rainfall peaks in few hours, which concentrate a large part of the daily precipitation. In general, the EXP2CT and EXP2T present greater agreement with the observation in the phase and amplitude of diurnal cycle of rainfall. They reproduce an adequate diurnal cycle of rainfall in most of the stations. Unfortunately, no experiment reproduces an acceptable diurnal cycle of rainfall in the Corongo and Ocros stations, indicating some local processes that the model can still not simulate. 

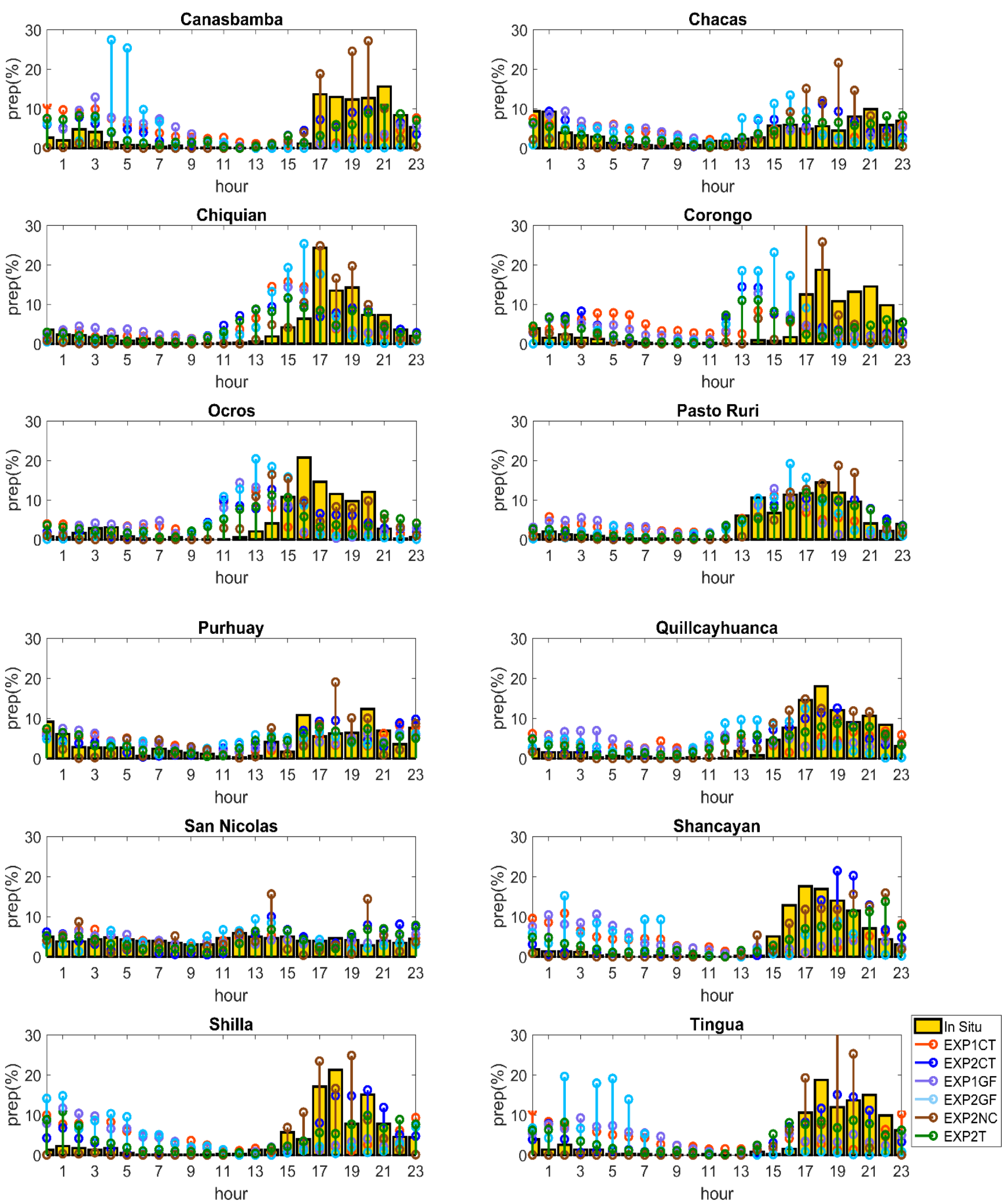

Figure 4.7 - Amount of hourly rainfall contribution to the total of the day in March 2013 for twelve automatic stations along the Santa River basin. In situ data are plotted in yellow bars and WRF outputs in color lines. 


\subsubsection{Selection of a WRF configuration}

In general, the circulation shown by ERA5 coincides with previous climatology of circulation patterns over South America (e.g. Marengo et al., 2004; Romatschke \& Houze, 2010; Vera et al., 2006), showing how a realistic data to compare with the WRF runs. EXP2CT is the one that has greater similarity with the circulation patterns of the ERA5 in the different vertical levels, mainly in reproducing correctly at low levels the wind turn from northeasterly over Amazon basin to northwesterly along the eastern side of Andes. However, there are differences in the simulated and observed circulation along Peruvian shore at $850 \mathrm{hPa}$. Due to the few studies and observations in this area, there is some uncertainty regarding the circulation patterns in the region.

In the spatial variability, all simulations of the WRF show a clear contrast of precipitation between the mountain ranges and the valley of the basin, having higher values above $3500 \mathrm{~m}$ altitude, which coincides with the estimated data of the TRMM3B42, CMORPH, and CHIRPS (Fig. 4.5). In addition, it is in agreement with the previous study of Mourre et al. (2016) that showed the same spatial distribution of precipitation over the Santa River basin.

For rainfall spatial pattern, all WRF simulations present a clear contrast between the mountain ranges and the valley of the basin, having higher precipitation amounts above 3500 $m$ altitude, which coincides with the estimated data (TRMM3B42, CMORPH, and CHIRPS). In addition, it is in agreement with the previous study of Mourre et al. (2016) that showed the same spatial distribution of precipitation over the Santa River basin.

EXP1CT does not have an acceptable skill to simulate the diurnal cycle of precipitation, although its setup is based on Mourre et al. (2016). It can be due to different modifications were made although the model setup remained the same, as the input data was changed by ERA5, nested domains, the dimension of the simulated region, and others. EXP2CT and EXP2T has large ability to adequately simulate the patterns present in the observed diurnal cycle of rainfall in most of stations. Considering this factor together the better statistical indices for monthly precipitation, EXP2CT has smaller overestimation of precipitation in the basin, it is selected to the simulations of the next step. 


\subsection{Validation of the Model}

\subsubsection{Spatial variability of precipitation}

Figure 4.8 shows the average daily rainfall of the four simulated months (DJFM) using the estimated data of the TMM3B42, CMORPH, CHIRPS, PISCO and the runs of the WRF at $6 \mathrm{~km}$ (WRF6) and $2 \mathrm{~km}$ (WRF2).. It is clear the strong precipitation over the Cordillera Blanca shown by TRMM 3B42, CMORPH, CHIRPS, and PISCO (Fig. 4.8). Considering only the basin, TRMM3B42 and CMORPH show a strong precipitation core $\left(\sim 9^{\circ} \mathrm{S}-77.6^{\circ} \mathrm{W}\right)$ on the Cordillera Blanca that contrasts with a more uniform distribution by the CHIRPS and PISCO. CHIRPS shows higher precipitation on the east side of the Cordillera Blanca while TRMM 3B42 and CMORPH display a strong precipitation core on the western slope. There are also differences between the CHIRPS and PISCO data. On the one hand, CHIRPS shows slightly higher values in the mountain ranges compared to the valley, while PISCO shows similar precipitation values in the Cordillera Blanca and the valley, and drier conditions in the Cordillera Negra.

WRF6 and WRF2 show a strong precipitation pattern on the north of the basin that contrasts with the precipitation in the valley, being also observed by TRMM3B42, CMORPH, CHIRPS, and PISCO. WRF2 simulates less precipitation over mountains and intensifies rainfall over the Amazon region compared to WRF6. Besides, the simulated precipitation amount is different between the Cordillera Blanca and Negra, which indicates that the dynamics associated with the generation of precipitation are different in these regions.

As a complement to the previous analysis, Figure 4.9 shows the mean daily rainfall in the meteorological stations on the basin. The stations show an increase in precipitation to the east, with less precipitation in stations of the coastal region (west of the basin) and higher values in stations closer to the Amazon (east of the basin). This contrast is best observed at the output of WRF2. Likewise, the CHIRPS, PISCO and WRF2 data have precipitation values closer to observations. However, TRMM3B42 and CMORPH underestimate the 
observed precipitation. Moreover, as mentioned earlier, WRF2 simulates less rainfall in the stations compared to the WRF6.

(a) TRMM3B42

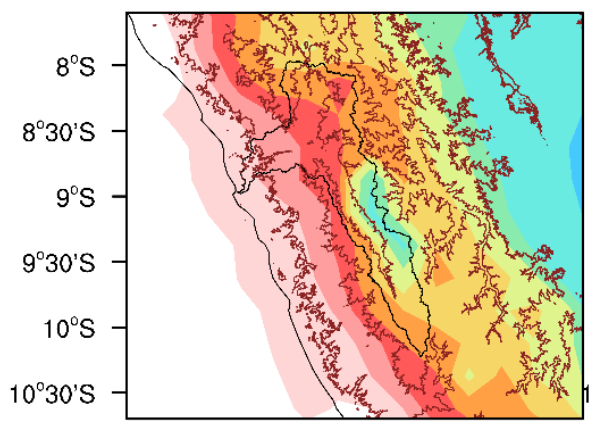

(d) PISCO

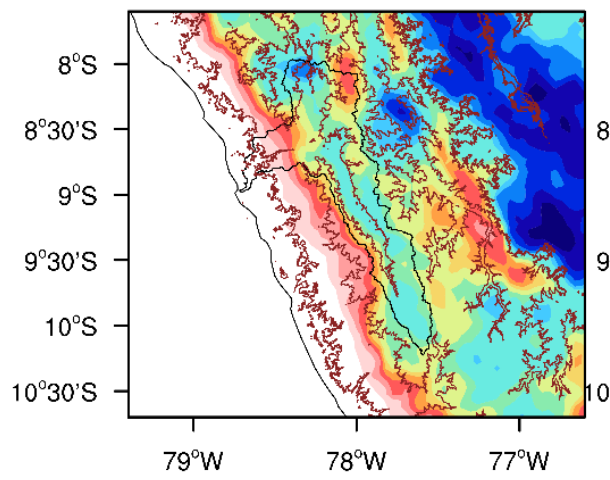

(b) CMORPH

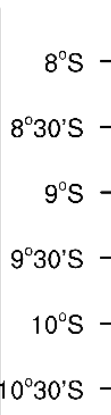

$30 \mathrm{~s}$

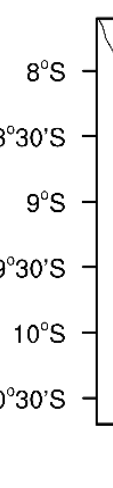

(e) WRF6

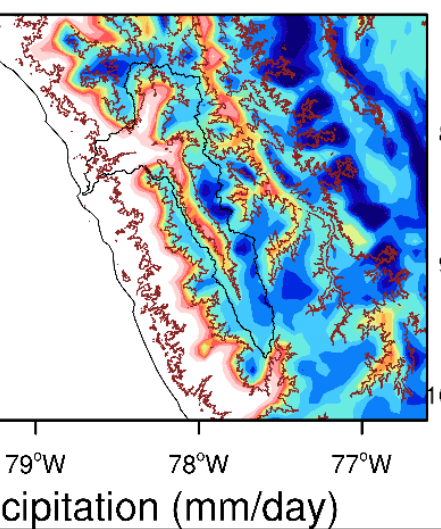

precipitation ( $\mathrm{mm} /$ day)
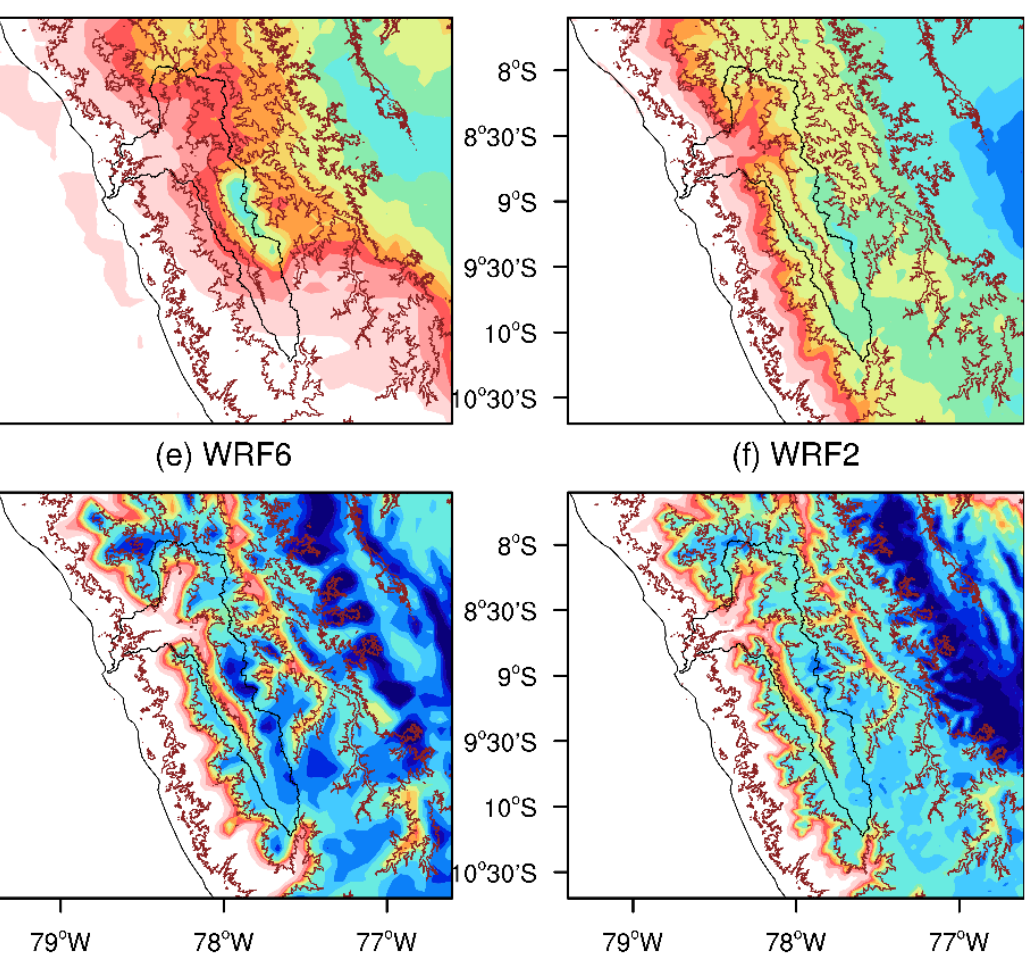

(c) CHIRPS

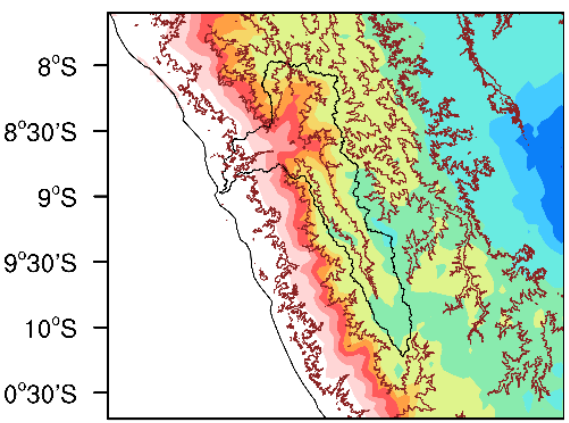

(f) WRF2

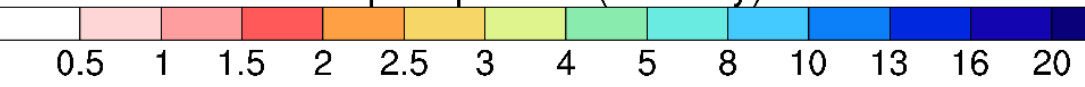

Figure 4.8 - DJFM precipitation mean from (a) TRMM3B42, (b) CMORPH, (c) CHIRPS, (d) PISCO data with the (e) WRF6 and (f) WRF2 run. Brown contours show 500 and 3500 m orography limits.

The spatial correlation shown by Taylor diagram (Fig. 4.10) corroborates Figure 4.9, presenting WRF2 with a correlation of 0.75 compared to rain-gauge, standard Deviation (SD) of $1.57 \mathrm{~mm} /$ day and Root Mean Standard Deviation (RMSD) of $2.04 \mathrm{~mm} /$ day. It presents greater correlation, standard deviation similar of rain gauges, smaller bias (Table 4.2) and RMSD Likewise, compared with the rain gauge data the CHIRPS also shows high correlation ( 0.76), smaller SD (1.33 mm/day) and low RMSD (1.44 mm/day). In contrast, the CMORPH has lowest correlation $(\sim 0.4)$ with very small SD $(0.87 \mathrm{~mm} /$ day $)$ and large RMSD (2.17 mm/day). 

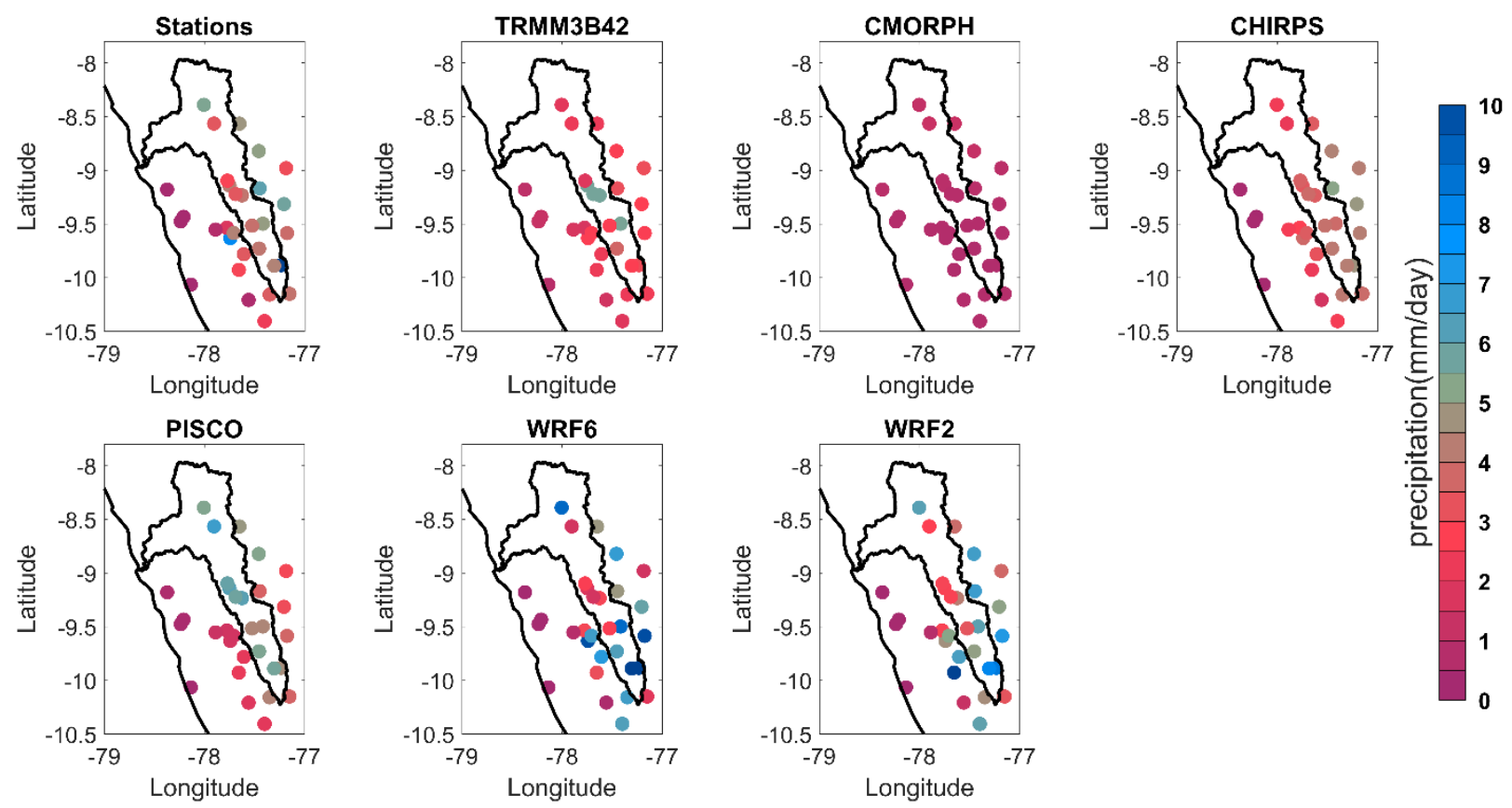

Figure 4.9 - Color dots indicate mean precipitation ( $\mathrm{mm} /$ day) located in the stations' positions, using all the resources of validation and WRF runs. Delimitation of the Rio Santa Basin watershed and the coastline are indicated in bold black lines.

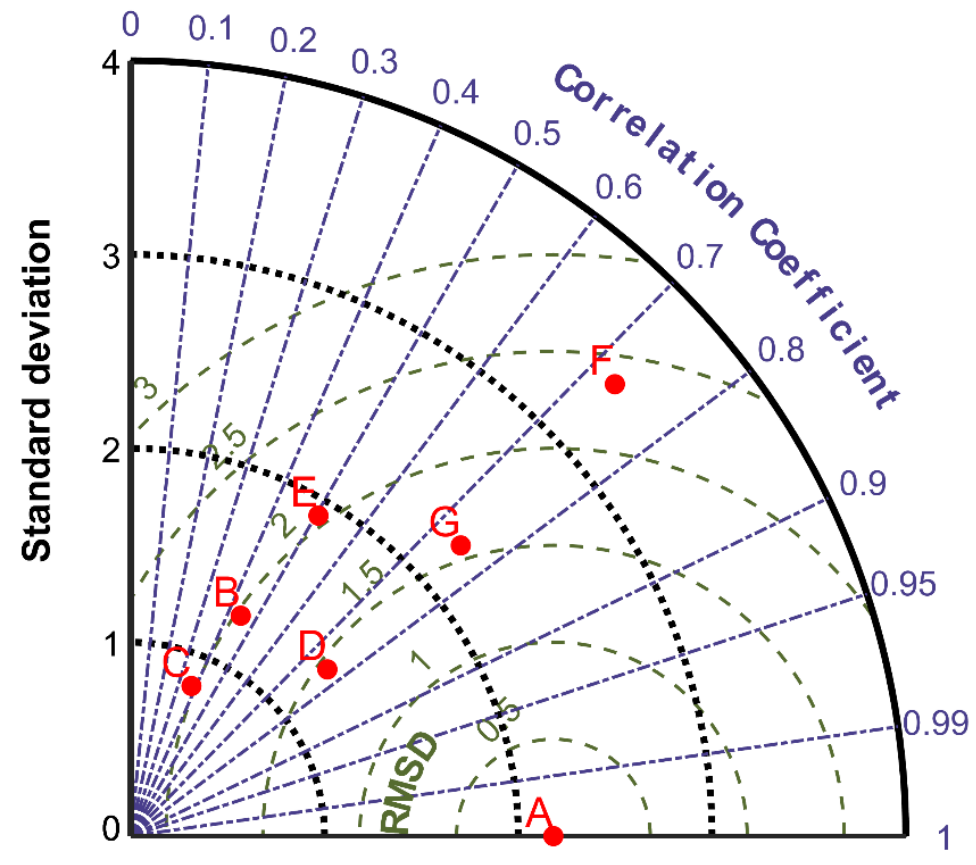

Figure 4.10 -Taylor Diagram of mean precipitation (mm/day) of TRMM3B42 (B), CMORPH (C), CHIRPS (D), PISCO (E), WRF6 (F), and WRF2 (G) compared to rain gauge precipitation (A). 
The bias is summarized in table 4.2. Among the WRF runs, WRF2 presents smaller overestimation of precipitation compared to rain gauge stations $(3.5 \mathrm{~mm} /$ day $)$ with a bias of $0.4 \mathrm{~mm} /$ day, while in WRF6 it is $0.8 \mathrm{~mm} /$ day. Therefore, quantitatively the nesting procedure improves the simulated precipitation amount. The TRMM3b42 underestimates the rainfall in 30\%, as found in previous studies over Andes regions (e.g. Chavez \& Takahashi, 2017; Espinoza et al., 2015; Ochoa-Sánchez et al., 2014; Zulkafli et al., 2013). In addition, comparing all the sources (estimations and models), CMORPH presents the greater underestimation of precipitation, up to $-85 \%$.

Table 4.2 - Statistics (Bias) for DJFM mean precipitation (mm/day) obtained from TRMM3B42, CMORPH, CHIRPS, PISCO data, and WRF simulations compared to all stations shown in Figure 4.9.

\begin{tabular}{cccc}
\hline Data source & Mean & Bias & Bias (\%) \\
\hline TRMM3B42 & 2.4 & -1.0 & -30 \\
\hline CMORPH & 1.2 & -2.3 & -65 \\
\hline CHIRPS & 3.0 & -0.5 & -14 \\
\hline PISCO & 3.3 & -0.2 & -4 \\
\hline WRF6 & 4.3 & 0.8 & 23 \\
\hline WRF2 & 3.9 & 0.4 & 12 \\
\hline
\end{tabular}

As analyzed in previous studies (e.g. Berg et al., 2006; Condom et al., 2011; Espinoza et al., 2015), data from TRMM3B42 underestimate precipitation in tropical mountain areas. On the other hand, despite having a higher spatial resolution $(\sim 8 \mathrm{~km}) \mathrm{CMORPH}$ data does not manage to represent the spatial variability of precipitation according to in situ data. In addition, both products use the TRMM algorithm that has a poor consideration of ice-covered surface, how was observed by Mourre et al. (2016). It is a problem to determine the precipitation over the Cordillera Blanca since the surface of ice on the glaciers disperses the energy in a similar way as the precipitation into the atmosphere. A proof occurs when analyzing the diurnal cycle of the CMORPH it shows precipitation at all hours of day over the Cordillera Blanca (Fig. A.1). Likewise, the PISCO data also shows a marked difference with observed data, indicating the necessity of improvements in this product. In the simulations, WRF2 presents great similarity with the rain gauge observed spatial variability supported by great correlation (small bias and RMSD), improving the results of WRF6. To 
sum up, nesting improves the model skill to capture the distribution of precipitation over complex topography of the Andes.

\subsubsection{Variability of wind speed and direction}

It is very difficult to recover wind data due to the complexity of the topography in the study area. Figure 4.11 shows the intensity and wind direction observed data from SENAMHI stations (OBS) compared to WRF2 at 13 LT. In the station Buena Vista, located on the coast, predominates southwesterly flow, while WRF2 simulates westerly wind. This wind direction is associated with the presence of the sea breeze at this time of day. In the stations located at the foot of the mountains (Aija, Chavin, and Pomabamba) present winds that are consistent with the anabatic ones, indicating the presence of the valley-mountain breeze. In general, the simulated wind directions are similar to the observations, although WRF2 overestimate the their intensity.

The fact that WRF2 is able to simulate most of the observed wind direction gives support to evaluate the circulation features over the region, to later discuss the behavior of the wind diurnal cycle affecting the humidity transport associated with the generation of precipitation. 

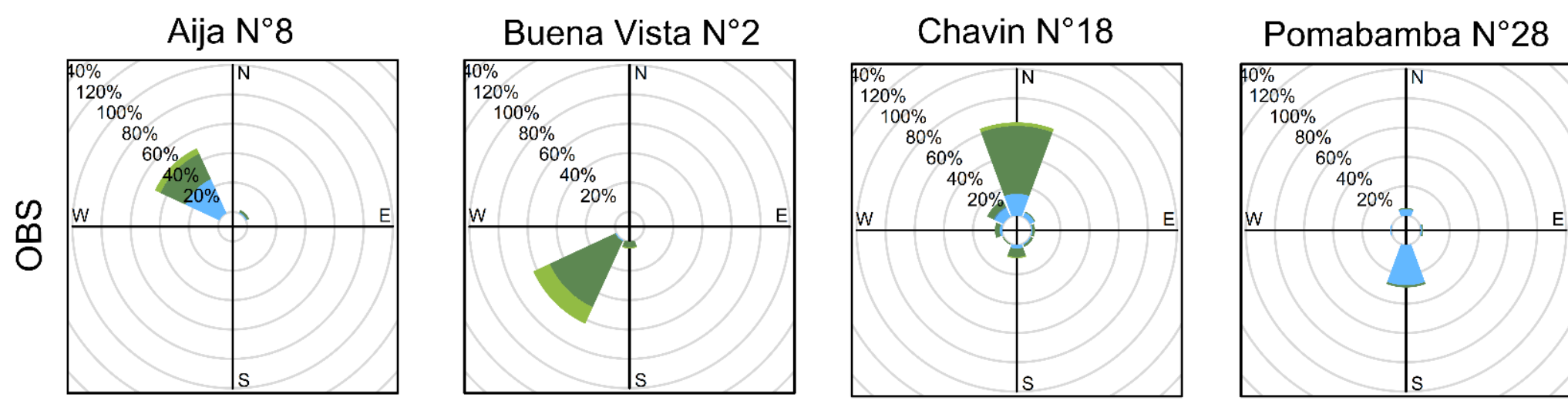

9.5 to 11

8 to 9.5

6.5 to 8
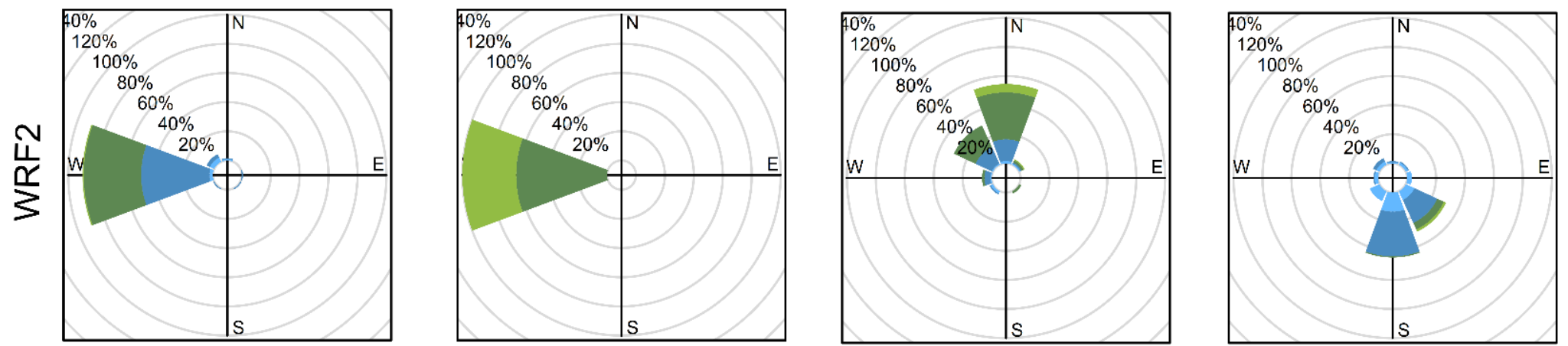

5 to 6.5

3.5 to 5

2 to 3.5

0.5 to 2

$\left(\mathrm{m} \mathrm{s}^{-1}\right)$

Figure 4.11 - Observed (OBS) and simulated (WRF2) wind rose in the coordinates of measurements in situ. 


\subsubsection{Diurnal cycle of precipitation}

Figure 4.12 exhibits the observed and simulated (WRF6 and WRF2) diurnal cycle of precipitation. It is expressed in percentage units because it is well known that the model overestimates the precipitation (Table 4.2), and the objective is to evaluate the simulated times of maximum and minimum rainfall. Besides, both simulations are used to understand the impacts of grid resolution in the diurnal cycle.

The stations located over the valley (such as Canasbamba, Corongo, Quillcayhuanca, Shancayan, Shilla, and Tingua) have a clear period of intense precipitation from 16 to 21 LT with the peaks between 17 and 18 LT. The model is able to simulate this main feature of observed diurnal cycle. However, there are peaks with strong rainfall that WRF6 and WRF2 simulate with time lag or simply not simulate. For the stations located in south of the basin (such as Chiquian, Ocros, and Pasto Ruri), precipitation begins earlier, between 14 and 20 LT. WRF6 and WRF2 simulations have a similar diurnal time evolution of rainfall according to Pastoruri observation. WRF6 anticipates in 3 hours the maximum observed at Ocros, while it decreases to 2 hours with WRF2. Finally, WRF2 simulation improves the representation of the diurnal cycle compared to WRF6 simulation at Purhuay (east of the basin). In this way, the increase of spatial resolution is improving the representation of the observed diurnal rainfall.

In this context, WRF6 and WRF2 have a similar behavior to simulate the observed diurnal cycle of precipitation. That is important to understand the failures and successes of moist processes parameterization used by them (da Rocha et al., 2009). In addition, the diurnal cycle is crucial in the glaciology since it controls the phase of precipitation, which consequently affects the albedo (Mourre et al., 2016). Then, having a realistic representation of the diurnal cycle of rainfall allows understanding the dynamics that govern Rio Santa basin circulation. Although there are not enough observations to validate the model, especially in high altitude areas, it can be justified the behavior of precipitation by knowing the theory of valley-mountain processes (Houze, 2012; Roe, 2005; Whiteman, 2000). 

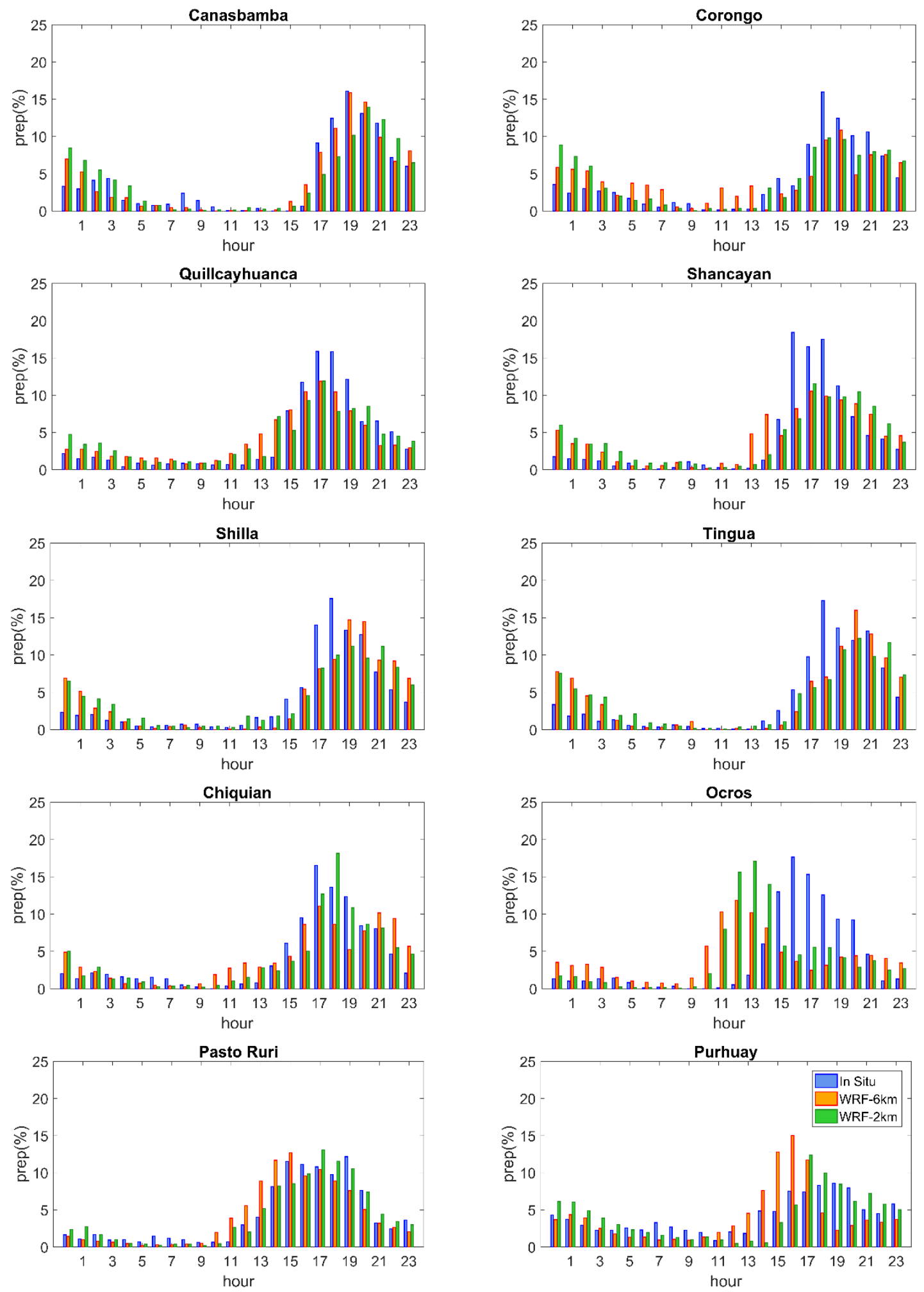

Figure 4.12 - Amount of hourly rainfall contribution to the total of the day during the summer season (December 2012- March 2013) for twelve automatic stations along the Santa River basin. 


\subsection{Atmospheric processes associated with the diurnal cycle precipitation}

\subsubsection{Diurnal cycle of precipitation and moisture flux}

This section, since the objective is the evaluation of processes associated with the diurnal cycle of precipitation, will focus on using only the WRF2 due its higher spatial resolution $(2 \mathrm{~km})$.

The simulated precipitation pattern is different during the day and the night (Figure 4.13). Great precipitation amount is simulated in western slope of the Cordillera Negra during the day (Fig. 4.13.b), while intense precipitation occurs in eastern side of the Cordillera Blanca during the night (Fig 4.13.c). The precipitation in the eastern slope of the Andes is associated with maximum values found during the night by previous works (Kikuchi \& Wang, 2008; Killeen et al., 2007). In the valley, a large day-night contrast is simulated. In addition, the north and south of the basin are characterized by intense daytime precipitation, in the altitudes above $3500 \mathrm{~m}$. In contrast, the Amazon region exhibits intense precipitation in both day and night.

Unfortunately, it is not possible to validate this temporal distribution of precipitation with estimated data of the TRMM at high resolution because the simulation period is not enough to be compared with data from the $2 \mathrm{~A} 25$ product of the TRMM, which has a high spatial resolution but low temporal resolution, as in the study of Junquas et al. (2018). However, the simulated precipitation patterns are similar to those described in that study.

According to the simulated diurnal cycle of precipitation above $3500 \mathrm{~m}$ (Fig. 4.13.d), it is clear that there is maximum precipitation on western side of the Cordillera Negra in the afternoon (13 LT), while in eastern of the Cordillera Blanca this occurs in the late afternoon and early night (16-19 LT). In other words, intense precipitation falls in the western highlands during the day, and large precipitation happens in the eastern highlands during the night. Another pattern shown is the delimitation of precipitation above the altitude of $3500 \mathrm{~m}$, which

contrasts with the precipitation over the valley, demonstrating the altitudinal effect on the Santa River basin. However, this process cannot be summarized simply as a period of day 
(a) All day mean

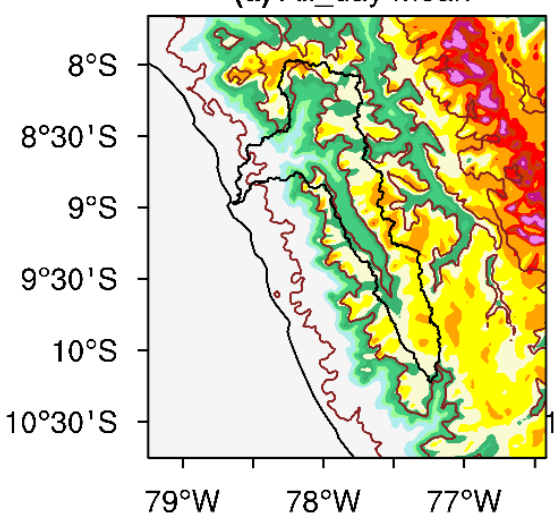

(b) Daytime mean

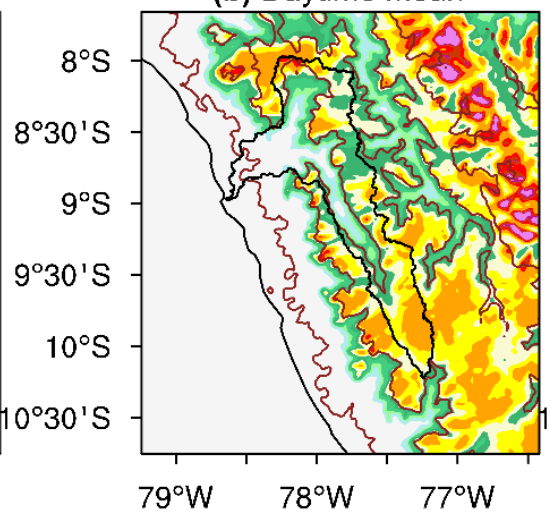

(c) Nighttime mean

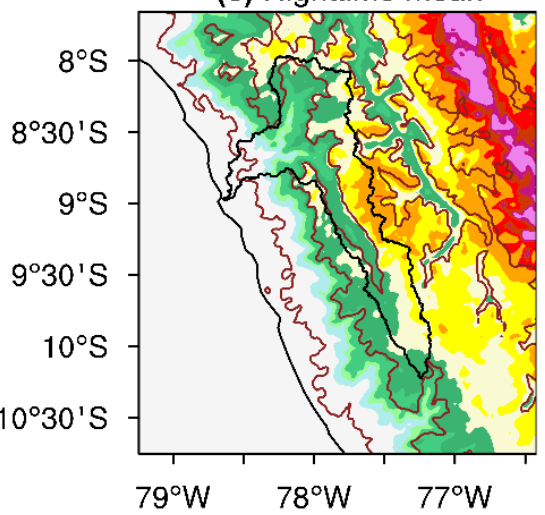

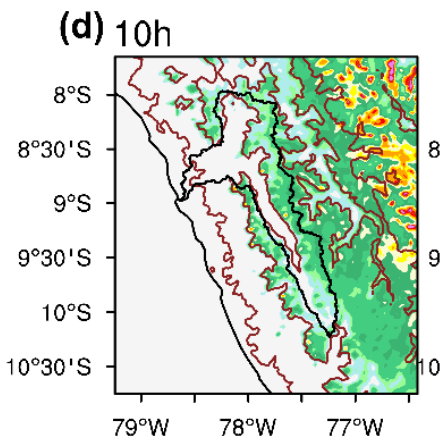

$13 \mathrm{~h}$

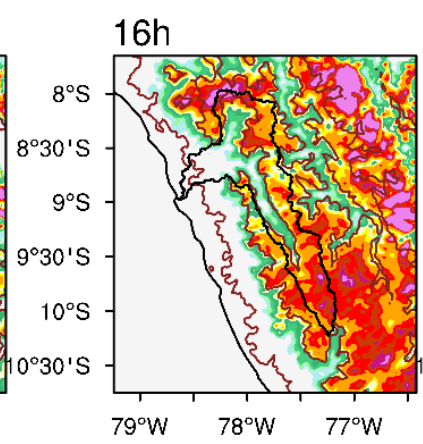

$19 \mathrm{~h}$
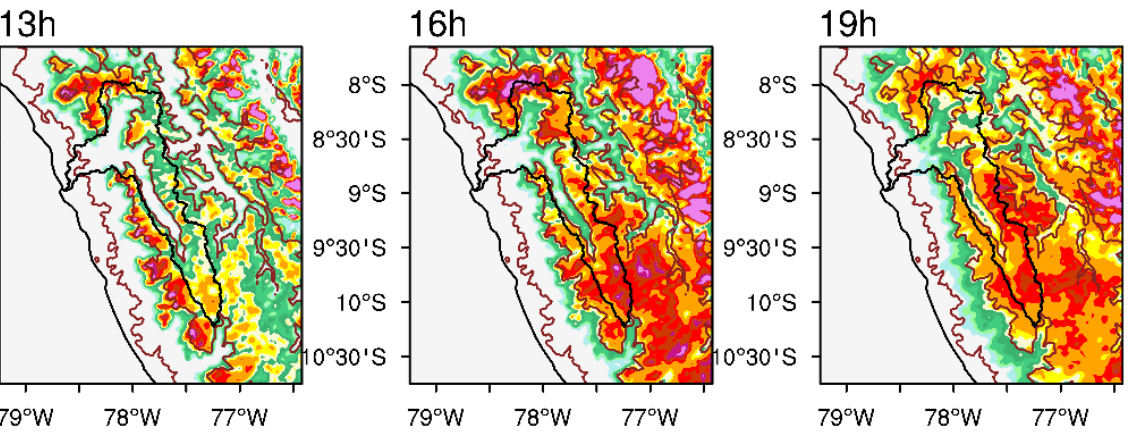

$04 \mathrm{~h}$

$07 \mathrm{~h}$
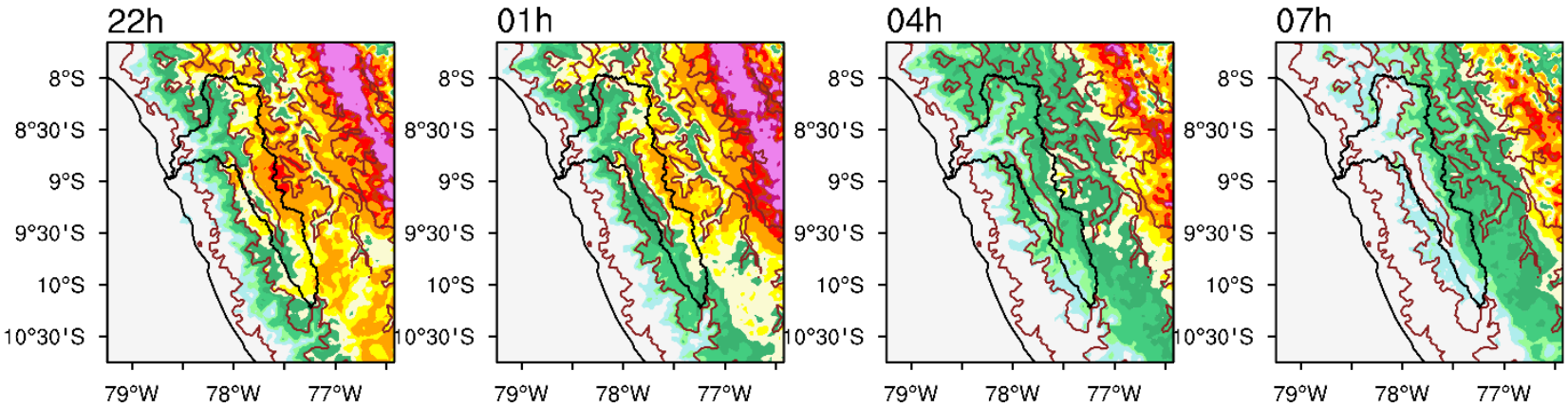

precipitation ( $\mathrm{mm} /$ day)

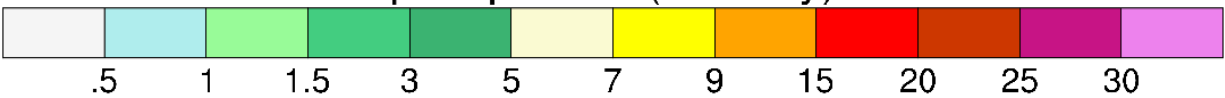

Figure 4.13 - DFJM precipitation mean (mm/day) from WRF2 to (a) all times step mean, (b) daytime mean (7$18 \mathrm{hr} \mathrm{LT})$, (c) nighttime mean (19-6hr LT), and (d) One hour time step mean. Brown contours show 500 and 3500 m orography limits. Delimitation of the Rio Santa Basin watershed and the coastline are indicated in bold black lines.

and night, since the precipitation over the Cordillera Blanca begins at $13 \mathrm{LT}$ and reaches a maximum at $19 \mathrm{LT}$, while it is decreasing in this period over the Cordillera Negra. In the Santa valley, the precipitation occurs at night (19-04 LT), with similar behavior of the Marañon valley. This temporal distribution of precipitation is not watched in the valley 
stations (Fig. 4.12), because most of them are closer to the eastern slopes of the Cordillera Blanca. Subsequently, the period from 13 to 19 LT will be analyzed in details to evaluate the processes associated with precipitation formation.

The vertically-integrated (from the surface to $200 \mathrm{hPa}$ ) moisture flux is calculated following the method used by Doyle \& Barros (2002) and Labraga et al. (2000). During the summertime (DJFM), the moisture flux, its convergence, and the convergence zones (Fig. 4.14.a) match with precipitation zones (Fig. 4.13.a). The maximum moisture flux convergence is positioned below $3500 \mathrm{~m}$, unlike of the spatial distribution of precipitation where the maxima are above $3500 \mathrm{~m}$, except in Amazon region. Another aspect to keep in mind is related to the convergence zone in daytime anomalies (Fig 4.14.b) corresponding with intense daytime precipitation (Fig. 4.13.b). Nevertheless, surprisingly the east of the Cordillera Blanca exhibits larger precipitation in the nighttime (Fig. 4.13.c), which is not associated with moisture flux convergence (Fig. 4.14.c). It indicates that the precipitation over this region would be linked to another process (surface and/or local) since the vertically integrated moisture flux generally is linked to the large-scale processes, which have a strong effect on atmospheric circulation. Returning to daytime anomalies (Fig. 4.14.b), there is a clear incoming flow to the basin at the latitude of $8.7^{\circ} \mathrm{S}$. After that, it is divided into two flows, one to the north and other to the south, covering all Santa valley. In contrast, a return flow coming out of the valley occurs during the nighttime (Fig. 4.14.c). Besides, great moisture flux convergence is found over the Pacific coast, Marañon Valley, and Amazon region.

The diurnal cycle of moisture flux (Fig. 4.14.d) presents the intensification of the southward moist flow in the eastern of the Andes during the night (19-01 LT), which is associated with the presence of SALLJ. Besides, in this period the moisture flux becomes more parallel to the Andes, decreasing the Amazon flux over the basin. Another important feature is the convergence of the coastal flow to the valley at the latitude of $8.7^{\circ} \mathrm{S}$. This flow intensifies at $13 \mathrm{LT}$ associated with the increase in precipitation over the valley, which occurs in the late afternoon (Fig. 4.13; 16 LT) and early night (Fig. 4.13; 19 LT). In addition, this moisture flux favors the precipitation in the basin highlands, when the humidity transported 


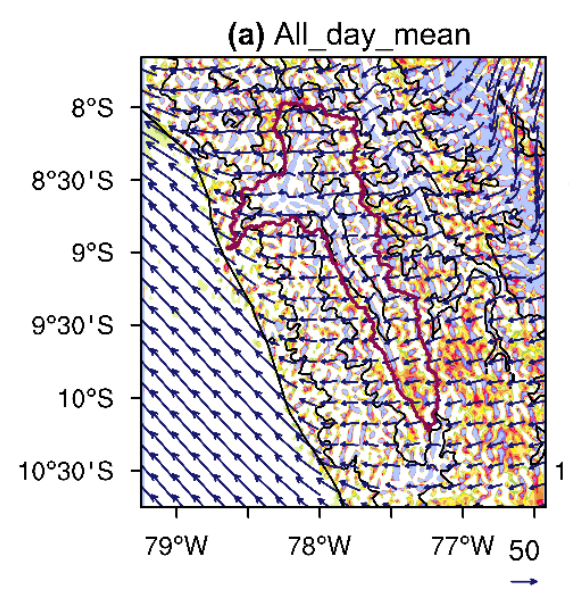

(d) $10 \mathrm{~h}$

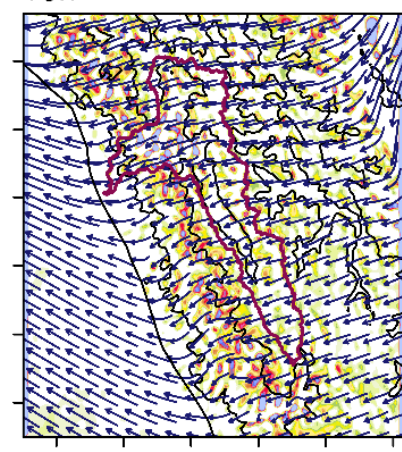

(b) Daytime anomalies

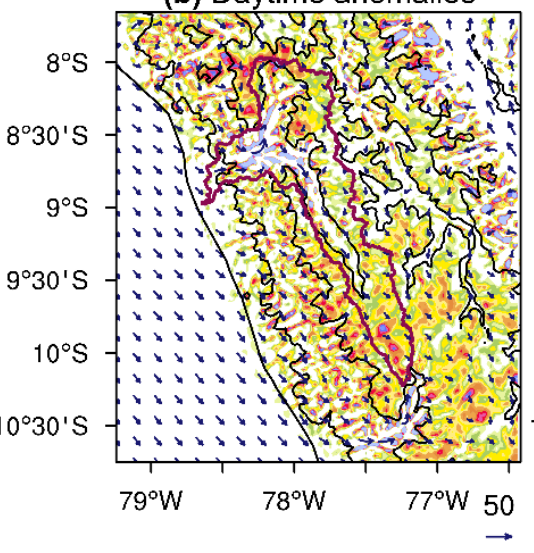

$13 \mathrm{~h}$
$16 \mathrm{~h}$

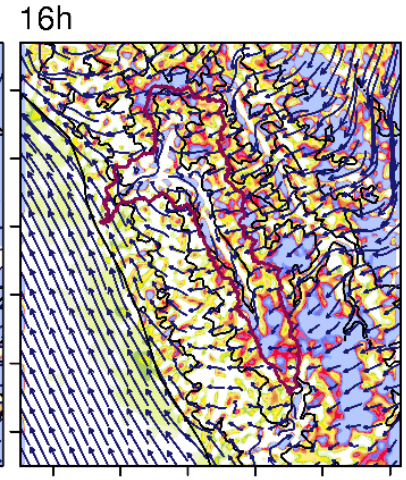

50

$04 \mathrm{~h}$

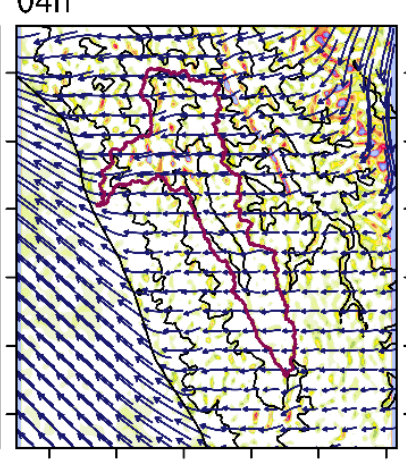

(c) Nighttime anomalies

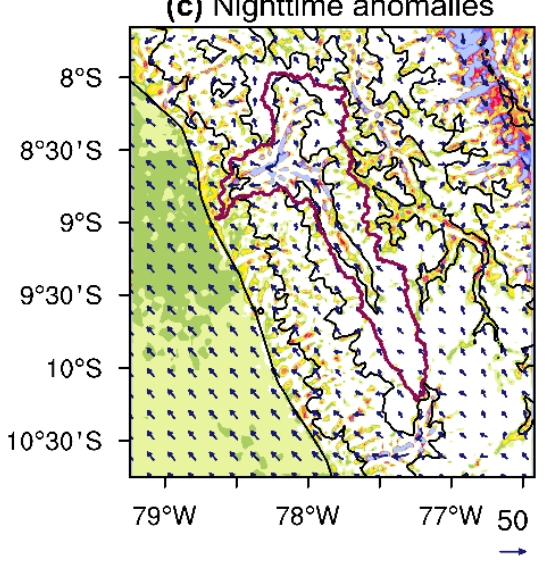

$19 \mathrm{~h}$

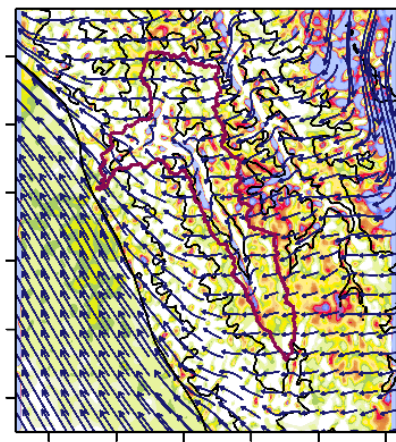

50

\section{7h}

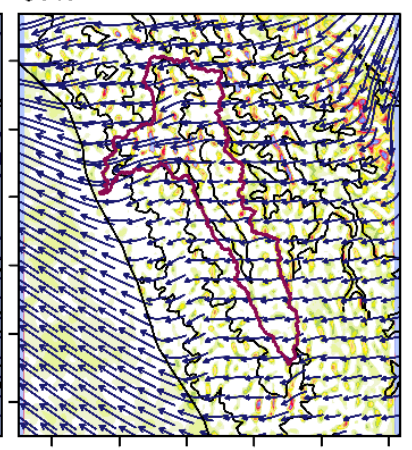

50

Figure 4.14 - DFJM Vertically-integrated moisture flux (arrows) and its divergence (color) from WRF2 to (a) all times step mean, (b) daytime mean (7-18hr LT), (c) nighttime mean (19-6hr LT), and (d) One hour time step mean. Reference vector in $\mathrm{g} \mathrm{kg}^{-1} \mathrm{~m} \mathrm{~s}^{-1}$ is displayed at the lower right corner of each panel. Units of the divergence: $10^{3} \mathrm{~g} \mathrm{~kg}^{-1} \mathrm{~s}^{-1}$. Black contours show 500 and $3500 \mathrm{~m}$ orography limits, and the coastline. Delimitation of the Rio Santa Basin watershed is indicated in bold dark red lines. 
reaches the slopes. Besides, a strong convergence of the moisture flux parallel to the coast is noted over the Pacific in the late afternoon, what would weaken the coastal moisture flux.

Only considering the Rio Santa basin, it is not absolutely concluded that precipitation over highlands of the Andes occurs mostly during the daytime since during the night there is maximum precipitation in the eastern slope of the Cordillera Blanca. This behavior could be due to this side of the Cordillera is more exposed to the Amazon region. However, when analyzing the moisture flux at this time, this hypothesis is discarded. Therefore, it is still necessary to understand the process associated with the formation of precipitation in this region. Furthermore, the location of the basin means that the Amazon basin, due to the complexity of the topography, does not directly influence it.

\subsubsection{Diurnal cycles: wind at $10 \mathrm{~m}$, specific humidity and temperature at $2 \mathrm{~m}$}

In connection with the previous analysis, the diurnal cycle of near surface variable is evaluated. Figure 4.15 shows the diurnal cycle of the wind at $10 \mathrm{~m}$ and its convergence, while the arrow colors indicate the temperature at $2 \mathrm{~m}$. Figure 4.15 shows an intensification of the perpendicular coastal flow alongshore associated with differential heating between the sea and land during the day (10-16 LT) with a maximum contrast at $13 \mathrm{LT}$, characterizing the well-known sea-land breeze (Kikuchi \& Wang, 2008; Wallace \& Hobbs, 2006). In the same period, the solar heating over high mountain regions establishes a convergence at the top of the mountain, allowing the air parcels to reach the level of free convection and the development of deep convective clouds. This process is possible by heat transferred from the ground to the air, so the air over slopes become warmer than the air over the center of the valley, creating the upslope flow, which characterize the valley-mountain breeze. The upvalley winds prevail by an unstable convective boundary layer between valley floor and slopes. During the night (01-07 LT), the cold air inhibits the convection in the highlands areas; as a result, there is cold air descending over the sidewalls and converging with lowlevel moist unstable air current. 


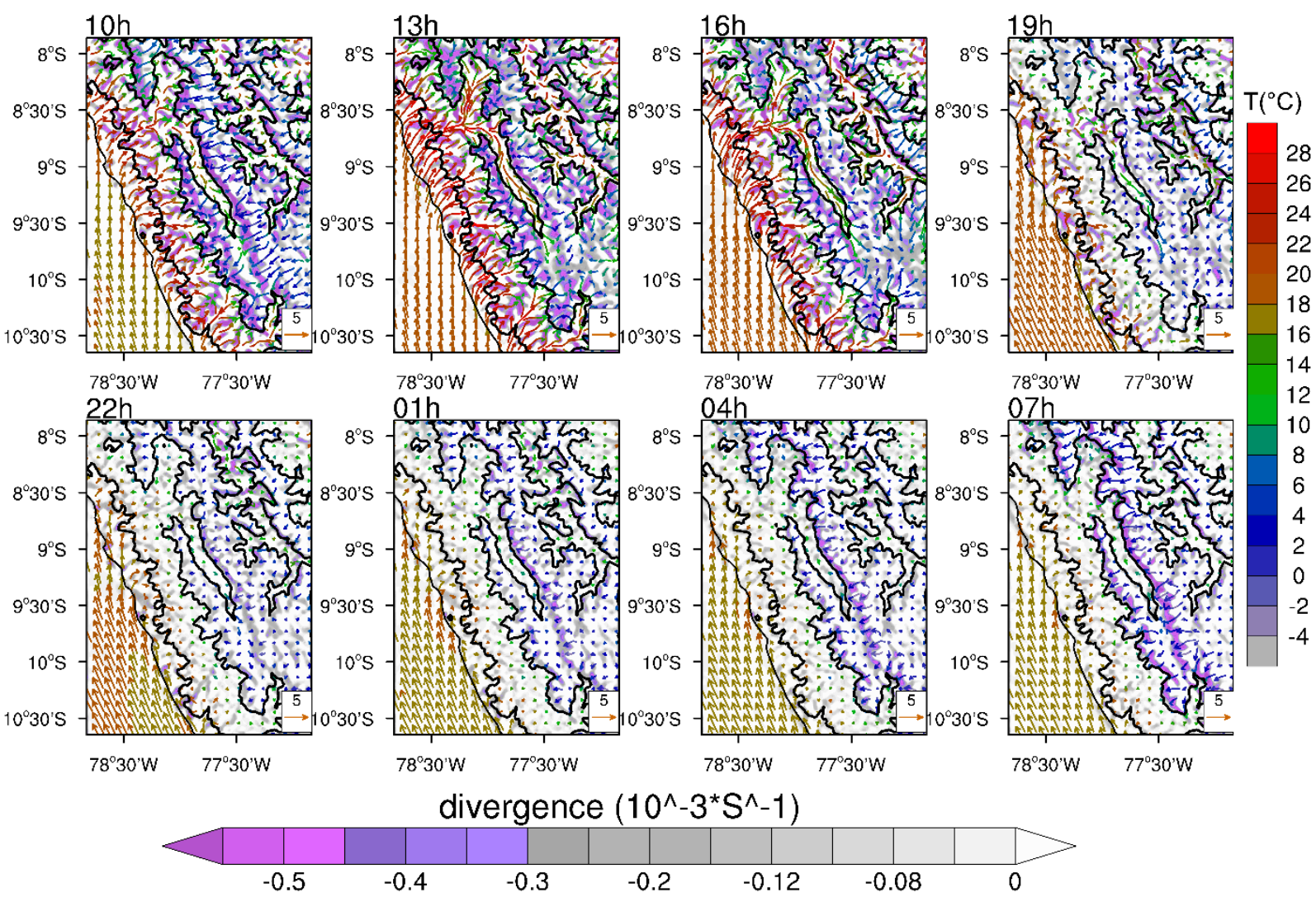

Figure 4.15 - Diurnal cycle of surface wind (arrows) at $10 \mathrm{~m}$, its divergence (color), and temperature (colored arrows) at $2 \mathrm{~m}$ from WRF2. Reference vector in $\mathrm{m} \mathrm{s}^{-1}$ is displayed at the lower right corner of each panel. Units of the divergence: $10^{-3} \mathrm{~s}^{-1}$. Bold black contours show 500 and $3500 \mathrm{~m}$ orography limits. Delimitation of the coastline is indicated in thin black line.

The intensity of wind influences the spatial distribution of specific humidity. The super-moist regions result of a favorable combination of topography, wind-flow orientation and local air circulation (Killeen et al., 2007). For example, the intensification of the perpendicular coastal western flow transports moisture during the day (Fig. 4.16; 10-16 LT) and early night (Fig. 4.16; 19 LT) over the valley. This mechanism also transports moisture to both sides of the Cordillera Negra and western side of the Cordillera Blanca. In addition, this flow increases its speed when passes through the narrow area of the valley, generating updrafts towards the eastern slopes of the Cordillera Negra that converge with its counterpart on the western side. To the east of the valley, this flow generates upward currents towards the western slopes of the Cordillera Blanca, which converge with the eastern flow from 
Amazon. It indicates the influence of coastal flow to the transport of moisture over highaltitude regions in the Santa Basin, which is a key factor for the generation of precipitation.

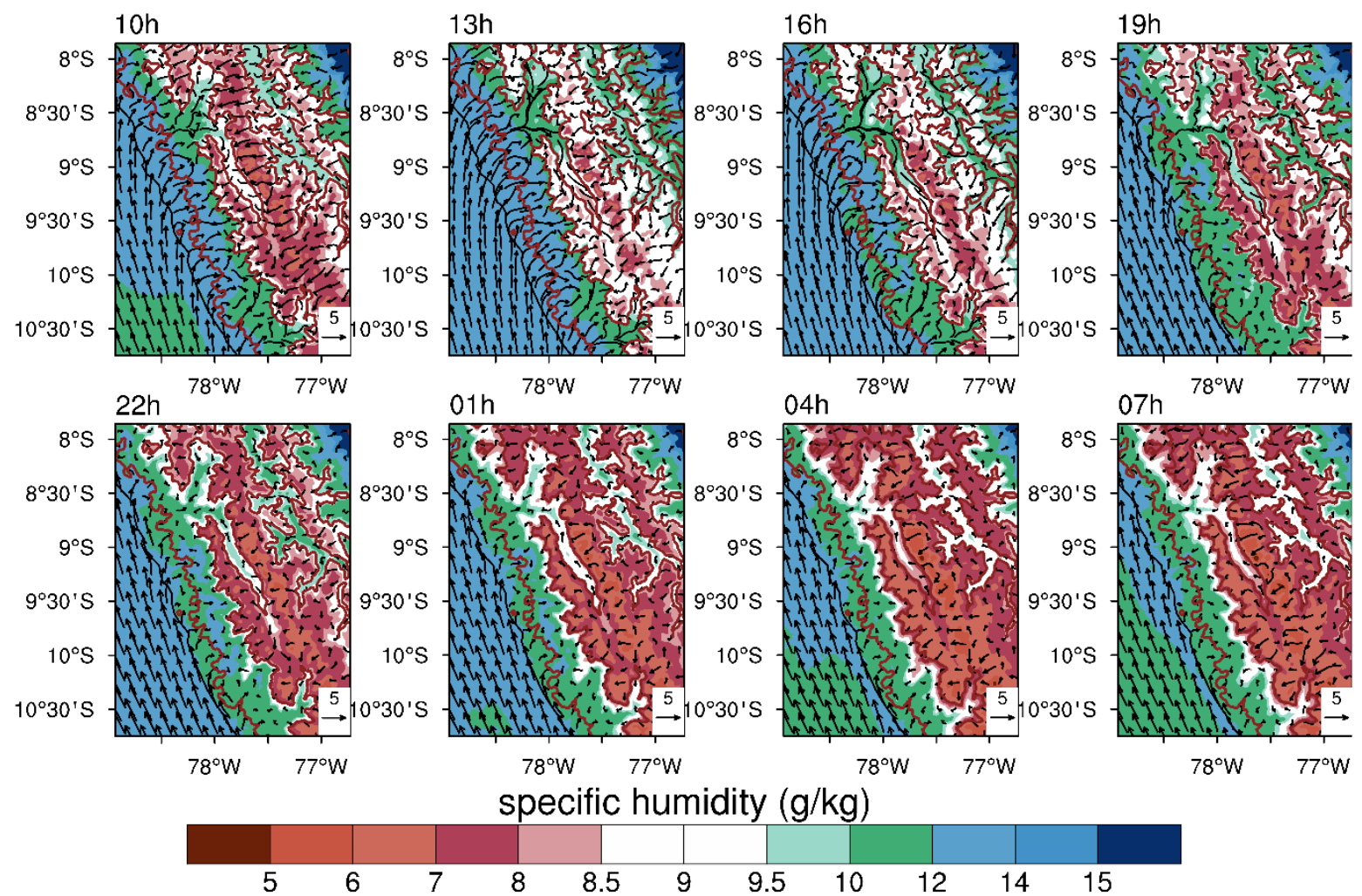

Figure 4.16 - Diurnal cycle of surface wind (arrows) at $10 \mathrm{~m}$ and specific humidity (color) at $2 \mathrm{~m}$ from WRF2. Reference vector in $\mathrm{m} \mathrm{s}^{-1}$ is displayed at the lower right corner of each panel. Bold brown contours show 500 and $3500 \mathrm{~m}$ orography limits. Delimitation of the coastline is indicated in thin black line.

\subsubsection{Influence of regional on the local circulation associated with precipitation}

Once the precipitation peak has been identified in the period of 13 to 19 LT based in the observations and simulations, regional and local scales circulation are explored. For the regional circulation at different pressure levels $(200,500$, and $850 \mathrm{hPa})$, the WRF6 is used since it has a larger domain. While WRF2 is used to discuss local near surface circulation (wind at $10 \mathrm{~m}$ ), since it has larger topography details. 


\section{Regional circulation}

In the upper-level $(200 \mathrm{hPa})$, it is noted a little westward displacement of Bolivian High core during the day (Fig. 4.17). It induces the intensification of northeasterly flow through the south coast of Peru at 17 LT. In the next hours, this region of wind speed higher than $7 \mathrm{~m} / \mathrm{s}$ extends towards the center of Peru, intensifying the winds over the basin. In the middle-level (500 hPa; Fig. 4.18) at 13 LT, the easterly winds dominate the center north of Peru, which is coherent with the circulation at $200 \mathrm{hPa}$. During 15-19 LT, there is an intensification of the southerly coastal winds reaching the center of Peru, while the easterly Amazon flow begins to weaken. At $850 \mathrm{hPa}$ (Fig. 4.19), the equatorial Pacific flow changes from northerly to westerly at $10^{\circ} \mathrm{S}$. These westerly winds are perpendicular and keep closer the Peruvian coast at 13 LT. While on the eastern side of the Santa basin, the winds are perpendicular to the basin and associated with moisture transport from Amazon. These conditions keep until 17 LT when near the entrance of basin starts southeasterly winds, a coast-parallel flow, at the same time the southward equatorial Pacific flow begins to weaken. Regarding the eastern side of the Andes, the change to southward flow weakens the winds perpendicular to the basin. 

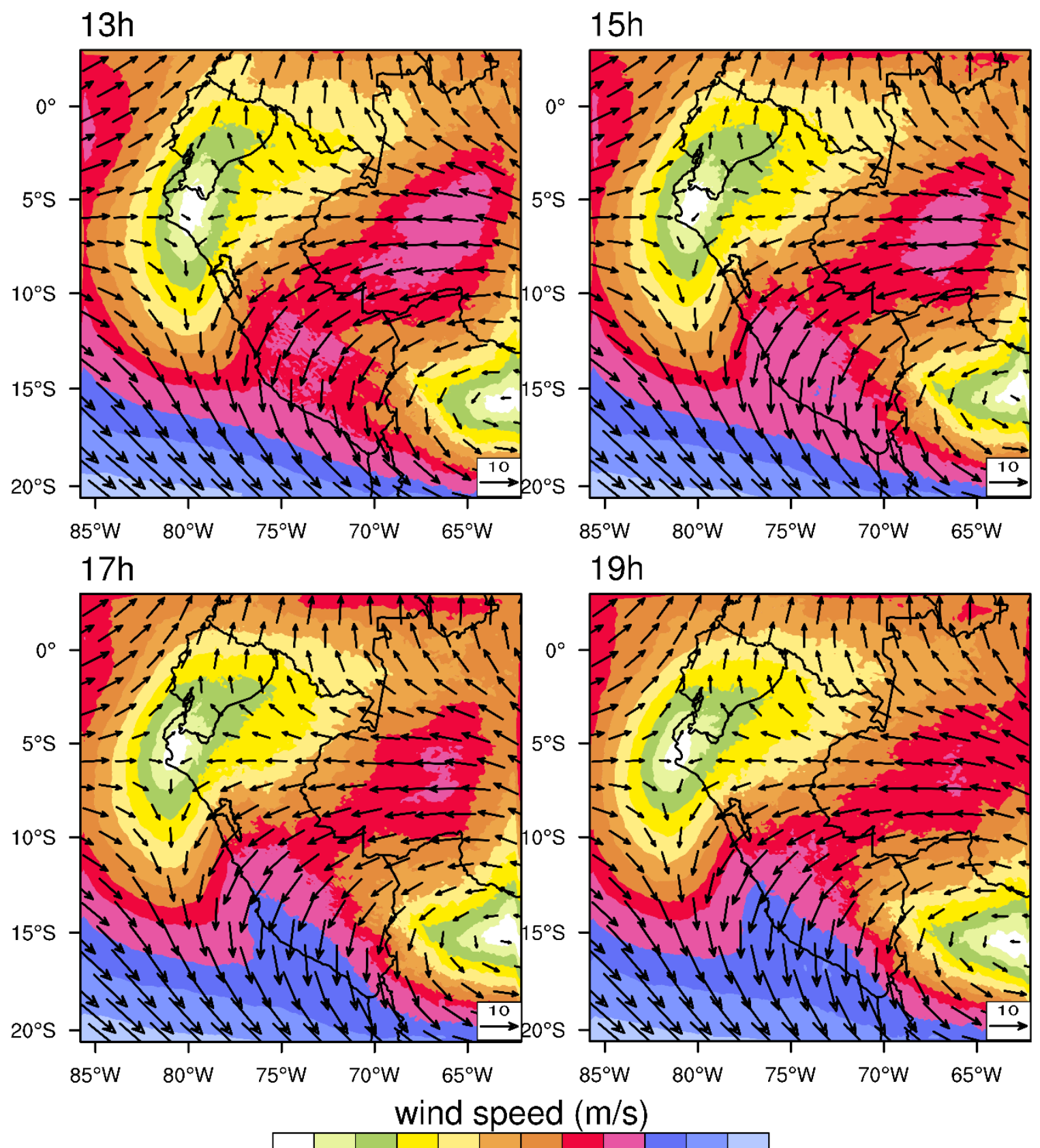

$\begin{array}{llllllllllll}1 & 2 & 3 & 4 & 5 & 6 & 7 & 8 & 10 & 12 & 15\end{array}$

Figure 4.17 - DJFM averaged horizontal wind speed (color shaded, $\mathrm{m} \mathrm{s}^{-1}$ ) as well as wind direction (arrows, $\mathrm{m}$ $\mathrm{s}^{-1}$ ) from WRF6 for 13, 15, 17, an19 LT at $200 \mathrm{hPa}$. Black contours indicate the delimitation of the countries and the Rio Santa watershed. 

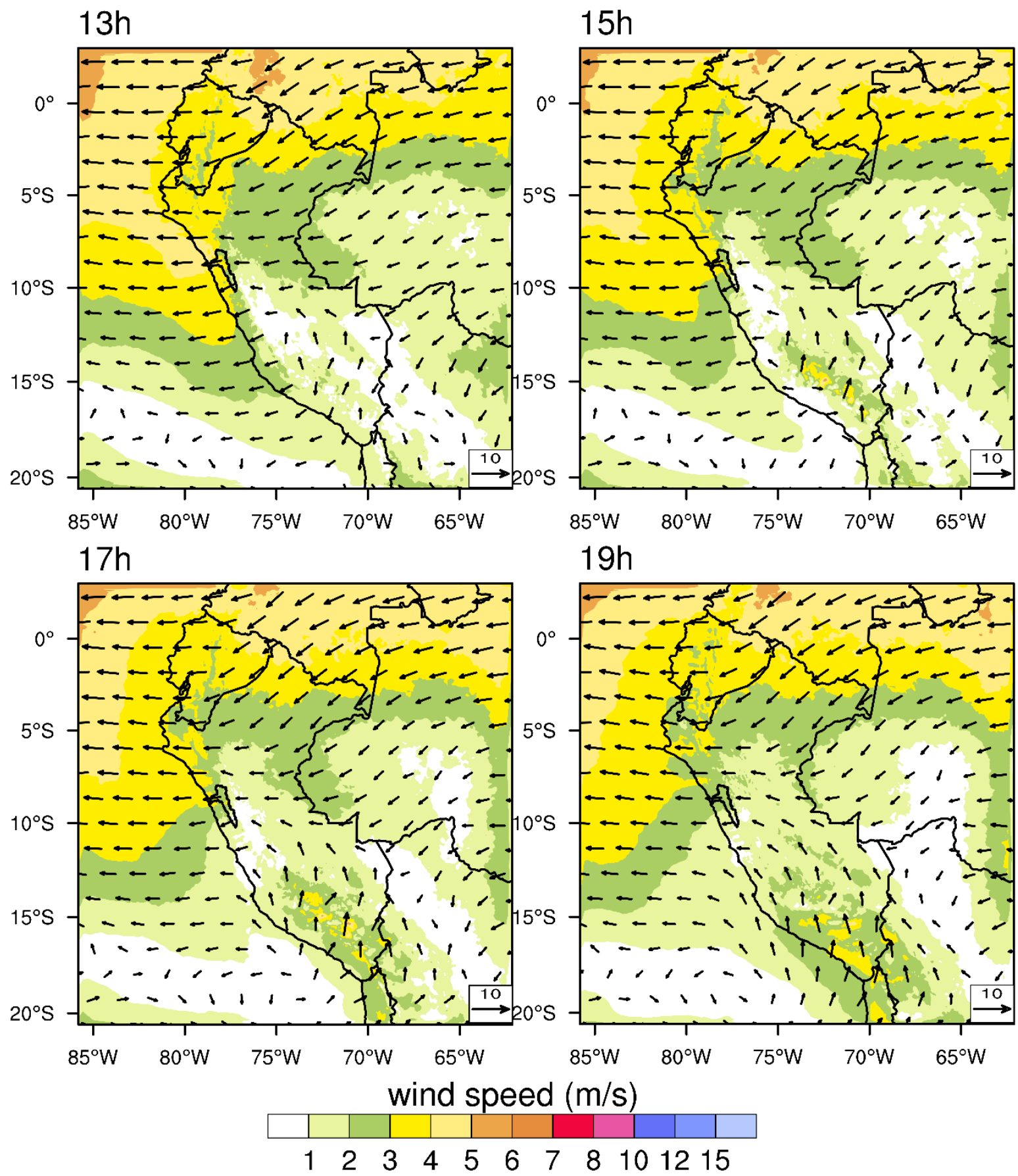

Figure 4.18 - DJFM averaged horizontal wind speed (color shaded, $\mathrm{m} \mathrm{s}^{-1}$ ) as well as wind direction (arrows, $\mathrm{m}$ $\mathrm{s}^{-1}$ ) from WRF6 for 13, 15, 17, an19 LT at $500 \mathrm{hPa}$. Black contours indicate the delimitation of the countries and the Rio Santa watershed. 

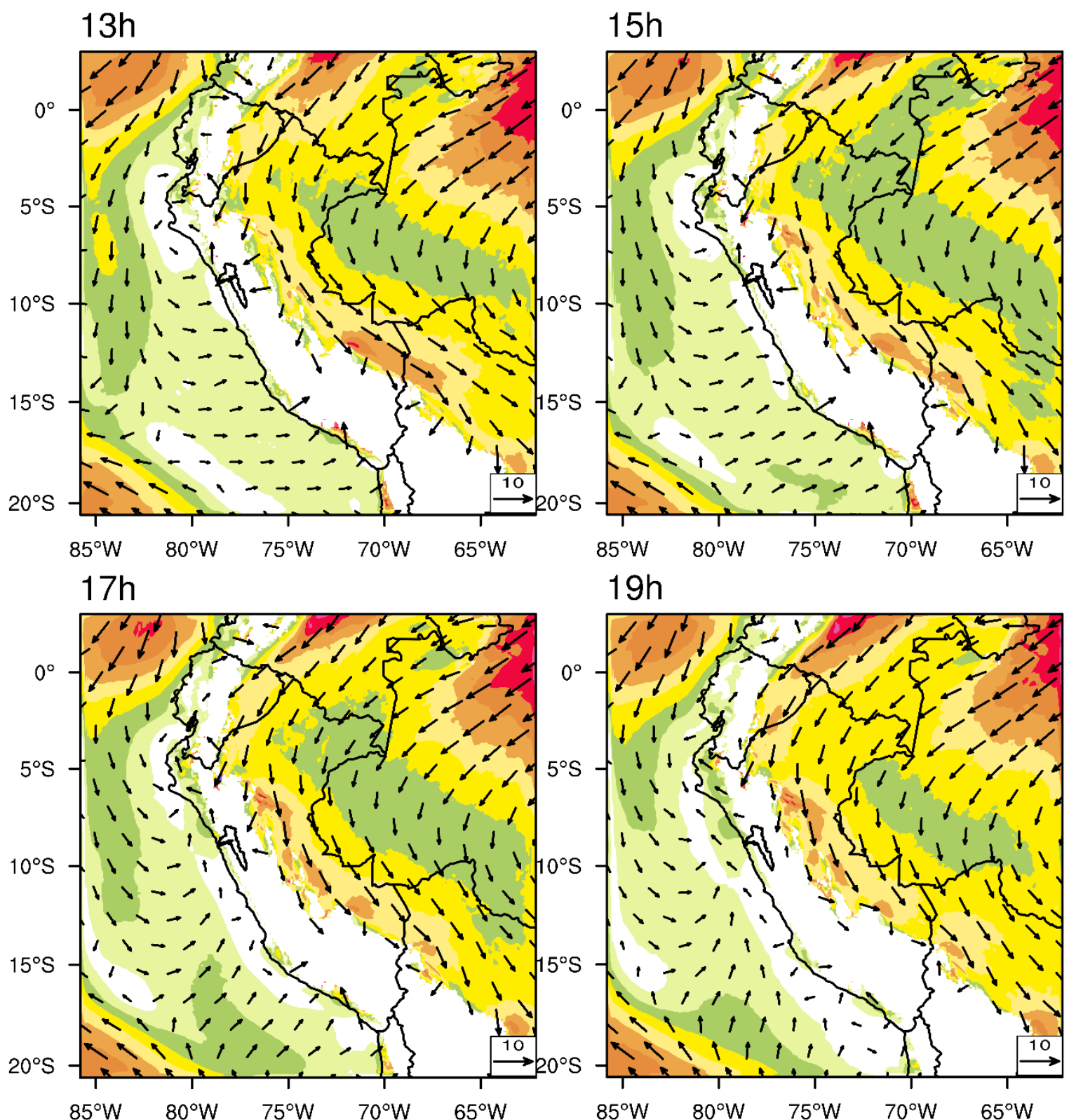

$19 \mathrm{~h}$

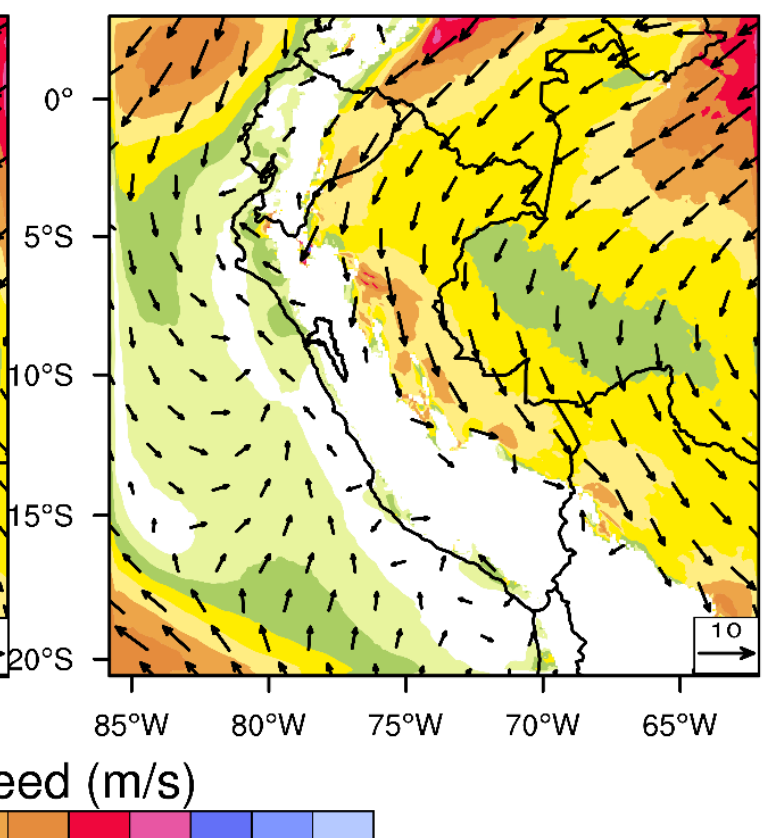

$\begin{array}{llllllllllll}1 & 2 & 3 & 4 & 5 & 6 & 7 & 8 & 10 & 12 & 15\end{array}$

Figure 4.19 - DJFM averaged horizontal wind speed (color shaded, $\mathrm{m} \mathrm{s}^{-1}$ ) as well as wind direction (arrows, $\mathrm{m}$ $\mathrm{s}^{-1}$ ) from WRF6 for 13, 15, 17, an19 LTat $850 \mathrm{hPa}$. Black contours indicate the delimitation of the countries and the Rio Santa watershed. 


\section{Local circulation}

The Santa River basin has a complex topography. It is located between two adjacent mountain ranges and another eastward called the Cordillera Central, which separates it from the direct influence of the Amazon. As consequence, the main local process is the valleymountain circulation. Due to the morphology of local terrain, the strong surface winds are present in gaps (a low area between two high mountain peaks) and are produced by pressuredriven channeling. During the daytime, continent is warmer than the adjacent ocean, generating regional gradients of pressure. They produce the westerly flow through the gap (at latitude $8.7^{\circ} \mathrm{S}$ ) from the ocean to the interior of the basin (Fig. 4.20). Once cross the gap the flow is divided into two directions, one to the north and another to the south. During the trajectory, the flows are influenced by the Venturi effect, producing acceleration through the terrain constriction, reaching maximum speeds $(\sim 10 \mathrm{~m} / \mathrm{s})$ between 13 and $15 \mathrm{LT}$. The intensification of these allows them to reach the whole valley and to rise to the mountain slopes. In addition, there is a confluence of westerly coastal winds with easterly winds from the valley over the Cordillera Negra at 13 LT. Likewise, the winds of the Santa valley converge with the winds of the Marañon valley over the Cordillera Blanca. The intensity of the coastal winds decreases considerably at 19 LT, although in the valley remains an intense flow transporting humidity towards the slopes of the mountain ranges. In the same way, the wind from the Marañon valley continues acting on the eastern side of the Cordillera Blanca. In southern of the basin, four entries of the coastal wind and two wind entries from the Marañon valley are identified. These entries would be related to the moisture transport, convergence and precipitation development at 15 LT. While in the northern part, the confluence of coastal (westerly) and Amazon (easterly) winds dominate from 13 to 19 LT.

The interrelation between the regional and the local circulations is analyzed. At 13 LT, the regional westerly Pacific flow (at $850 \mathrm{hPa}$ ) is perpendicular to the Peruvian coast (Fig. 4.19). This intensifies the sea breeze, which is configured on the coast due to the sealand temperature contrasts. Besides, eastward of the basin, between 8 and $10^{\circ} \mathrm{S}$, the easterly winds are perpendicular to the Andes. Precipitation over the Cordillera Negra is associated 
with the strong plain-mountain winds supported by coastal westerly flow, which transports moisture, converges and generate intense rainfall nucleus on the western slopes of Cordillera Negra (??). In the next hours, both the flow and precipitation weaken. However, at 19 LT there is regular rainfall over the mountain range, since the moisture available on the valley is still carried by weak upslope winds, which persist on the eastern side of the mountain. The maximum precipitation is observed at $16 \mathrm{LT}$ on the Cordillera Blanca (Fig. 4.13.d) due to the intensification within of the basin of up-valley wind, which favors upslope wind in the eastern side of the mountain (Fig. 4.20; 15 LT). It converges with upslope winds from Marañon valley that is intensified by the regional Amazon flow. The Cordillera Blanca experiments another precipitation peak, but on the eastern side at 19 LT (Fig. 4.13.d). At this time, the change of direction of the Amazonian flow would not be associated with the precipitation formation. However, there is considerable increase in the humidity of the Marañon valley where the presence of upslope winds is still occurring. Then, this local flow could be enough to sustain the precipitation formation in the region. Southward of the basin, the previously identified four (from coast) and two (from Marañon valley) entries of winds to the basin channel the near surface wind. In addition, the regional circulation at $850 \mathrm{hPa}$ over the Peruvian coast at $13 \mathrm{LT}$ intensifies the coastal wind. The superficial winds reach maximum magnitude at $15 \mathrm{LT}$ converging with the upslope winds of the Marañon valley, which increase with the easterly Amazon flow. The convergence of coastal and Amazon wind transports very moist air and generates the greater amount and area of precipitation over the study region. Finally, to the north of the basin, the convergence of coastal winds inside and outside the valley, together with the Amazonian flow, promotes the development of intense precipitation, starting at $13 \mathrm{LT}$ with a peak at $16 \mathrm{LT}$. It is important to clarify that according to the simulation the change of direction of the upslope winds not occur immediately, which justifies that the precipitation at $19 \mathrm{LT}$ would be sustained by the effect of this residual circulation. 

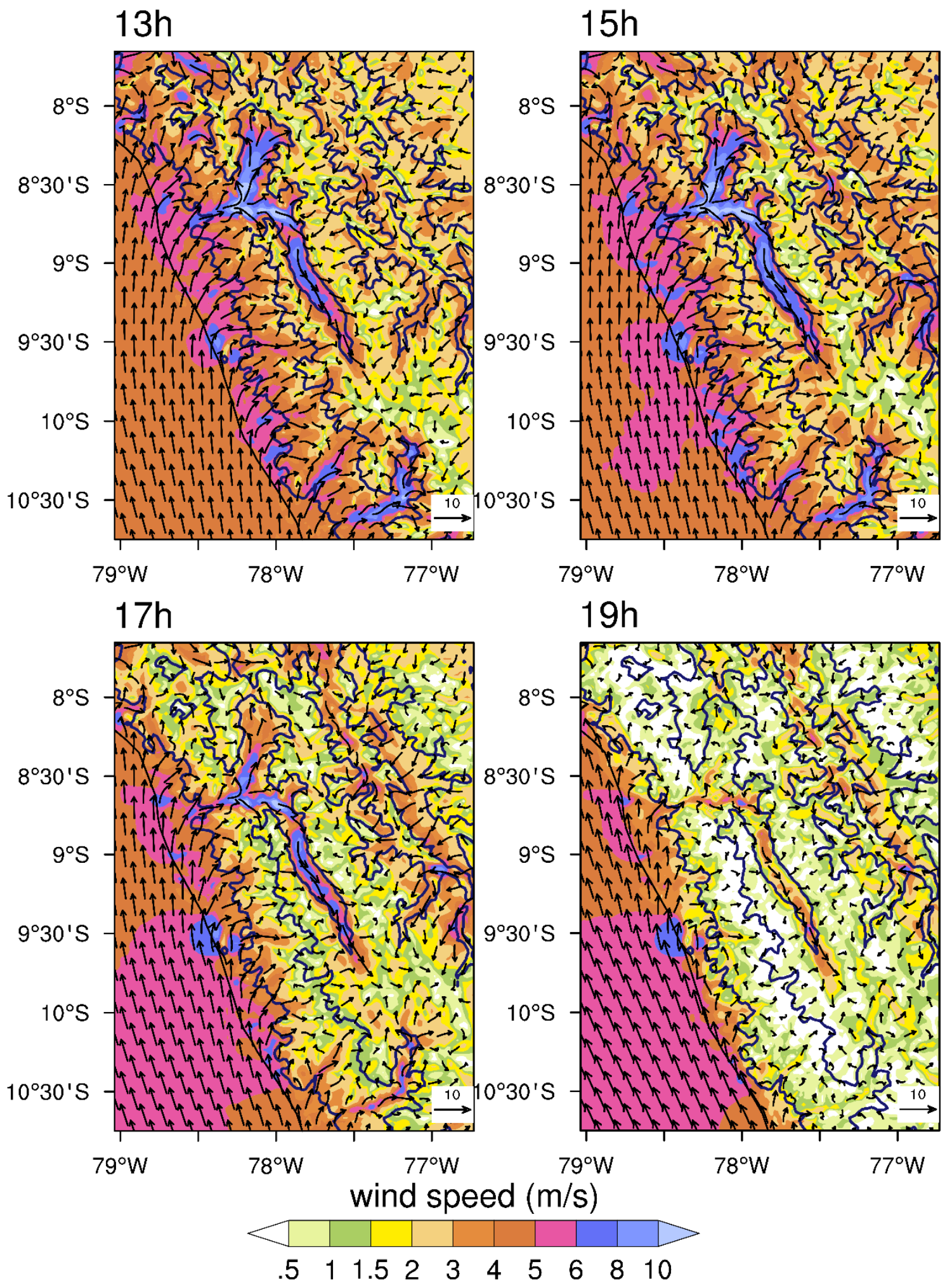

Figure 4.20 - DJFM averaged horizontal wind speed (color shaded, $\mathrm{m} \mathrm{s}^{-1}$ ) as well as wind direction (arrows, $\mathrm{m}$ $\mathrm{s}^{-1}$ ) at $10 \mathrm{~m}$ from WRF2 for 13, 15, 17, an19 LT. Bark blue contours show 500 and $3500 \mathrm{~m}$ orography limits. Delimitation of the coastline and the Rio Santa watershed are indicated in thin black line. 


\subsubsection{Valley-mountain processes observed in cross-sections.}

WRF2 simulation is used to discuss the main features of the wind through vertical cross-sections to understand the interrelation of these circulations in the afternoon and early night periods (from 13 to 19 LT). The vertical cross sections show the distribution of specific humidity, its anomalies and the presence of cloud water as an indicator associated with the development of precipitation. Three vertical latitudinal cross sections are discussed between $79.4^{\circ}-76^{\circ} \mathrm{W}$ longitude. The first in the north of the basin $\left(8.66^{\circ} \mathrm{S}\right)$, the second in the central part $\left(9.15^{\circ} \mathrm{S}\right)$ near the Huascaran peak, and the last in the southern part $\left(9.75^{\circ} \mathrm{S}\right)$. Finally, a longitudinal vertical cross-section is analyzed along the valley. All presented cross sections are mean for December to March of 2013 rainy season. Only the first cross-section of specific humidity is shown in this section, while the others are in the appendix.

\section{North of the basin:}

It is evident the strong mean alongshore surface wind, which transports moisture to the entrance of the basin (Fig. 4.21). Because of the known atmospheric stability on the coast (Garreaud \& Muñoz, 2004), the vertical profile of the wind shows a strong zonal component over the coastal region. At the height of $1500 \mathrm{~m}$, the presence of easterly winds begins to be observed (13 LT), which will predominate in this level in the next hours. Above this layer, it is noted the presence of westerly winds at $2500 \mathrm{~m}$, intensifying the coastal flow towards the basin. The presence of these two layers flow is associated with the entrance of a southern flow (lower) (Fig. A.3) superimposed by a northern flow (upper) (Fig. A.2), both identified in previous in the latitude of $15^{\circ} \mathrm{S}$ (e.g. Belmadani et al., 2014; Chamorro et al., 2018) as part of the Pacific coastal temperature inversion. In this way, the easterly flow at higher levels does not have a direct influence on coastal circulation. On the Amazon side, the vertical profile contrasts with the coastal one, the easterly Amazon flow generates turbulence and intensifies the winds on the highlands. In addition, the strong convective activity with the upslope wind acts favoring the moisture transport to the mountain ranges and high levels of the atmosphere. 

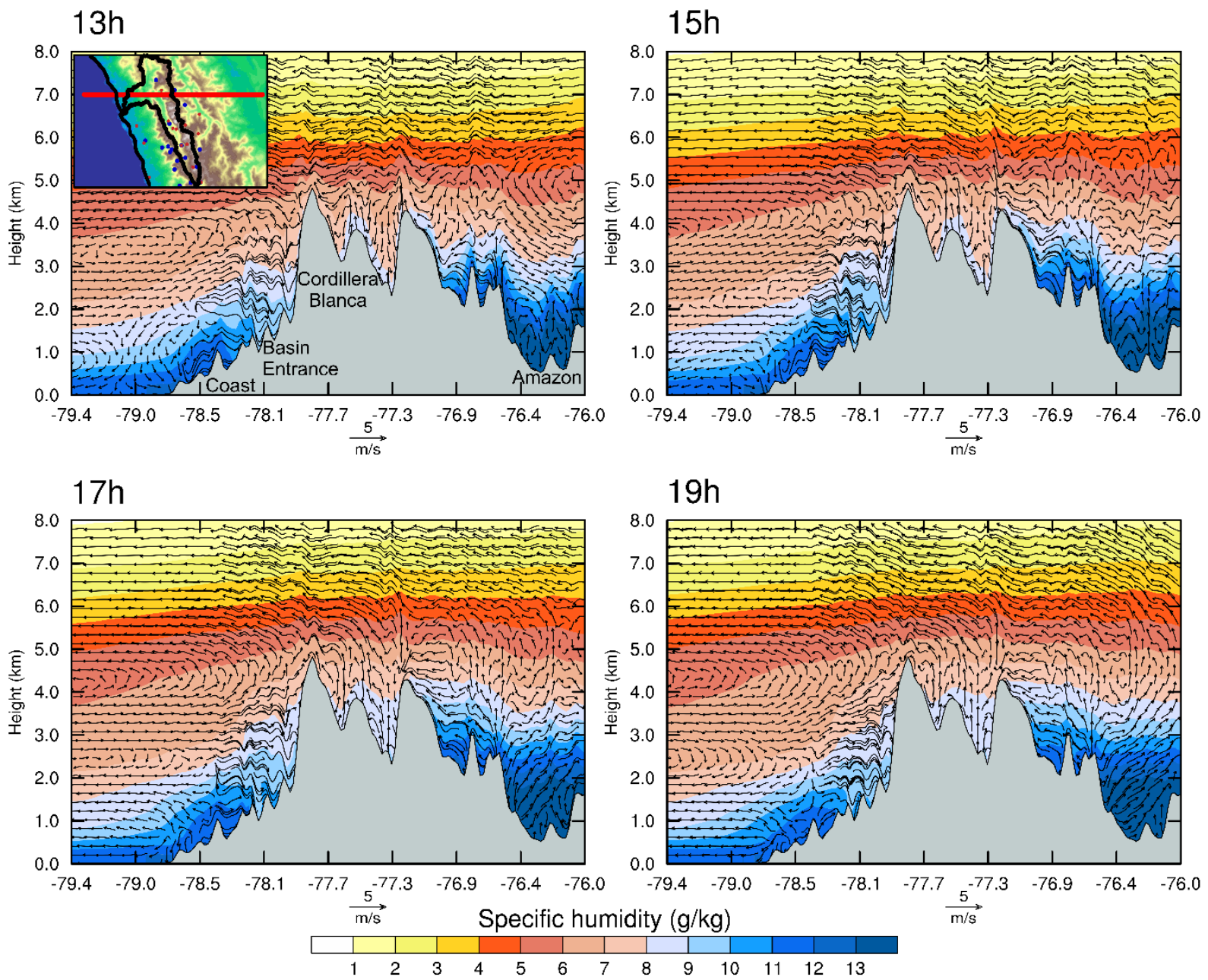

Figure 4.21 - Vertical cross-section of zonal and vertical (x 10) winds (arrows, $\mathrm{m} \mathrm{s}^{-1}$ ) and specific humidity (color, $\mathrm{g} \mathrm{kg}^{-1}$ ) for the times $13,15,17$, and $19 \mathrm{LT}$ obtained from WRF2 at $8.66^{\circ} \mathrm{S}$ (north section).

A zoom in the cross-section indicates that during the daytime (13-17 LT), the upslope winds prevail (Fig. 4.22). The convective boundary layer becomes deeper and no uniform winds are observed allowing the increasing of cloud water concentration. The strong westerly coastal flow dominates the near surface circulation in the western side of the Cordillera Blanca, and it is intensified by synoptic westerly flow (between 3-4 km) and the Venturi effect due to the morphology of the basin. Near-surface wind speeds increase with the time, and encounter at higher altitudes the stronger easterly Amazon flow in the eastern side of the Cordillera Blanca. This easterly flow triggers two individual cloud systems, which initiated at $13 \mathrm{LT}$ and evolve into one at $19 \mathrm{LT}$. 

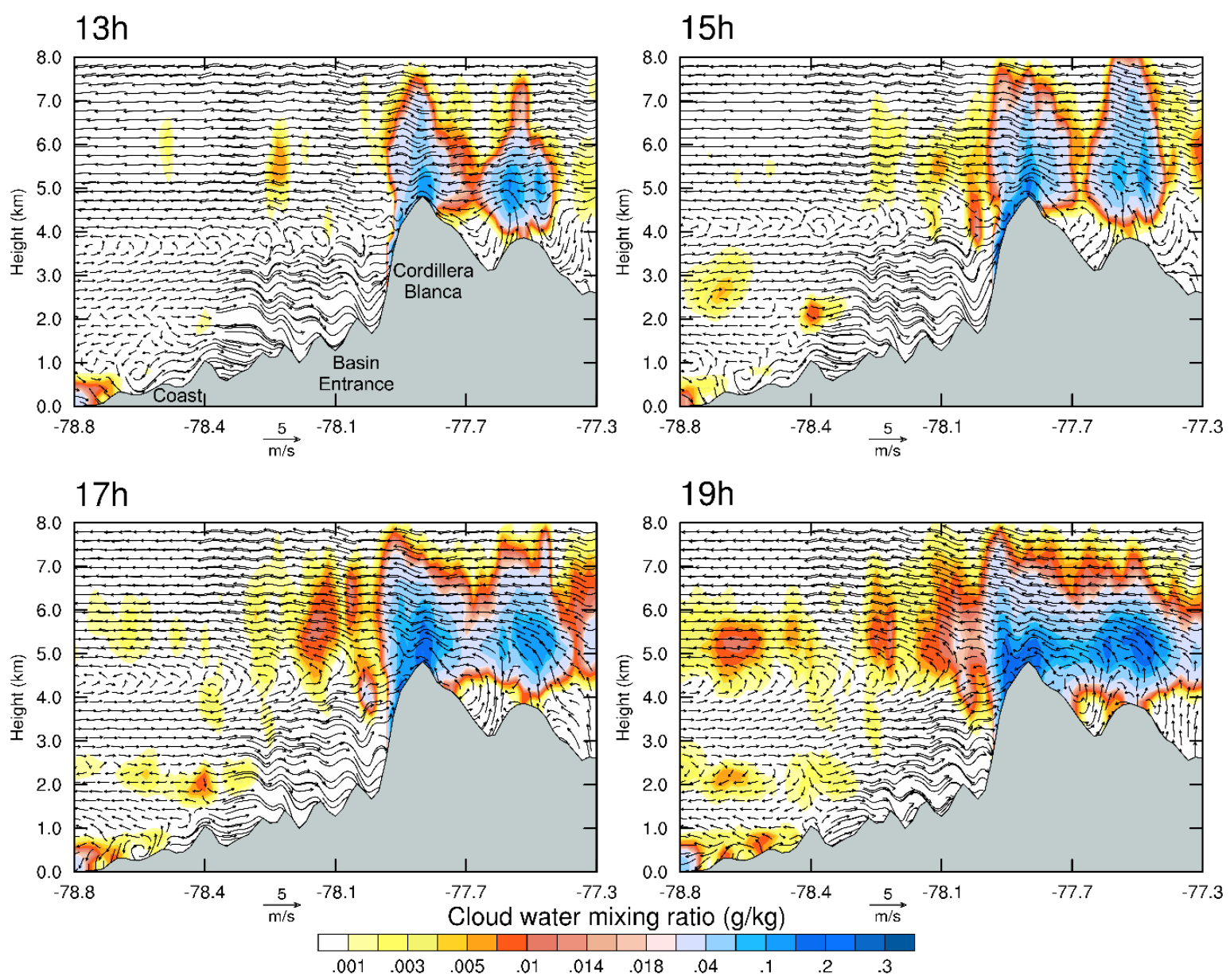

Figure 4.22 - Vertical cross-section of zonal and vertical (x 10) winds (arrows, $\mathrm{m} \mathrm{s}^{-1}$ ) and cloud water mixing ratio (color, $\mathrm{g} \mathrm{kg}^{-1}$ ) for the times $13,15,17$, and $19 \mathrm{LT}$ obtained from WRF2 at $8.66^{\circ} \mathrm{S}$ (north section).

In terms of anomaly (times-step mean minus the daily average), the valley-mountain breeze circulation pattern dominates the surface flow (Fig. 4.23). Large anomalies of moisture concentrate over the basin entrance and summits during the times 13, 15 and 17 LT since the strong westerly flow brings the humidity from the coastal zone to the slopes and intensifies the anabatic winds in the western side of the Cordillera Blanca. Large verticalaxis eddies result from the flow over mountains, which contribute to the vertical transport of humidity. In addition, this transport is directly related to the development of cloudiness because the anomalous moister air over the summits is associated with high contents of cloud water during the daytime. At the late afternoon (17 LT) and the early night (19 LT), a bridge is established between the moisture at $5 \mathrm{~km}$ and on the surface. 

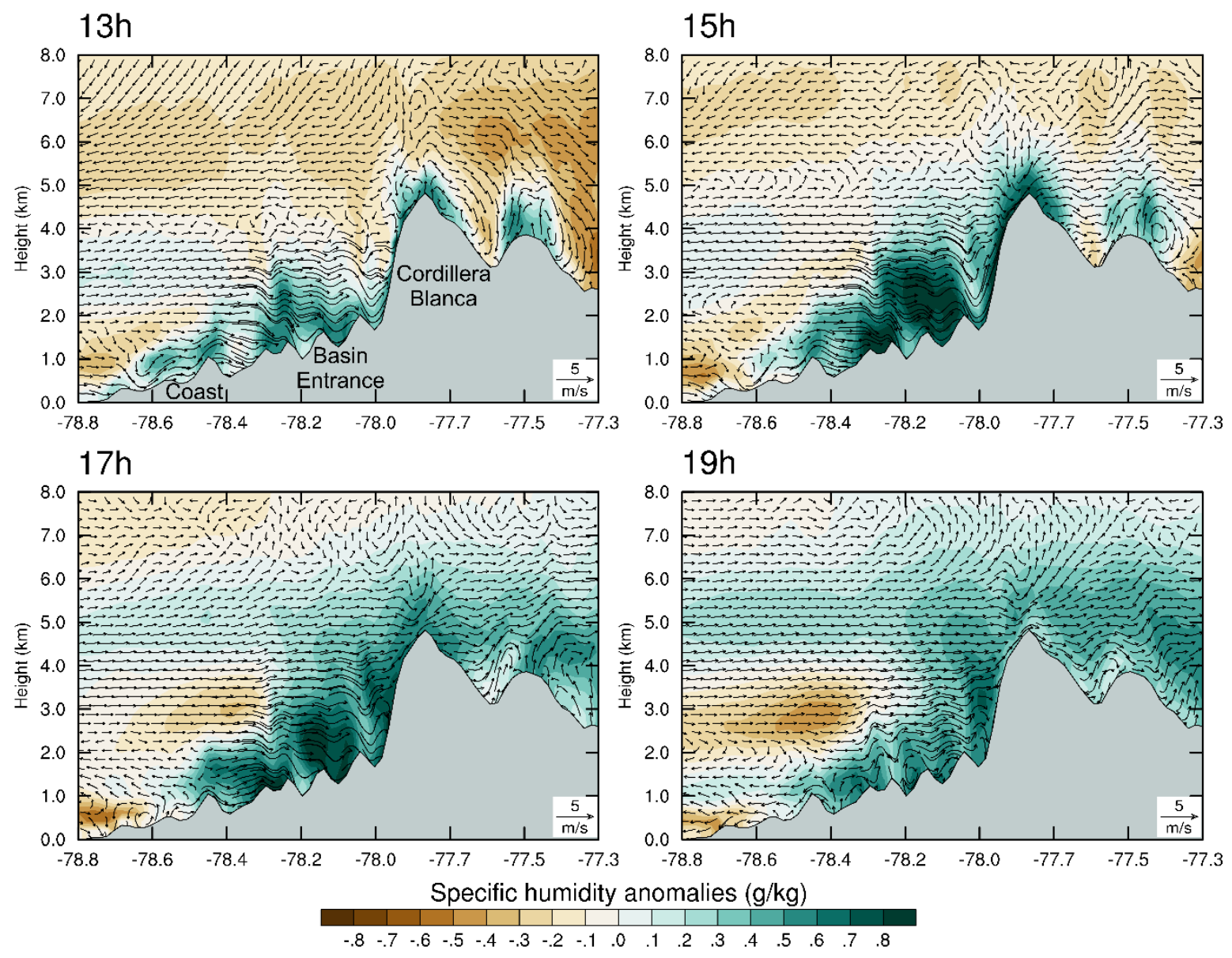

Figure 4.23 - Vertical cross-section of zonal and vertical (x 10) winds (arrows, $\mathrm{m} \mathrm{s}^{-1}$ ) and specific humidity (color, $\mathrm{g} \mathrm{kg}^{-1}$ ) anomalies (time-step mean minus the daily average) for 13, 15, 17, and 19 LT from WRF2 at latitude $8.66{ }^{\circ} \mathrm{S}$ (north section).

\section{Center of the basin:}

In the center of the basin, due to complex topography, there is a mountain between the Cordillera Blanca and Marañon valley, which forms part of the mountain range (Fig. 4.24). The intensification of the near surface upslope winds by westerly winds at $4 \mathrm{~km}$ in the western side of the Cordillera Negra favors the development of deep convection, which is strongly associated with the presence of intense precipitation at 13 LT (Fig. 4.13.d). At this time, various cloud systems, with higher cloud water, form over the summits supported by intense upslope valley winds and high anomalous moisture concentration (Fig. 4.25). In the next hours (15 and 17 LT), these systems reach great vertical development. In addition, these systems begin forming individually but over time, they agglomerate. At 19 LT, the vertical 
flow decreases due to the stable conditions created by the thermal inversion. The core of the cloud water formed over the Cordillera Blanca moves eastward at same time that it is intensifying and approaching the surface on the eastern slope, there is still an upslope wind from Marañon valley. These features would be associated with strong precipitation in the eastern slope of the Cordillera Blanca at this hour.
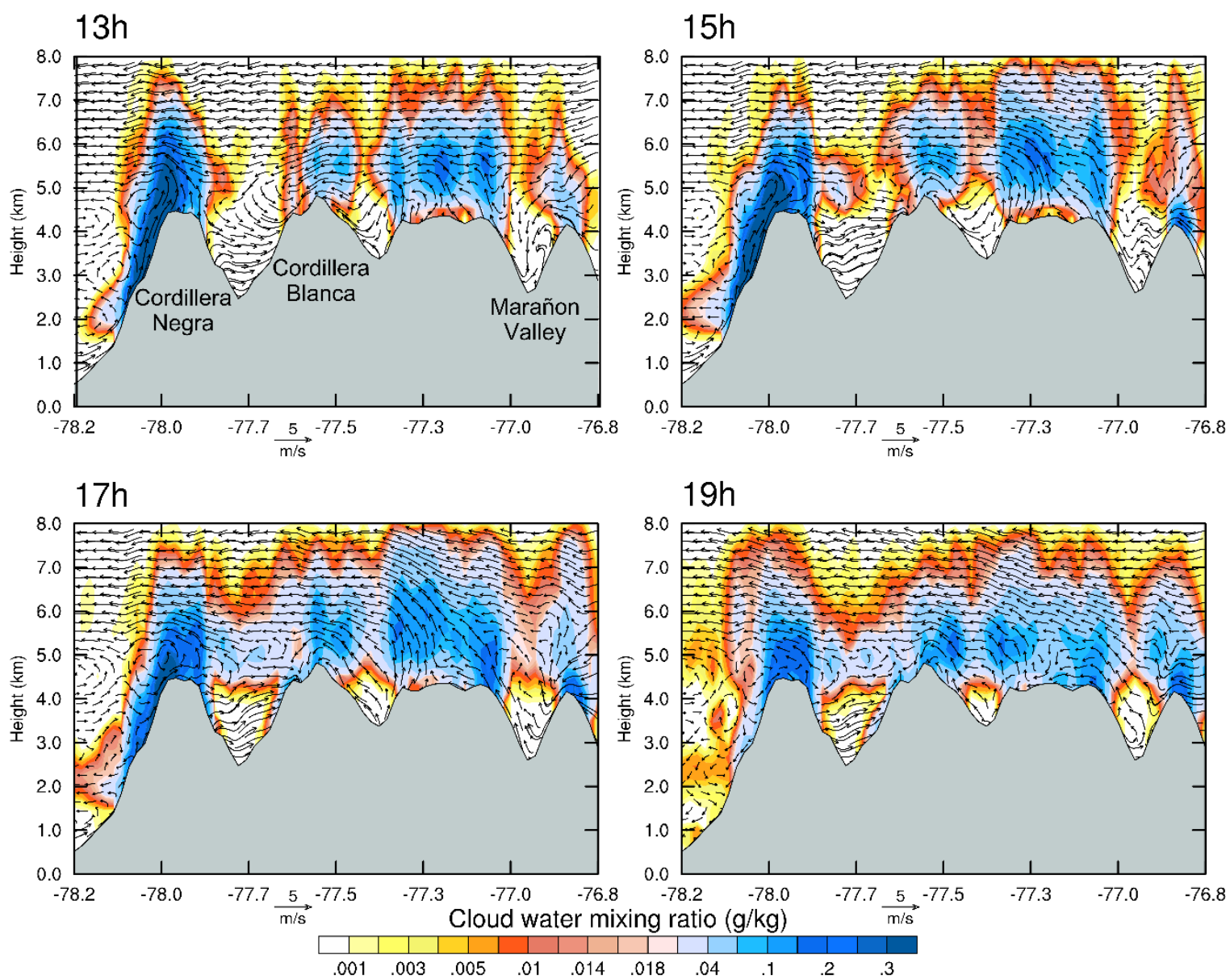

Figure 4.24 - Vertical cross-section of zonal and vertical (x 10) winds (arrows, $\mathrm{m} \mathrm{s}^{-1}$ ) and cloud water mixing ratio (color, $\mathrm{g} \mathrm{kg}^{-1}$ ) for the times $13,15,17$, and $19 \mathrm{LT}$ obtained from WRF2 at $9.15^{\circ} \mathrm{S}$ (center section) and between $78.2^{\circ}-76.8^{\circ} \mathrm{W}$ of longitude.

In the anomaly field (Fig. 4.25), the strong upslope flows impose the greatest amount of humidity on the sidewalls and the top of the mountain ranges between 13 and 15 LT. The upslope winds allow the passage of humidity from the western side of the Cordillera Negra 
to the valley of the basin. Likewise, the moisture transport from the Amazonia to the Marañon valley occurs, which would be associated with the presence of light precipitation over the valleys (Fig. 4.13.d; 13-15 LT). The slope winds reverse from upslope to downslope and decrease of intensity at 17 LT. At 19 LT, this reversion is more marked, due to the radiative cooling, and the moisture flux converges on the valleys.
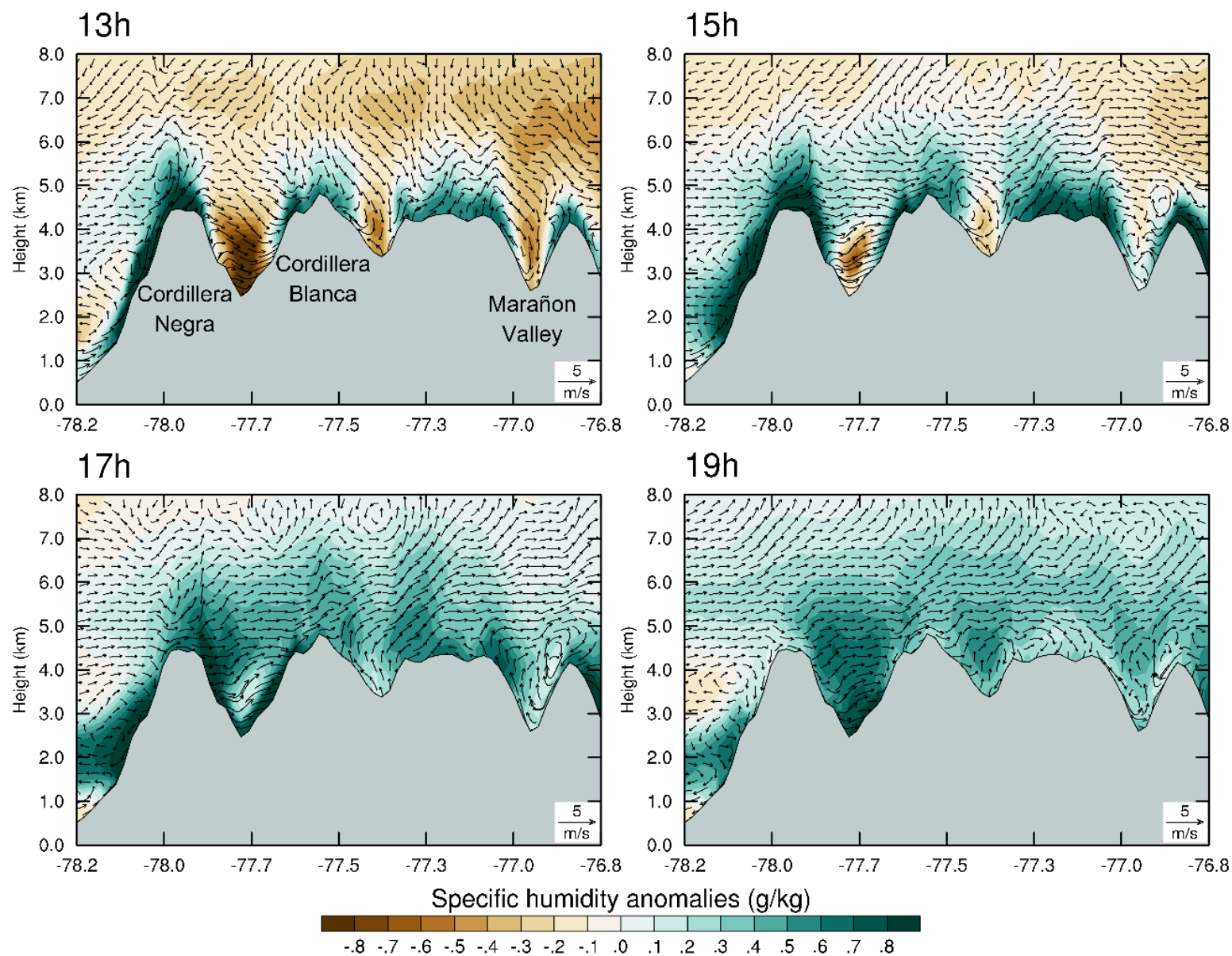

Figure 4.25 - Vertical cross-section of zonal and vertical (x 10) winds (arrows, $\mathrm{m} \mathrm{s}^{-1}$ ) and specific humidity (color, $\mathrm{g} \mathrm{kg}^{-1}$ ) anomalies (time-step mean minus the daily average) for 13, 15, 17, and 19 LT from WRF2 at latitude $9.15^{\circ} \mathrm{S}$ (central section) and between $78.2^{\circ}-76.8^{\circ} \mathrm{W}$ of longitude. 


\section{South of the basin:}

In this region of the basin, the cloud systems form earlier than in the other sectors of the basin (Fig. 4.26). Thus, these systems are already agglomerated and associated with heavy precipitation in the middle of the afternoon (15 LT). The generation of a vertical-axis eddy in the eastern side of the Cordillera Blanca organizes a strong ascension of the air and conditions of instability, which favors the vertical development of the cloudiness.
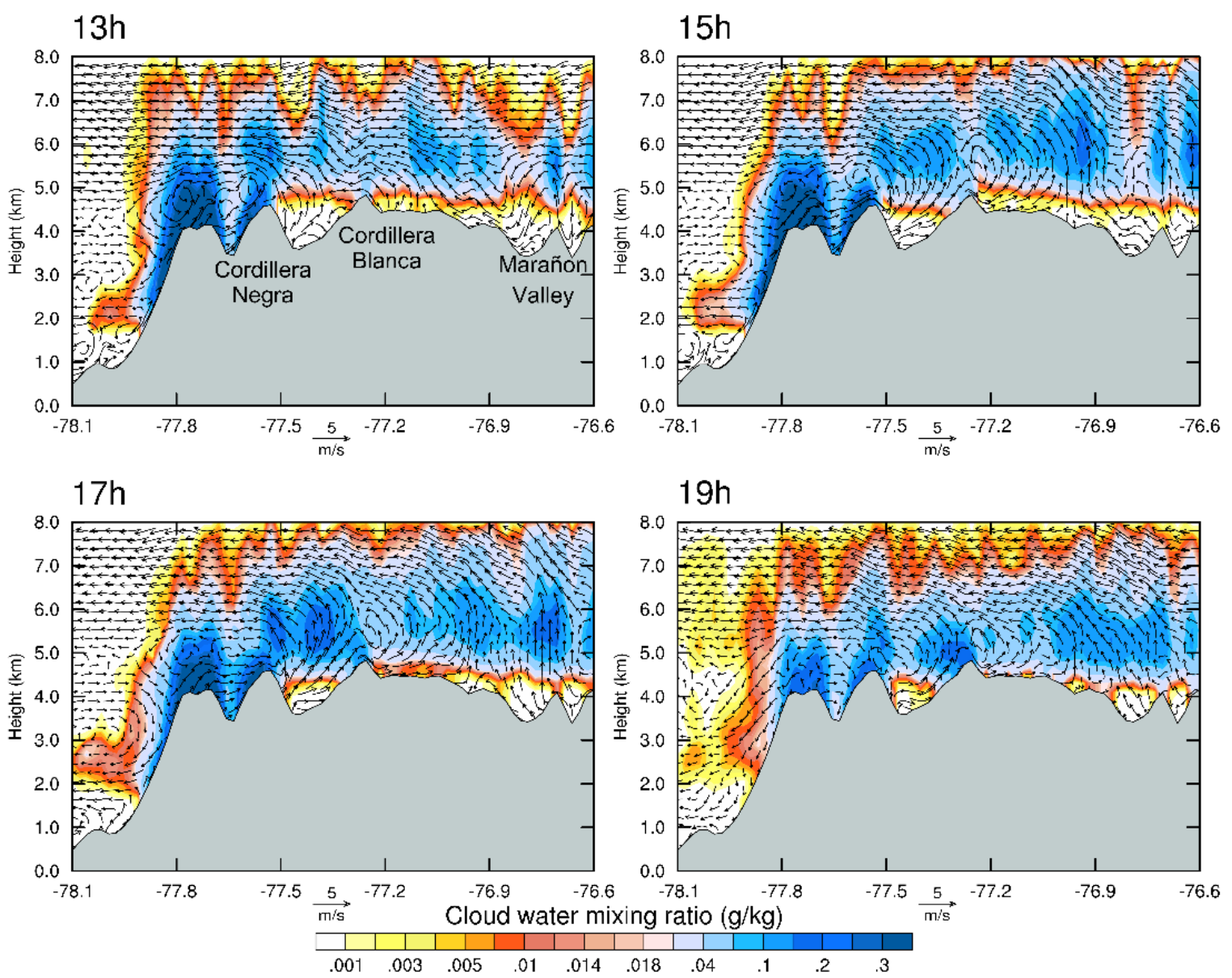

Figure 4.26 - Vertical cross-section of zonal and vertical (x 10) winds (arrows, $\mathrm{m} \mathrm{s}^{-1}$ ) and cloud water mixing ratio (color, $\mathrm{g} \mathrm{kg}^{-1}$ ) for the times $13,15,17$, and $19 \mathrm{LT}$ obtained from WRF2 at $9.75^{\circ} \mathrm{S}$ (south section) and between $78.1^{\circ}-76.6^{\circ} \mathrm{W}$ of longitude.

The cross-section is located in the latitude of one of the four main entrances of the coastal flow towards the basin, which implies in a strong anomalous transport of moisture 
that enters the Cordillera Negra (Fig. 4.27). In the middle afternoon (15-17 LT), the moisture moves towards the valley and continues its journey in direction to the Cordillera Blanca, where it converges with Amazon moist easterly flow. Consequently, the atmosphere gains high humidity favoring heavy precipitation during the late afternoon and early night. At the beginning of the night (19 LT), humidity is suppressed of the lowest levels of atmosphere.
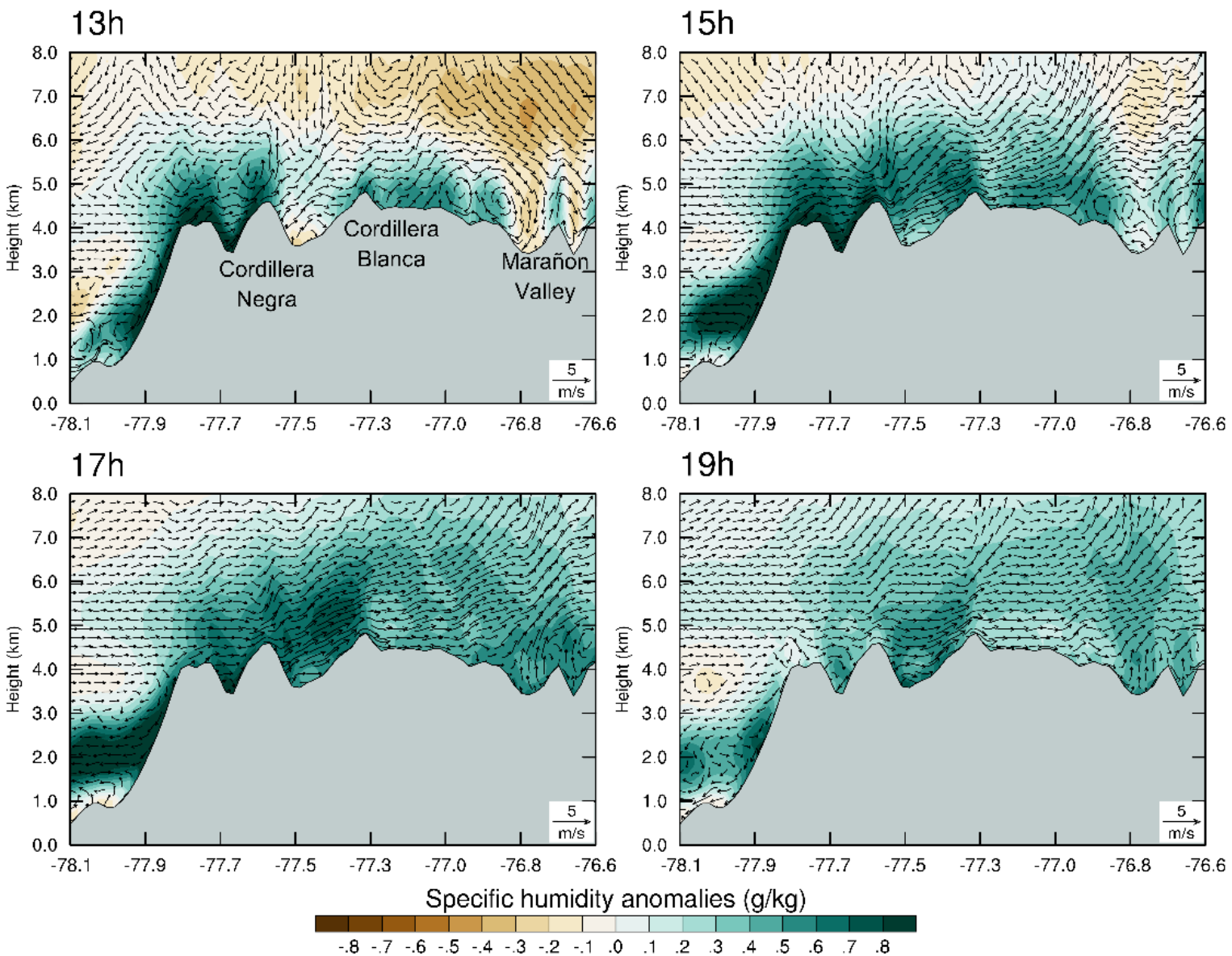

Figure 4.27 - Vertical cross-section of zonal and vertical (x 10) winds (arrows, $\mathrm{m} \mathrm{s}^{-1}$ ) and specific humidity (color, $\mathrm{g} \mathrm{kg}^{-1}$ ) anomalies (time-step mean minus the daily average) for 13, 15, 17, and $19 \mathrm{LT}$ from WRF2 at latitude $9.75^{\circ} \mathrm{S}$ (south section) and between $78.1^{\circ}-76.6^{\circ} \mathrm{W}$ of longitude.

\section{Basin Valley:}

The presence of high cloud water contents over the southern sector of the valley indicates that there are favorable conditions for the development of intense precipitation (Fig. 
4.28). At upper-levels $(7 \mathrm{~km})$ there are three vertical-axis eddies over the valley during the daytime (13-17 LT), which favor the vertical development of the cloudiness. Because of the atmosphere stabilizes in the early night (19 LT), these eddies broken.
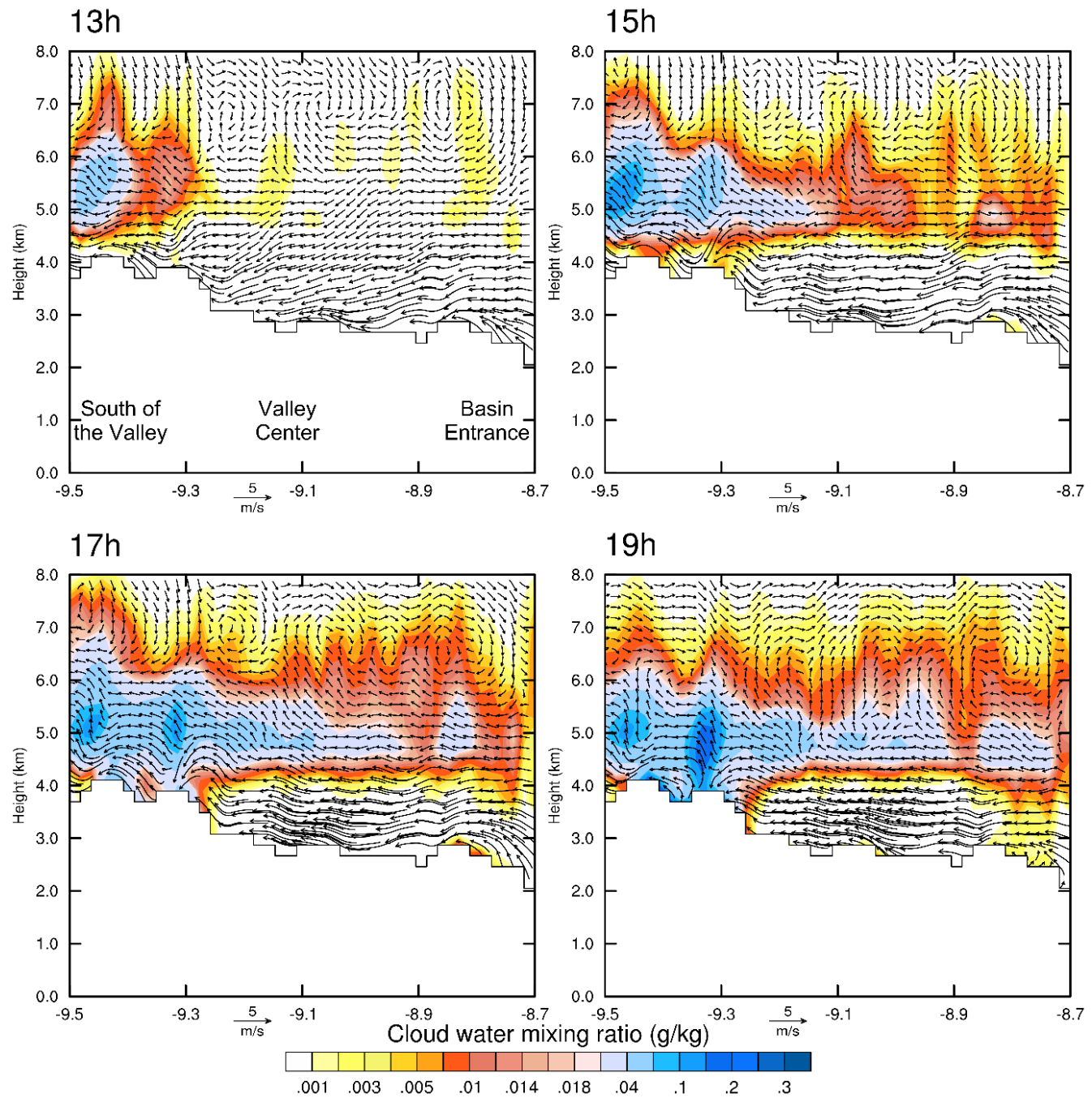

Figure 4.28 - Vertical cross-section of meridional and vertical (x 10) winds (arrows, $\mathrm{m} \mathrm{s}^{-1}$ ) and cloud water mixing ratio (color, $\mathrm{g} \mathrm{kg}^{-1}$ ) for the times $13,15,17$, and $19 \mathrm{LT}$ obtained from WRF2 starting at $8.70^{\circ} \mathrm{S}-77.98^{\circ} \mathrm{W}$ to $9.52^{\circ} \mathrm{S}-77.58^{\circ} \mathrm{W}$.

In the meridional cross-section over the valley, anomalous dry conditions are identified near the surface in early afternoon (13 LT), which begin to decrease with the entrance of coastal moist flow from the northern valley part (Fig. 4.29). Above the surface of the valley $(\sim 5 \mathrm{~km})$, the formations of anomalous moist cores (at $9.5^{\circ}, 9.3^{\circ}$, and $9.1^{\circ} \mathrm{S}$ ) are observed. This suggests that moisture also enters from the mountain ranges towards the 
valley. However, during the afternoon (15-17 LT) and early night (19 LT), most of the valley does not experience convective activity, thus the humidity gets confined to the surface level.
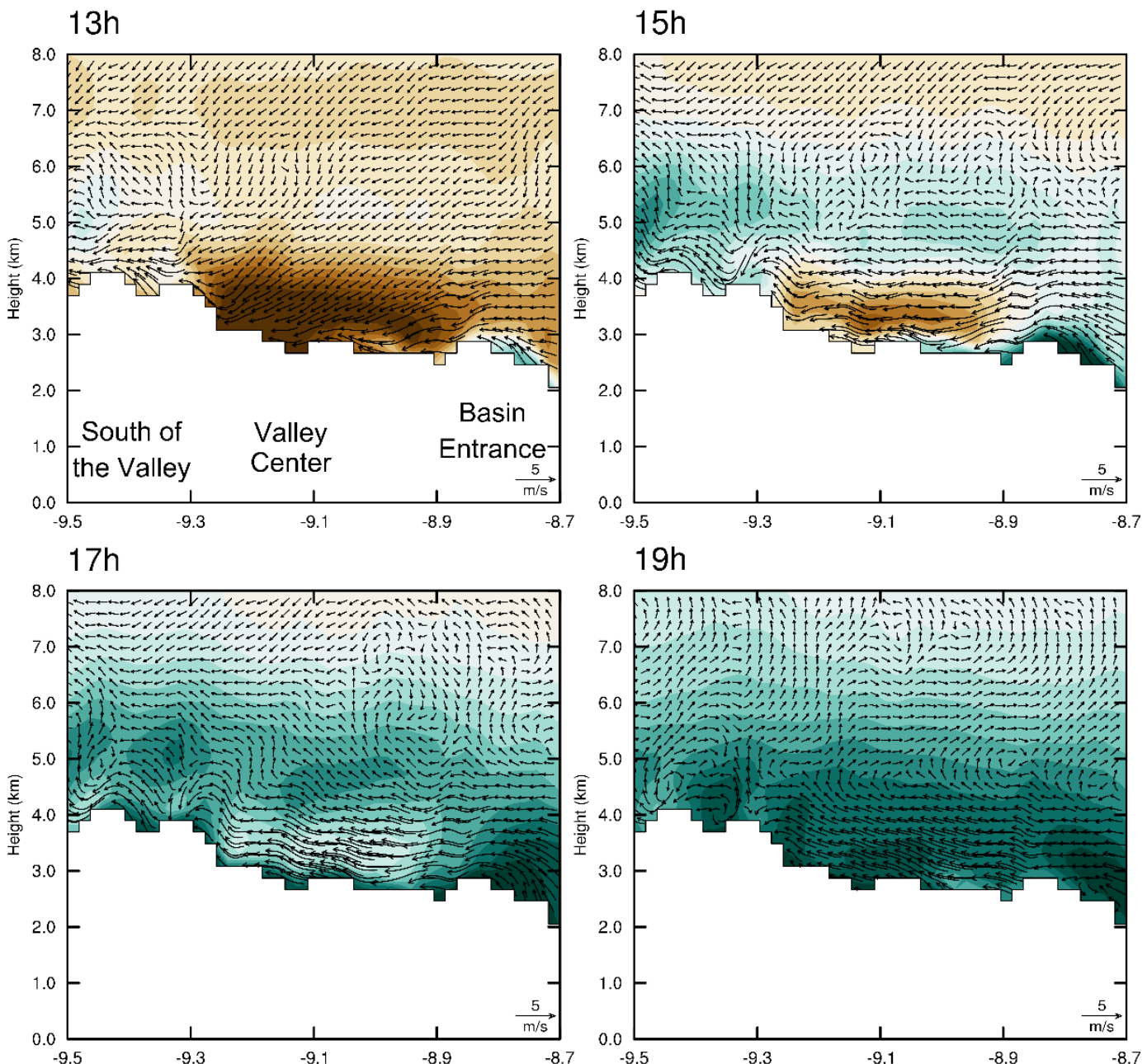

$19 \mathrm{~h}$

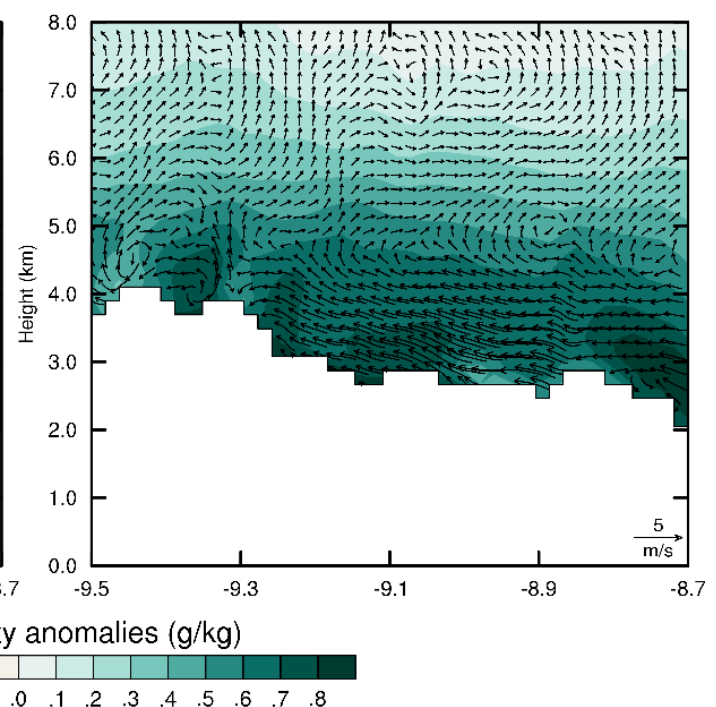

Figure 4.29 - Cross-section of meridional and vertical (x 10) winds (arrows, $\mathrm{m} \mathrm{s}^{-1}$ ) and specific humidity (color, $\mathrm{g} \mathrm{kg}^{-1}$ ) anomalies (time-step mean minus the daily average) for the times 13, 15, 17, and $19 \mathrm{LT}$ obtained from WRF2 starting at $8.70^{\circ} \mathrm{S}-77.98^{\circ} \mathrm{W}$ to $9.52^{\circ} \mathrm{S}-77.58^{\circ} \mathrm{W}$. 


\section{Conclusions}

In this work, fine resolution simulation and local observed data were used to discuss the interaction between local and regional flows controlling the rainfall over elevated areas of Andes (Rio Santa basin). In the sensitivity test, the simulations for the month of March 2013 with $5 \mathrm{~km}$ of grid spacing tested various parameterizations. After defined the best configuration, a rainy season (December of 2012 to March of 2013) one-way nested simulation, with $6 \mathrm{~km}$ (WRF6) and $2 \mathrm{~km}$ (WRF2), was conduced to analyze local circulations. All WRF simulations were nested in ERA5 reanalysis.

In the sensitivity analysis (WRF simulations), it was concluded that the use of the Goddard microphysics with cumulus parameterizations of Betts-Miller-Janjic (EXP2CT) simulates a diurnal precipitation cycle closer to the observed data. In addition, this configuration results in smaller errors in precipitation amounts (lower average rainfall bias). Besides, the change of the cumulus (to Grell-Freitas) and microphysics (to Thompson) schemes showed differences in the simulated circulation, making clear the influence of the parameterizations on the simulated wind on a large scale. For example, these schemes are not able to correctly simulate the low-levels wind turning from northeasterly, from Amazon basin, to northwesterly along eastern side of the Andes. Finally, in the experiment with the deactivation of the cumulus parameterization some deficiencies in the simulation of precipitation are noted, as the dry conditions over east and north of the basin. In addition, in terms of diurnal cycle, the time of peaks of the rainfall do not correspond to the observed ones. Giving to understand that to this horizontal grid spacing the use of the cumulus parameterization is still required.

In the second part, WRF2 simulates the spatial pattern and amount of precipitation closer the observed ones than WRF6. In the diurnal cycle, WRF2 improves the triggering of convection by decreasing the time delay in starting rainfall. Therefore, the nesting procedure improves the simulation of local and regional -scale processes associated with the formation of precipitation over the elevated parts of Andes. 
The next results are derived from local and regional circulation simulated by WRF:

A westerly coastal flow (sea breeze) is identified during the daytime. It has a maximum intensity at $13 \mathrm{LT}$ when the contrast of the temperature sea-land is stronger. This flow enters the basin, transporting moisture into the valley, and intensifies the anabatic winds associated with the development of rain. It indicates the Pacific as a source of moisture for Andean precipitation. This result differs from most previous ones that have indicated the Amazon basin as an exclusive moisture source for the formation of precipitation over the Andes.

The morphology of the mountains in the study area is associated with the mechanical process of channeling winds acting in the basin. This is important for the intensification of the mean coastal flow that reaches the north of the basin and transports moisture for the entire valley during the day. In this way, it is demonstrated the important role of topography in the configuration of large and local scales circulation.

The circulation associated with the formation of precipitation over the Cordilleras Negra and Blanca is different. In the Cordillera Negra, precipitation is strongly associated with the westerly coastal flow (sea breeze) during the daytime. This flow reaches perpendicularly the western side of the Cordillera Negra, and upon entering the valley, as an up-valley flow, intensifies the upslope valley winds on the east side of the Cordillera Negra, converging and transporting moisture. For the Cordillera Blanca, the convergence of the upslope Santa valley winds (intensified by the up-valley flow) on the western side with the upslope winds on the eastern side (intensified by the upper-level easterly Amazon flow) are associated with development of precipitation in the midafternoon.

The precipitation to the south of the basin is associated with the convergence of two near surface flows in the middle of the afternoon. The first is from the Pacific coast, which is channeled by the topography as anabatic wind, intensifies by the westerly flow at high levels $(\sim 3.5 \mathrm{~km})$ when it is rising the mountain range; the second is from upslope Marañon valley winds intensified by the easterly Amazonian flow. The precipitation in northern end of the basin is also associated with the convergence of anabatic winds inside and outside the basin in the same period. The intensification of these winds is connected to the presence of 
near surface westerly coastal flow, and the easterly Amazon flow at high levels during the daytime.

The precipitation in the Santa basin results from the interaction of local and regional processes. During the daytime (Fig. 5.1.a-b), the presence of westerly surface flows transports moisture from the Pacific Ocean to the basin, intensifying the up-valley and upslope winds within the basin. At the same time, at higher levels the easterly Amazon flow is also transporting moisture and intensifying the anabatic winds on the eastern slopes, which suppresses the winds in the opposite side slopes. The convergence of both flows favors the development of precipitation. At the end of the afternoon, both flows begin to weaker, allowing the local valley-mountain flow to dominate the circulation. Since to the slope winds reversion is not instantaneous, several upslope winds are associated with the sustenance of precipitation. During the night (Fig. 5.1.c), under conditions of atmospheric stability, katabatic winds prevail and cold air is transported towards the valley forming a temperature inversion and down-valley winds blow within the inversion layer.

(a) 13 LT

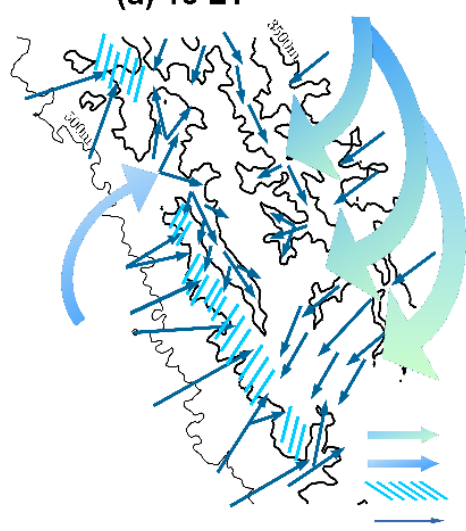

(b) $16 \mathrm{LT}$

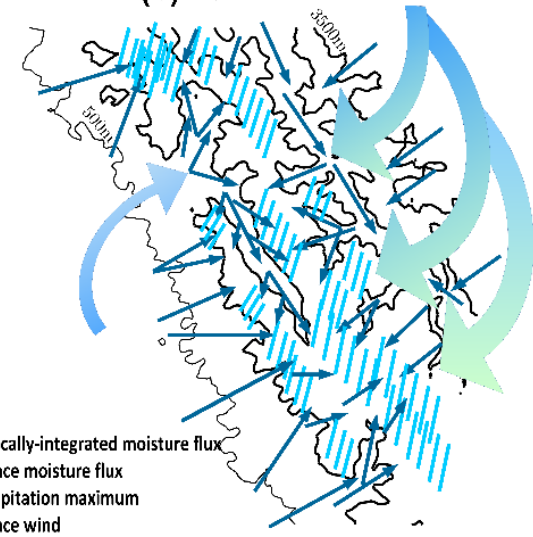

(c) $19 \mathrm{LT}$

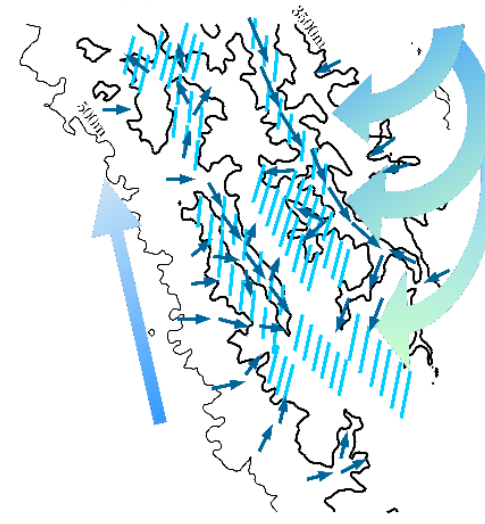

Figure 5.1 - Schematic diagram of the main circulation from model outputs at (a) 13, (b) 16, and (c) 19 LT. Blue dashed zones correspond to precipitation maxima. Light blue-green arrows indicate vertically-integrated moisture flux, thin light blue arrows are surface moisture flux and thin dark blue arrows are surface winds. 


\section{Suggestions}

It is necessary to make clear that the results of this research are based on the WRF simulations and should be taken with caution since there is not enough observed data to validate the processes described previously. In this way, an important recommendation is to carry out observational campaigns on the higher altitude zones in addition to installing a station at the northern entrance of the basin to validate the flow. 


\section{Bibliography}

Aceituno, P., \& Montecinos, A. (1993). Circulation anomalies associated with dry and wet periods in the South American Altiplano. In Proc. Fourth Int. Conf. on Southern Hemisphere Meteorology (pp. 330-331). Amer. Meteor. Soc).

Beljaars, A. C. M. (1995). The parametrization of surface fluxes in large-scale models under free convection. Quarterly Journal of the Royal Meteorological Society, 121(522), 255-270. https://doi.org/10.1002/qj.49712152203

Belmadani, A., Echevin, V., Codron, F., Takahashi, K., \& Junquas, C. (2014). What dynamics drive future wind scenarios for coastal upwelling off Peru and Chile? Climate Dynamics, 43(7), 18931914. https://doi.org/10.1007/s00382-013-2015-2

Berbery, E. H., \& Barros, V. R. (2002). The Hydrologic Cycle of the La Plata Basin in South America. Journal of Hydrometeorology, 3(6), 630-645. https://doi.org/10.1175/15257541(2002)003<0630:THCOTL>2.0.CO;2

Berg, W., L'Ecuyer, T., \& Kummerow, C. (2006). Rainfall Climate Regimes: The Relationship of Regional TRMM Rainfall Biases to the Environment. Journal of Applied Meteorology and Climatology, 45(3), 434-454. https://doi.org/10.1175/JAM2331.1

Betts, A. K. (1986). A new convective adjustment scheme. Part I: Observational and theoretical basis. Quarterly Journal of the Royal Meteorological Society, 112(473), 677-691. https://doi.org/10.1002/qj.49711247307

Betts, A. K., \& Miller, M. J. (1986). A new convective adjustment scheme. Part II: Single column tests using GATE wave, BOMEX, ATEX and arctic air-mass data sets. Quarterly Journal of the Royal Meteorological Society, 112(473), 693-709. https://doi.org/10.1002/qj.49711247308

Chamorro, A., Echevin, V., Colas, F., Oerder, V., Tam, J., \& Quispe-Ccalluari, C. (2018). Mechanisms of the intensification of the upwelling-favorable winds during El Niño 1997-1998 in the Peruvian upwelling system. Climate Dynamics, 51(9), 3717-3733. https://doi.org/10.1007/s00382-018-4106-6

Chavez, S. P., \& Takahashi, K. (2017). Orographic rainfall hot spots in the Andes-Amazon transition according to the TRMM precipitation radar and in situ data. Journal of Geophysical Research: Atmospheres, 122(11), 5870-5882. https://doi.org/10.1002/2016JD026282 
Condom, T., Escobar, M., Purkey, D., Pouget, J. C., Suarez, W., Ramos, C., ... Gomez, J. (2012). Simulating the implications of glaciers' retreat for water management: a case study in the Rio Santa basin, Peru. Water International, 37(4), 442-459. https://doi.org/10.1080/02508060.2012.706773

Condom, T., Rau, P., \& Espinoza, J. C. (2011). Correction of TRMM 3B43 monthly precipitation data over the mountainous areas of Peru during the period 1998-2007. Hydrological Processes, 25(12), 1924-1933. https://doi.org/10.1002/hyp.7949

da Rocha, R. P., Morales, C. A., Cuadra, S. V, \& Ambrizzi, T. (2009). Precipitation diurnal cycle and summer climatology assessment over South America: An evaluation of Regional Climate Model version 3 simulations. Journal of Geophysical Research: Atmospheres, 114(D10). https://doi.org/10.1029/2008JD010212

Doyle, M. E., \& Barros, V. R. (2002). Midsummer Low-Level Circulation and Precipitation in Subtropical South America and Related Sea Surface Temperature Anomalies in the South Atlantic. Journal of Climate, 15(23), 3394-3410. https://doi.org/10.1175/15200442(2002)015<3394:MLLCAP>2.0.CO;2

Dudhia, J. (1988). Numerical Study of Convection Observed during the Winter Monsoon Experiment Using a Mesoscale Two-Dimensional Model. Journal of the Atmospheric Sciences, 46(20), 3077-3107. https://doi.org/10.1175/1520-0469(1989)046<3077:NSOCOD>2.0.CO;2

Enfield, D. B. (1981). Thermally driven wind variability in the planetary boundary layer above Lima, Peru. Journal of Geophysical Research: Oceans, 86(C3), 2005-2016. https://doi.org/10.1029/JC086iC03p02005

Espinoza, J. C., Chavez, S., Ronchail, J., Junquas, C., Takahashi, K., \& Lavado, W. (2015). Rainfall hotspots over the southern tropical Andes: Spatial distribution, rainfall intensity, and relations with large-scale atmospheric circulation. Water Resources Research, 51(5), 3459-3475. https://doi.org/10.1002/2014WR016273

Figueroa, S. N., Satyamurty, P., \& Da Silva Dias, P. L. (1995). Simulations of the Summer Circulation over the South American Region with an Eta Coordinate Model. Journal of the Atmospheric Sciences, 52(10), 1573-1584. https://doi.org/10.1175/15200469(1995)052<1573:SOTSCO >2.0.CO;2

Gandu, A. W., \& Silva Dias, P. L. (1998). Impact of tropical heat sources on the South American tropospheric upper circulation and subsidence. Journal of Geophysical Research: Atmospheres, 
103(D6), 6001-6015. https://doi.org/10.1029/97JD03114

García-Ortega, E., López, L., \& Sánchez, J. L. (2009). Diagnosis and sensitivity study of two severe storm events in the Southeastern Andes. Atmospheric Research, 93(1), 161-178. https://doi.org/https://doi.org/10.1016/j.atmosres.2008.10.030

Garreaud, R. D. (1999). Multiscale Analysis of the Summertime Precipitation over the Central Andes. Monthly Weather Review, 127(5), 901-921. https://doi.org/10.1175/15200493(1999)127<0901:MAOTSP>2.0.CO;2

Garreaud, R. D. (2009). The Andes climate and weather. Advances in Geosciences, 22, 3-11. https://doi.org/10.5194/adgeo-22-3-2009

Garreaud, R., \& Muñoz, R. (2004). The Diurnal Cycle in Circulation and Cloudiness over the Subtropical Southeast Pacific: A Modeling Study. Journal of Climate, 17(8), 1699-1710. https://doi.org/10.1175/1520-0442(2004)017<1699:TDCICA>2.0.CO;2

Georges, C. (2004). 20th-Century Glacier Fluctuations in the Tropical Cordillera Blanca, Perú. Arctic, Antarctic, and Alpine Research, 36(1), 100-107. https://doi.org/10.1657/15230430(2004)036[0100:TGFITT]2.0.CO;2

Gimeno, L., Drumond, A., Nieto, R., Trigo, R. M., \& Stohl, A. (2010). On the origin of continental precipitation. Geophysical Research Letters, 37(13). https://doi.org/10.1029/2010GL043712

Grell, G. A., \& Dévényi, D. (2002). A generalized approach to parameterizing convection combining ensemble and data assimilation techniques. Geophysical Research Letters, 29(14), 38-1-38-4. https://doi.org/10.1029/2002GL015311

Grell, G. A., \& Freitas, S. R. (2014). A scale and aerosol aware stochastic convective parameterization for weather and air quality modeling. Atmospheric Chemistry and Physics, 14(10), 5233-5250. https://doi.org/10.5194/acp-14-5233-2014

Gutman, G. J., \& Schwerdtfeger, W. (1965). The role of latent and sensible heat for the development of a high pressure system over the subtropical Andes, in the summer. Meteor. Rundsch, 18(3), 69-75.

Hierro, R., Pessano, H., Llamedo, P., de la Torre, A., Alexander, P., \& Odiard, A. (2013). Orographic effects related to deep convection events over the Andes region. Atmospheric Research, 120121, 216-225. https://doi.org/https://doi.org/10.1016/j.atmosres.2012.08.020 
Hofer, M., Marzeion, B., \& Mölg, T. (2012). Comparing the skill of different reanalyses and their ensembles as predictors for daily air temperature on a glaciated mountain (Peru). Climate Dynamics, 39(7-8), 1969-1980. https://doi.org/10.1007/s00382-012-1501-2

Hong, S.-Y., Noh, Y., \& Dudhia, J. (2006). A New Vertical Diffusion Package with an Explicit Treatment of Entrainment Processes. Monthly Weather Review, 134(9), 2318-2341. https://doi.org/10.1175/MWR3199.1

Houze, R. A. (1993). Cloud Dynamics. Academic Press.

Houze, R. A. (2012). Orographic effects on precipitating clouds. Reviews of Geophysics, 50(1). https://doi.org/10.1029/2011RG000365

Huffman, G. J., Bolvin, D. T., Nelkin, E. J., Wolff, D. B., Adler, R. F., Gu, G., ... Stocker, E. F. (2007). The TRMM Multisatellite Precipitation Analysis (TMPA): Quasi-Global, Multiyear, Combined-Sensor Precipitation Estimates at Fine Scales. Journal of Hydrometeorology, 8(1), 38-55. https://doi.org/10.1175/JHM560.1

Iacono, M. J., Delamere, J. S., Mlawer, E. J., Shephard, M. W., Clough, S. A., \& Collins, W. D. (2008). Radiative forcing by long-lived greenhouse gases: Calculations with the AER radiative transfer models. Journal of Geophysical Research: Atmospheres, 113(D13). https://doi.org/10.1029/2008JD009944

Janjić, Z. I. (1994). The Step-Mountain Eta Coordinate Model: Further Developments of the Convection, Viscous Sublayer, and Turbulence Closure Schemes. Monthly Weather Review, 122(5), 927-945. https://doi.org/10.1175/1520-0493(1994)122<0927:TSMECM>2.0.CO;2

Joyce, R. J., Janowiak, J. E., Arkin, P. A., \& Xie, P. (2004). CMORPH: A Method that Produces Global Precipitation Estimates from Passive Microwave and Infrared Data at High Spatial and Temporal Resolution. Journal of Hydrometeorology, 5(3), 487-503. https://doi.org/10.1175/1525-7541(2004)005<0487:CAMTPG>2.0.CO;2

Junquas, C., Li, L., Vera, C. S., Le Treut, H., \& Takahashi, K. (2016). Influence of South America orography on summertime precipitation in Southeastern South America. Climate Dynamics, 46(11), 3941-3963. https://doi.org/10.1007/s00382-015-2814-8

Junquas, C., Takahashi, K., Condom, T., Espinoza, J.-C., Chavez, S., Sicart, J.-E., \& Lebel, T. (2018). Understanding the influence of orography on the precipitation diurnal cycle and the associated atmospheric processes in the central Andes. Climate Dynamics, 50(11), 3995-4017. 
https://doi.org/10.1007/s00382-017-3858-8

Kaser, G., Ames, A., \& Zamora, M. (1990). Glacier Fluctuations and Climate in the Cordillera Blanca, Peru. Annals of Glaciology, 14, 136-140. https://doi.org/DOI: $10.3189 / \mathrm{S} 0260305500008430$

Kikuchi, K., \& Wang, B. (2008). Diurnal Precipitation Regimes in the Global Tropics. Journal of Climate, 21(11), 2680-2696. https://doi.org/10.1175/2007JCLI2051.1

Killeen, T. J., Douglas, M., Consiglio, T., Jørgensen, P. M., \& Mejia, J. (2007). Dry spots and wet spots in the Andean hotspot. Journal of Biogeography, 34(8), 1357-1373. https://doi.org/10.1111/j.1365-2699.2006.01682.x

Kodama, Y. (1992). Large-scale common features of subtropical precipitation zones (the Baiu frontal zone, the SPCZ, and the SACZ) Part I: Characteristics of subtropical frontal zones. Journal of the Meteorological Society of Japan. Ser. II, 70(4), 813-836.

Kummerow, C., Simpson, J., Thiele, O., Barnes, W., Chang, A. T. C., Stocker, E., ... Nakamura, K. (2000). The Status of the Tropical Rainfall Measuring Mission (TRMM) after Two Years in Orbit. Journal of Applied Meteorology, 39(12), 1965-1982. https://doi.org/10.1175/15200450(2001)040<1965:TSOTTR>2.0.CO;2

Labraga, J. C., Frumento, O., \& López, M. (2000). The Atmospheric Water Vapor Cycle in South America and theTropospheric Circulation. Journal of Climate, 13(11), 1899-1915. https://doi.org/10.1175/1520-0442(2000)013<1899:TAWVCI>2.0.CO;2

Lenters, J. D., \& Cook, K. H. (1999). Summertime Precipitation Variability over South America: Role of the Large-Scale Circulation. Monthly Weather Review, 127(3), 409-431. https://doi.org/10.1175/1520-0493(1999)127<0409:SPVOSA>2.0.CO;2

Liebmann, B., \& Marengo, J. (2001). Interannual Variability of the Rainy Season and Rainfall in the Brazilian Amazon Basin. Journal of Climate, 14(22), 4308-4318. https://doi.org/10.1175/15200442(2001)014<4308:IVOTRS>2.0.CO;2

Marengo, J. A., Douglas, M. W., \& Silva Dias, P. L. (2002). The South American low-level jet east of the Andes during the 1999 LBA-TRMM and LBA-WET AMC campaign. Journal of Geophysical Research: Atmospheres, 107(D20), LBA 47-1-LBA 47-11. https://doi.org/10.1029/2001JD001188

Marengo, J. A., Liebmann, B., Grimm, A. M., Misra, V., Silva Dias, P. L., Cavalcanti, I. F. A., ... 
Alves, L. M. (2012). Recent developments on the South American monsoon system. International Journal of Climatology, 32(1), 1-21. https://doi.org/10.1002/joc.2254

Marengo, J. A., Liebmann, B., Kousky, V. E., Filizola, N. P., \& Wainer, I. C. (2001). Onset and End of the Rainy Season in the Brazilian Amazon Basin. Journal of Climate, 14(5), 833-852. https://doi.org/10.1175/1520-0442(2001)014<0833:OAEOTR>2.0.CO;2

Marengo, J. A., Soares, W. R., Saulo, C., \& Nicolini, M. (2004). Climatology of the Low-Level Jet East of the Andes as Derived from the NCEP-NCAR Reanalyses: Characteristics and Temporal Variability. Journal of Climate, 17(12), 2261-2280. https://doi.org/10.1175/15200442(2004)017<2261:COTLJE>2.0.CO;2

Mejía, F., \& Douglas, M. (2006). Flow around the Andean elbow from WRF Simulations and P-3 Aircraft measurements during the SALLJEX. Proceedings of the 8 ICSHMO, Foz de Iguaçu, Brazil, INPE, 795-802.

Mourre, L., Condom, T., Junquas, C., Lebel, T., E. Sicart, J., Figueroa, R., \& Cochachin, A. (2016). Spatio-temporal assessment of WRF, TRMM and in situ precipitation data in a tropical mountain environment (Cordillera Blanca, Peru). Hydrology and Earth System Sciences, 20(1), 125-141. https://doi.org/10.5194/hess-20-125-2016

Moya-Álvarez, A. S., Martínez-Castro, D., Flores, J. L., \& Silva, Y. (2018). Sensitivity Study on the Influence of Parameterization Schemes in WRF _ ARW Model on Short- and Medium-Range Precipitation Forecasts in the Central Andes of Peru. Advances in Meteorology, 2018, 16. https://doi.org/10.1155/2018/1381092

Moya-Álvarez, A. S., Martínez-Castro, D., Kumar, S., Estevan, R., \& Silva, Y. (2019). Response of the WRF model to different resolutions in the rainfall forecast over the complex Peruvian orography. Theoretical and Applied Climatology. https://doi.org/10.1007/s00704-019-02782-3

Nakanishi, M., \& Niino, H. (2006). An Improved Mellor-Yamada Level-3 Model: Its Numerical Stability and Application to a Regional Prediction of Advection Fog. Boundary-Layer Meteorology, 119(2), 397-407. https://doi.org/10.1007/s10546-005-9030-8

Niu, G.-Y., Yang, Z.-L., Mitchell, K. E., Chen, F., Ek, M. B., Barlage, M., ... Xia, Y. (2011). The community Noah land surface model with multiparameterization options (Noah-MP): 1. Model description and evaluation with local-scale measurements. Journal of Geophysical Research: Atmospheres, 116(D12). https://doi.org/doi:10.1029/2010JD015139 
Ochoa-Sánchez, A. E., Pineda Ordonez, L. E., Crespo, P., \& Willems, P. (2014). Evaluation of TRMM 3B42 precipitation estimates and WRF retrospective precipitation simulation over the Pacific-Andean region of Ecuador and Peru. Hydrology and Earth System Sciences. European Geophysical Society. https://doi.org/10.1080/1573062X.2013.831914

Paulson, C. A. (1970). The Mathematical Representation of Wind Speed and Temperature Profiles in the Unstable Atmospheric Surface Layer. Journal of Applied Meteorology, 9(6), 857-861. https://doi.org/10.1175/1520-0450(1970)009<0857:TMROWS>2.0.CO;2

Posada-Marín, J. A., Rendón, A. M., Salazar, J. F., Mejía, J. F., \& Villegas, J. C. (2018). WRF downscaling improves ERA-Interim representation of precipitation around a tropical Andean valley during El Niño: implications for GCM-scale simulation of precipitation over complex terrain. Climate Dynamics. https://doi.org/10.1007/s00382-018-4403-0

Poveda, G., Mesa, O. J., Salazar, L. F., Arias, P. A., Moreno, H. A., Vieira, S. C., ... Alvarez, J. F. (2005). The Diurnal Cycle of Precipitation in the Tropical Andes of Colombia. Monthly Weather Review, 133(1), 228-240. https://doi.org/10.1175/MWR-2853.1

Roe, G. H. (2005). OROGRAPHIC PRECIPITATION. Annual Review of Earth and Planetary Sciences, 33(1), 645-671. https://doi.org/10.1146/annurev.earth.33.092203.122541

Romatschke, U., \& Houze, R. A. (2010). Extreme Summer Convection in South America. Journal of Climate, 23(14), 3761-3791. https://doi.org/10.1175/2010JCLI3465.1

Skamarock, W. C., Klemp, J. B., Dudhia, J., Gill, D. O., Barker, D. M., Duda, M. G., .. Powers, J. G. (2008). A Description of the Advanced Research WRF Version 3, 125.

Smiatek, G., Kunstmann, H., Knoche, R., \& Marx, A. (2009). Precipitation and temperature statistics in high-resolution regional climate models: Evaluation for the European Alps. Journal of Geophysical Research: Atmospheres, 114(D19). https://doi.org/10.1029/2008JD011353

Spiga, A., Teitelbaum, H., \& Zeitlin, V. (2008). Identification of the sources of inertia-gravity waves in the Andes Cordillera region. In Annales geophysicae: atmospheres, hydrospheres and space sciences (Vol. 26, p. 2551).

Takahashi, K. (2012). Thermotidal and land-heating forcing of the diurnal cycle of oceanic surface winds in the eastern tropical Pacific. Geophysical Research Letters, 39(4). https://doi.org/10.1029/2011GL050692

Tang, M., \& Reiter, E. R. (1984). Plateau Monsoons of the Northern Hemisphere: A Comparison 
between North America and Tibet. Monthly Weather Review, 112(4), 617-637. https://doi.org/10.1175/1520-0493(1984)112<0617:PMOTNH>2.0.CO;2

Tao, W.-K., Simpson, J., \& McCumber, M. (1989). An Ice-Water Saturation Adjustment. Monthly Weather Review, 117(1), 231-235. https://doi.org/10.1175/15200493(1989)117<0231:AIWSA>2.0.CO;2

Thompson, G., Field, P. R., Rasmussen, R. M., \& Hall, W. D. (2008). Explicit Forecasts of Winter Precipitation Using an Improved Bulk Microphysics Scheme. Part II: Implementation of a New Snow Parameterization. Monthly Weather Review, 136(12), 5095-5115. https://doi.org/10.1175/2008MWR2387.1

Tripoli, G. J., \& Cotton, W. R. (1989). Numerical Study of an Observed Orogenic Mesoscale Convective System. Part 1: Simulated Genesis and Comparison with Observations. Monthly Weather Review, $\quad 117(2), \quad 273-304 . \quad$ https://doi.org/10.1175/15200493(1989)117<0273:NSOAOO>2.0.CO;2

Vera, C., Higgins, W., Amador, J., Ambrizzi, T., Garreaud, R., Gochis, D., ... Zhang, C. (2006). Toward a Unified View of the American Monsoon Systems. Journal of Climate, 19(20), 49775000. https://doi.org/10.1175/JCLI3896.1

Vignon, F. (2002). Glaciares y recursos hidricos en el valle alto del rio Santa. Université Paris 7; IRD; INRENA. Retrieved from http://www.documentation.ird.fr/hor/fdi:010053310

Virji, H. (1981). A Preliminary Study of Summertime Tropospheric Circulation Patterns over South America Estimated from Cloud Winds. Monthly Weather Review, 109(3), 599-610. https://doi.org/10.1175/1520-0493(1981)109<0599:APSOST>2.0.CO;2

Vuille, M., Kaser, G., \& Juen, I. (2008). Glacier mass balance variability in the Cordillera Blanca, Peru and its relationship with climate and the large-scale circulation. Global and Planetary Change, 62(1), 14-28. https://doi.org/https://doi.org/10.1016/j.gloplacha.2007.11.003

Wallace, J. M., \& Hobbs, P. V. (2006). Atmospheric science: an introductory survey (Vol. 92). Elsevier.

Whiteman, C. D. (2000). Mountain meteorology: fundamentals and applications. Oxford University Press.

Wilks, D. S. (2006). Statistical Methods in the Atmospheric Sciences (International Geophysics Series; V. 91). Academic Press. 
Yang, Z.-L., Niu, G.-Y., Mitchell, K. E., Chen, F., Ek, M. B., Barlage, M., ... Xia, Y. (2011). The community Noah land surface model with multiparameterization options (Noah-MP): 2. Evaluation over global river basins. Journal of Geophysical Research: Atmospheres, 116(D12). https://doi.org/10.1029/2010JD015140

Yáñez-Morroni, G., Gironás, J., Caneo, M., Delgado, R., \& Garreaud, R. (2018). Using the Weather Research and Forecasting (WRF) Model for Precipitation Forecasting in an Andean Region with Complex Topography. Atmosphere . https://doi.org/10.3390/atmos9080304

Zapata, M., Arnaud, Y., \& Gallaire, R. (2008). Inventario de glaciares de la Cordillera Blanca, 13th IWRA World Water Congreso. Montpellier, France.

Zhou, J., \& Lau, K.-M. (1998). Does a Monsoon Climate Exist over South America? Journal of Climate, $\quad 11(5), \quad$ 1020-1040. https://doi.org/10.1175/15200442(1998)011<1020:DAMCEO>2.0.CO;2

Zulkafli, Z., Buytaert, W., Onof, C., Manz, B., Tarnavsky, E., Lavado, W., \& Guyot, J.-L. (2013). A Comparative Performance Analysis of TRMM 3B42 (TMPA) Versions 6 and 7 for Hydrological Applications over Andean-Amazon River Basins. Journal of Hydrometeorology, 15(2), 581592. https://doi.org/10.1175/JHM-D-13-094.1 


\section{Appendix}

\subsection{Appendix A: Complementary figures to the results}

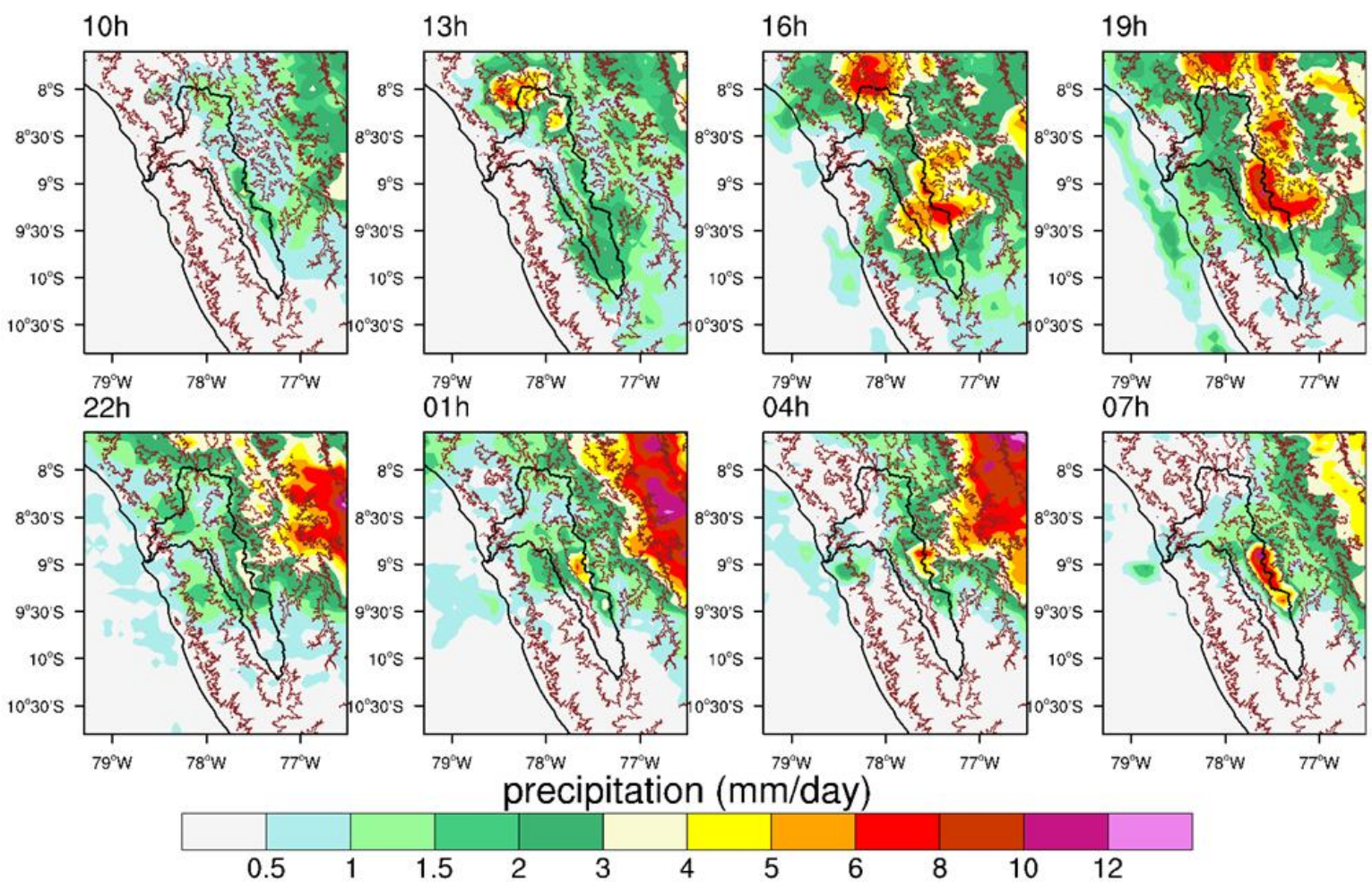

Figure A.8.1 - DFJM precipitation mean (mm/day) from CMORPH to one-hour time step mean. Brown contours show 500 and 3500 m orography limits. Delimitation of the Rio Santa Basin watershed and the coastline are indicated in bold black lines. 

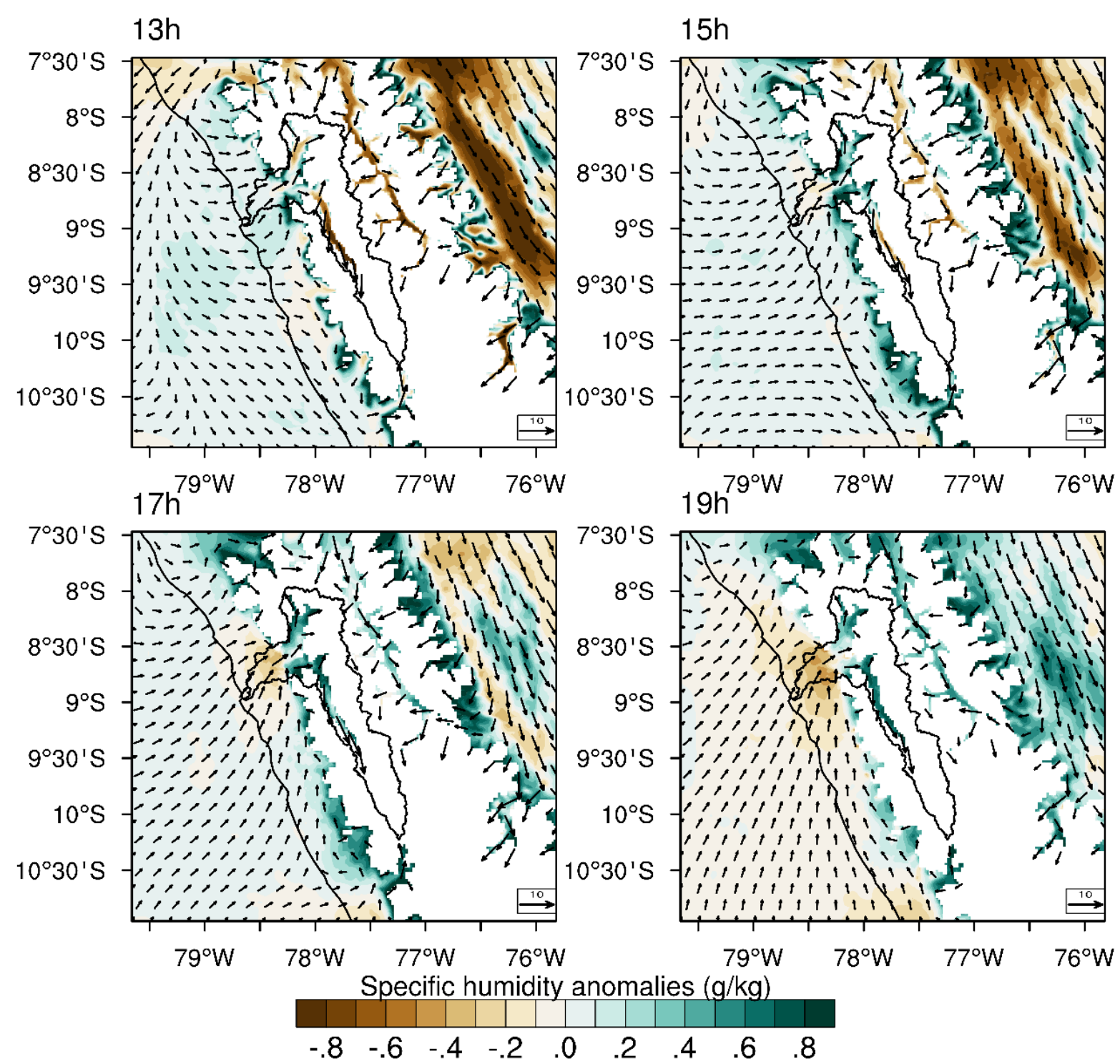

Figure A.8.2 - DJFM averaged horizontal wind direction (arrows, $\mathrm{m} \mathrm{s}^{-1}$ ) as well as anomalous specific humidity (color shaded, $\mathrm{g} \mathrm{kg}^{-1}$ ) from WRF2 for 13, 15, 17, an19 LT at $700 \mathrm{hPa}$. Black contours indicate the delimitation of the countries and the Rio Santa watershed. 

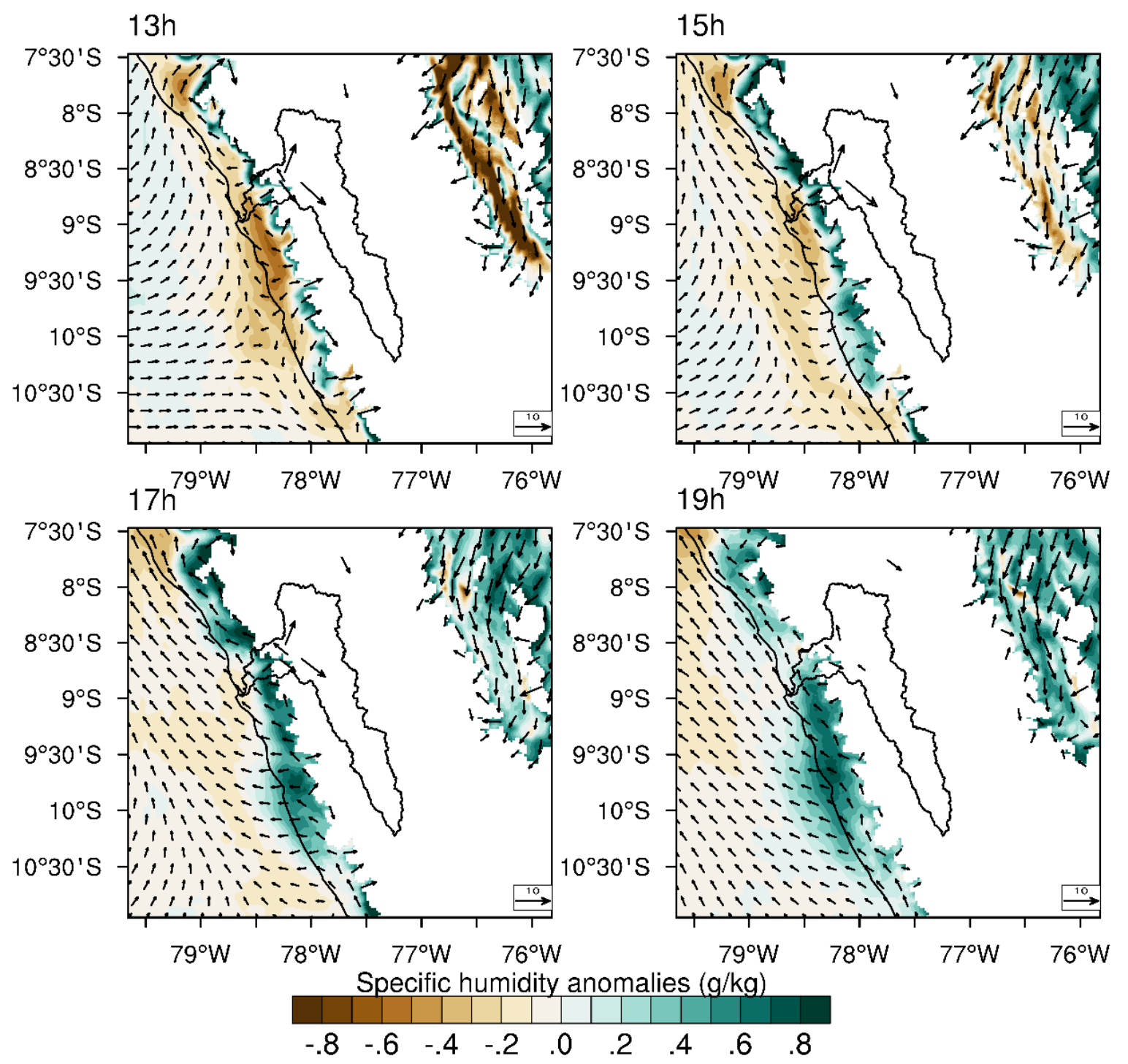

Figure A.8.3 - DJFM averaged horizontal wind direction (arrows, $\mathrm{m} \mathrm{s}^{-1}$ ) as well as anomalous specific humidity (color shaded, $\mathrm{g} \mathrm{kg}^{-1}$ ) from WRF2 for 13, 15, 17, an19 LT at $850 \mathrm{hPa}$. Black contours indicate the delimitation of the countries and the Rio Santa watershed. 

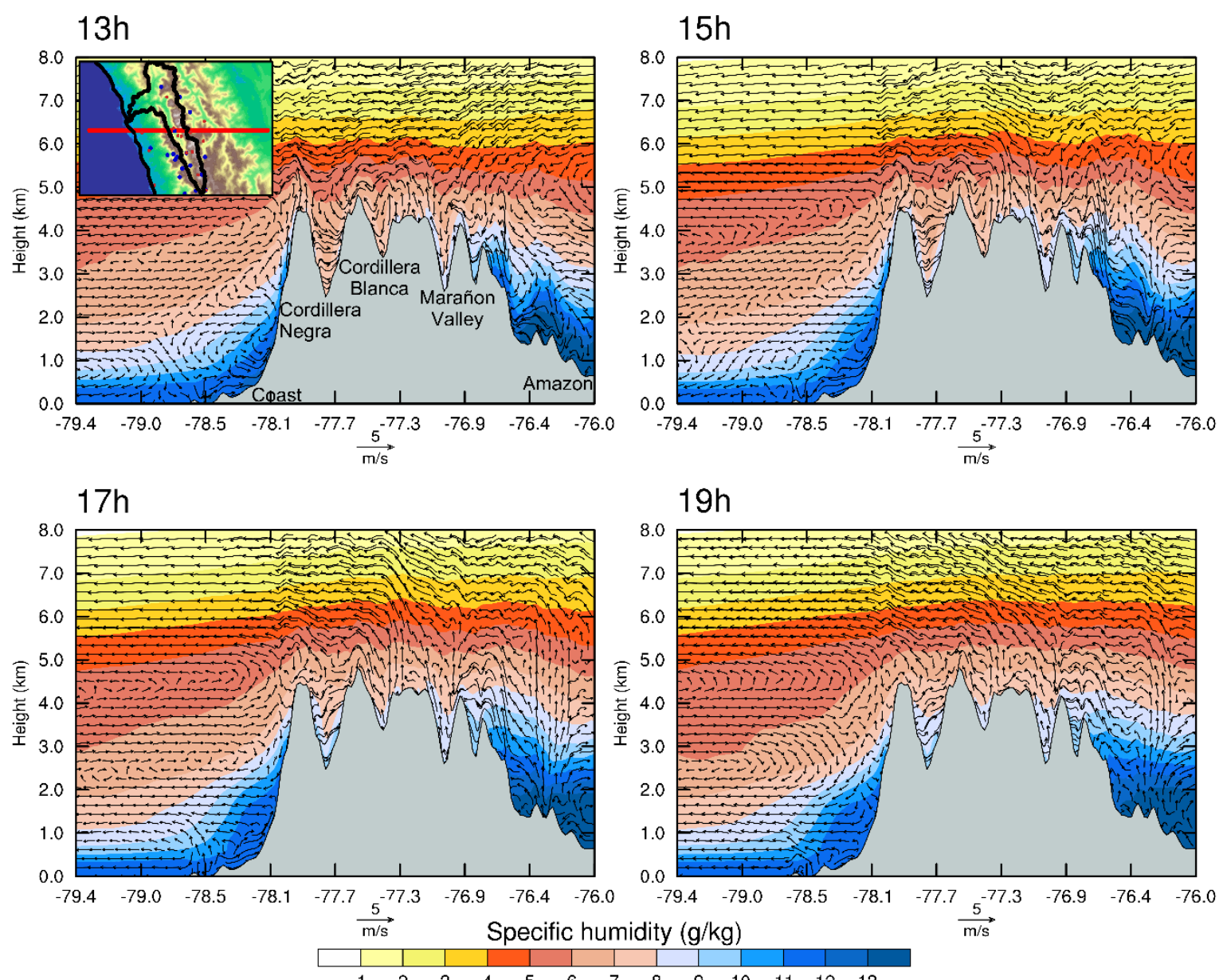

Figure A.8.4 - Vertical cross-section of zonal and vertical (x 10) winds (arrows, $\mathrm{m} \mathrm{s}^{-1}$ ) and specific humidity (color, $\mathrm{g} \mathrm{kg}^{-1}$ ) for the times $13,15,17$, and $19 \mathrm{LT}$ obtained from WRF2 at $9.15^{\circ} \mathrm{S}$ (central section). 

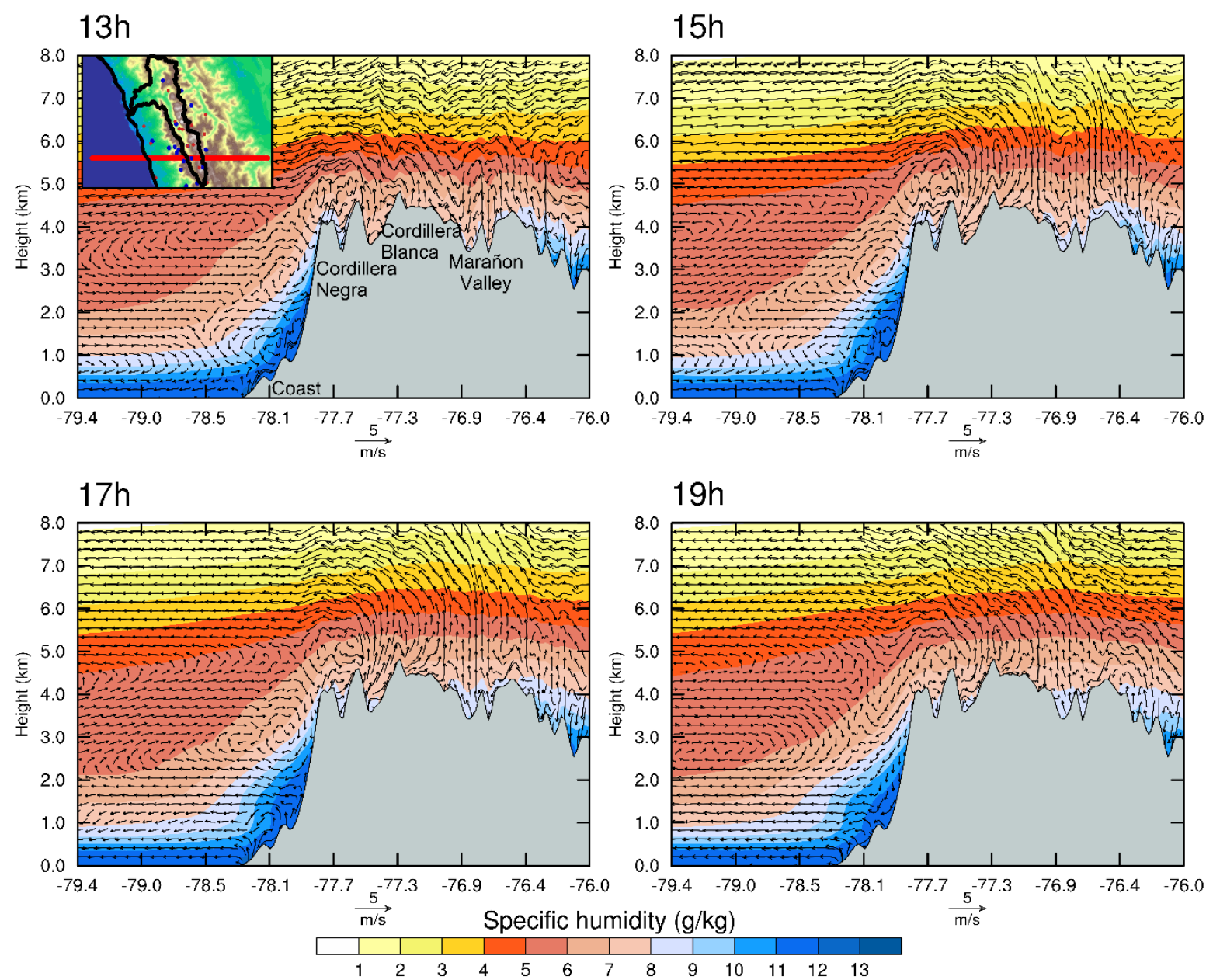

Figure A.8.5 - Vertical cross-section of zonal and vertical (x 10) winds (arrows, $\mathrm{m} \mathrm{s}^{-1}$ ) and specific humidity (color, $\mathrm{g} \mathrm{kg}^{-1}$ ) for the times $13,15,17$, and $19 \mathrm{LT}$ obtained from WRF2 at $8.66^{\circ} \mathrm{S}$ (south section). 

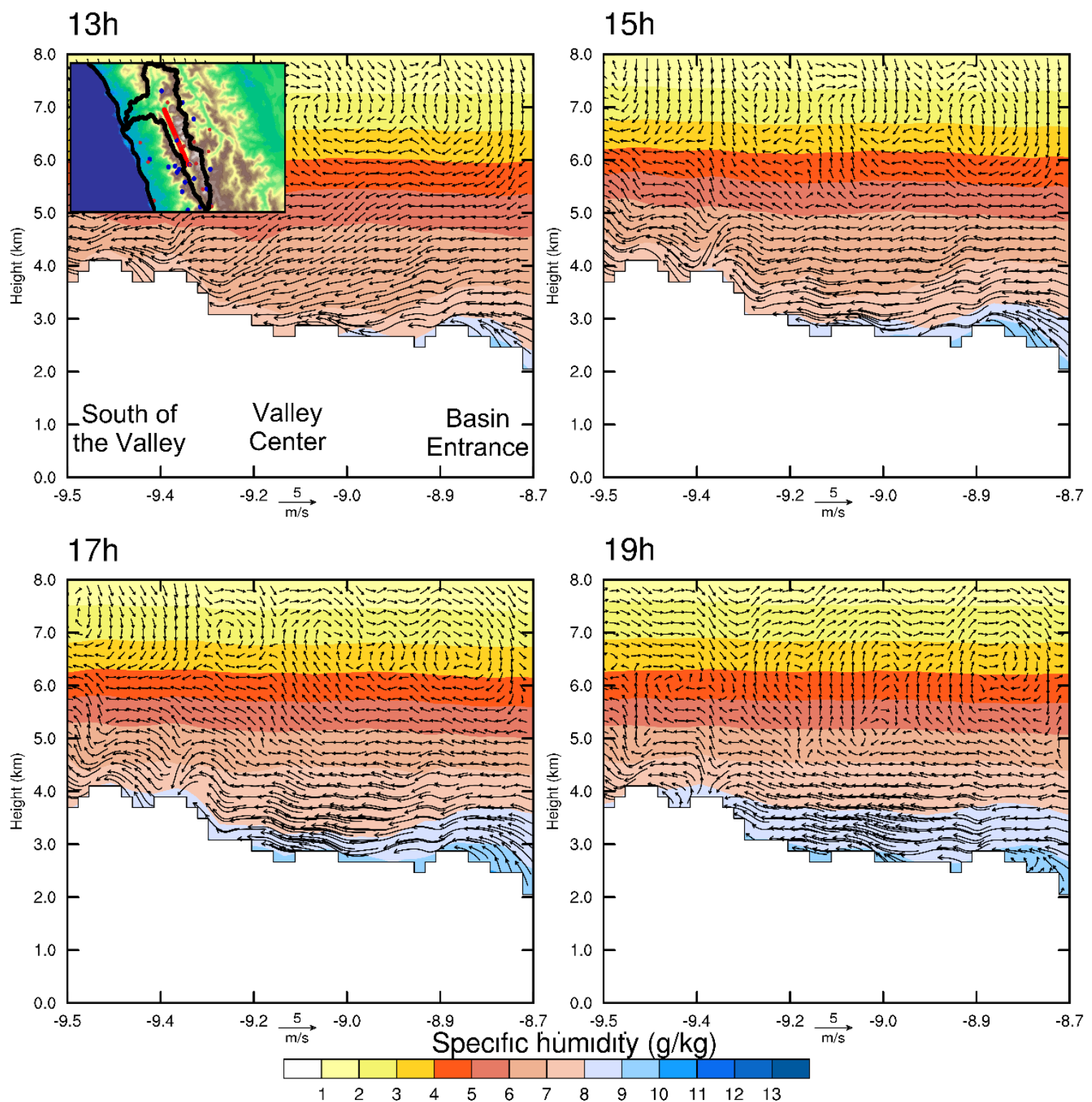

Figure A.8.6 - Vertical cross-section of meridional and vertical (x 10) winds (arrows, $\mathrm{m} \mathrm{s}^{-1}$ ) and specific humidity (color, $\mathrm{g} \mathrm{kg}^{-1}$ ) for the times $13,15,17$, and $19 \mathrm{LT}$ obtained from WRF2 starting at $8.70^{\circ} \mathrm{S}-77.98^{\circ} \mathrm{W}$ to $9.52^{\circ} \mathrm{S}-77.58^{\circ} \mathrm{W}$. 